Portland State University

PDXScholar

$1-1-2011$

\title{
Foreign Language Teaching in U.S. Higher Education Classrooms: An Investigation of the Relationship between Teacher Pedagogical Beliefs and Classroom Teaching
}

Shaojuan Lin

Portland State University

Follow this and additional works at: https://pdxscholar.library.pdx.edu/open_access_etds Let us know how access to this document benefits you.

\section{Recommended Citation}

Lin, Shaojuan, "Foreign Language Teaching in U.S. Higher Education Classrooms: An Investigation of the Relationship between Teacher Pedagogical Beliefs and Classroom Teaching" (2011). Dissertations and Theses. Paper 283.

https://doi.org/10.15760/etd.283

This Dissertation is brought to you for free and open access. It has been accepted for inclusion in Dissertations and Theses by an authorized administrator of PDXScholar. Please contact us if we can make this document more accessible: pdxscholar@pdx.edu. 
Foreign Language Teaching in U.S. Higher Education Classrooms: An Investigation of the Relationship between Teacher Pedagogical Beliefs and Classroom Teaching

by

Shaojuan Lin

A dissertation submitted in partial fulfillment of the requirements for the degree of

Doctor of Education

in

Educational Leadership: Postsecondary Education

Dissertation committee:
Christine Cress, Chair
Janine Allen
Christine Chaille
Samuel Henry
Jonathan Pease

Portland State University

(C)2011 


\begin{abstract}
Previous research indicates that former schooling is an important factor in shaping teachers' beliefs about teaching; teachers change the way they teach when their beliefs about foreign language teaching change. However, not much research has discovered direct evidence concerning the processes that effect change in teacher beliefs.

This study investigated the relationship between teachers’ pedagogical paradigms and practices in Chinese language classrooms. Specifically, a qualitative analysis of educated teachers born in China examined how early pedagogical frames were formed, and then transformed in the context of American classrooms.

Results of this study indicate that early schooling, language learning, and initial teaching experiences have a powerful affect on Chinese teachers' epistemological beliefs and pedagogical practices. Indeed, embedded and unexamined beliefs can inhibit effective teaching of Chinese language and lead to traditional behavioristcentered learning approaches. However, these data evidence that critical reflection on preconceptions, beliefs, values, principles, and practices can become a precursory for constructivist and transformational Chinese language teaching and learning. The Lin Transformational Teaching and Professional Development Model demonstrates how traditional Chinese language approaches can be transformed into more effective epistemological and pedagogical strategies through assessment and reframing, consideration of cultural contexts, incorporation of diversity, and inclusion of continual professional reflection. Implications of the Lin Model to increase teacher
\end{abstract}


competence and learner proficiency are recommended in four areas (individual professional development, collaborative professional development, teacher training program, and students of Chinese) and are applicable to three different types of departments: foreign languages and literatures, applied linguistics, and education. 


\section{ACKNOWLEDGEMENTS}

This dissertation would not have been possible without the guidance, help, and inspiration of a number of people. First and foremost, I would like to express my gratitude to Christine Cress, Janine Allen, and Jonathan Pease. Christine Cress is my academic adviser. She opened the gate to the field of adult learning for me, and has offered me great guidance in raising the arguments in this paper to a higher level. Janine Allen was the adviser for my Master’s degree. She encouraged me to continue my study in a doctoral program, and has served as a committee member through all the examinations and defense required for the doctoral degree. Jonathan Pease is my adviser in the foreign language teaching field. He has offered me great guidance in this paper, including help with the English.

Next, I would like to thank all the committee members for my proposal and dissertation defense: Christine Cress, Janine Allen, Christine Chaille, Samuel Henry, and Jonathan Pease. Your valuable comments, suggestions, ideas, critiques, and corrections provided depth and diversity.

Third, I would like to thank all the five Chinese teachers who contributed their learning experiences, classroom practices, and in-depth reflections. I appreciate their patience and time with the interviews and in reviewing all the transcripts.

Fourth, I would like to thank three former academic advisors. Frosti McClurken-Talley and Joan Strouse offered generous, thorough advice and help on my academic journey; and Susan Lenski offered essential guidance on passing the core and specialty examinations required for the doctoral degree. 
Fifth, I would like to thank all the professors from whom I have learned knowledge of different fields to support arguments in this paper: Christine Cress, Mary Kinnick, William Greenfield, Keren Noordhoff, Janine Allen, Carolyn S. Carr, Tom Chenoweth, Robert B. Everhart, Emily de la Cruz, Christine Chaille, Ramin Farathmandpur, Stevens Dannelle, Jacqueline B. Temple, Susan Conrad, Kimberley Brown, Jonathan Pease, Stephen Wadley, and many others.

Finally, my heartful appreciation goes to my two uncles, Louis Lim and Lin Wen-jiu, for their continuous engagement and incalculable support during the process of my study. 


\section{Table of Contents}

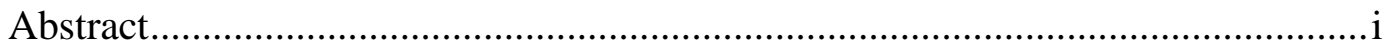

Acknowledgements ...............................................................................

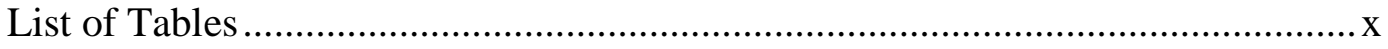

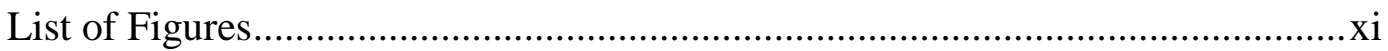

Chapter I

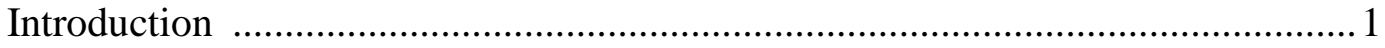

Teacher's Beliefs Impact Student Learning Outcomes ................................... 1

U.S. Need for Foreign Language Competence................................................ 3

Degree Issued in Foreign Languages and Literatures .................................... 4

Enrollments in Foreign Languages and Literatures......................................... 6

Shortage of Qualified Teachers of Critical Languages .................................. 8

Traditional Natural Science Oriented Curriculum, Instruction, and

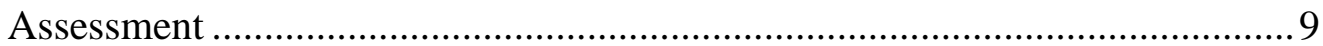

New Challenges to Teachers of Foreign Languages ...................................... 10

Purpose and Significance of the Study .................................................... 11

Chapter II

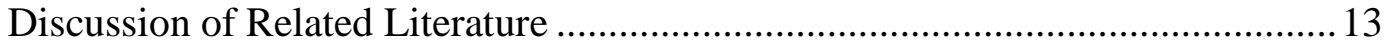

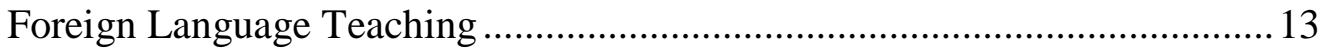

Traditional views on language.......................................................... 14

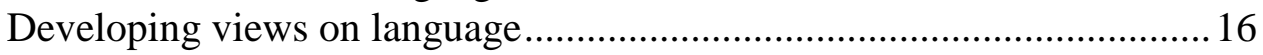

Foreign language teaching methodology............................................ 17

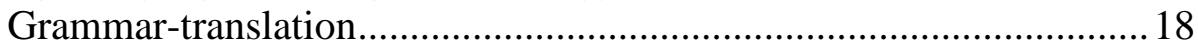

Audiolingualism ....................................................................... 19

Communicative Language Teaching (CLT) .................................... 22

Project-based Second/Foreign Language Learning (PBL)................. 25

Learning through experiences ....................................................... 28

Language proficiency ................................................................... 31

Attempts to improve the outcome of language learning ...........................35

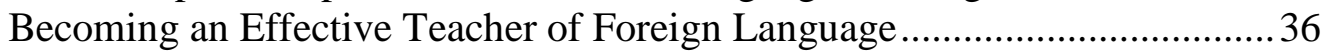

Knowledge of principles of practice.................................................. 37

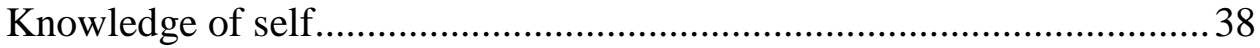

Beliefs, values, and attitudes ....................................................... 38

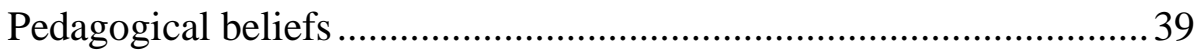

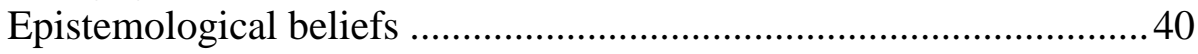

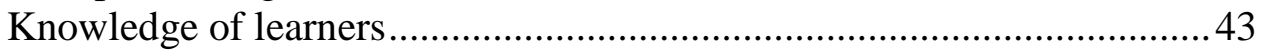

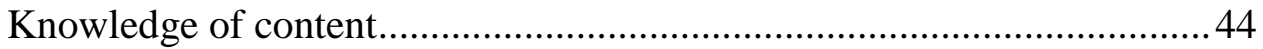

Knowledge of method ................................................................... 45 


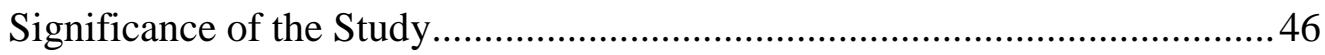

Summary and research gap.....................................................................4 46

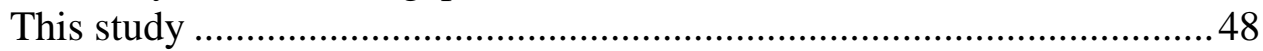

Context of this study and research questions ............................................... 49

Chapter III

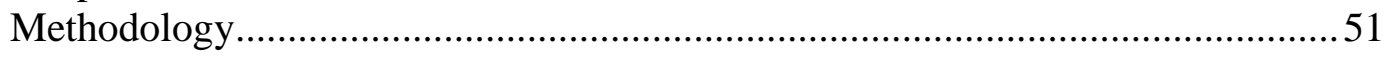

Purpose and Research Questions Restated ......................................................51

Research Design ....................................................................................... 52

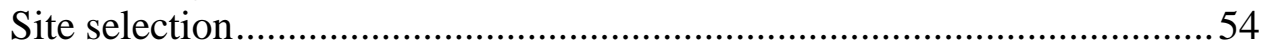

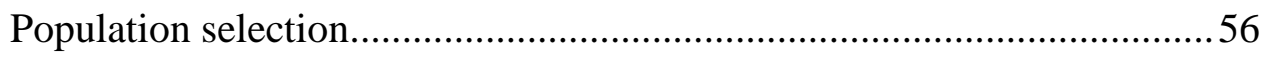

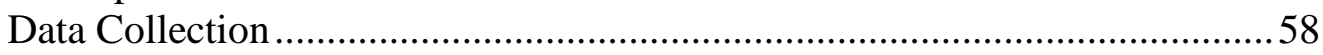

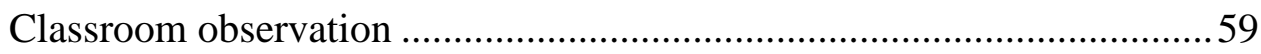

Rationale for observation ...............................................................59

Settings, duration, and occurrence of observation.................................61

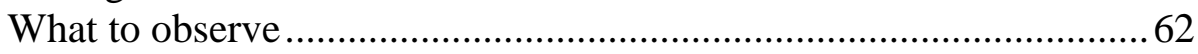

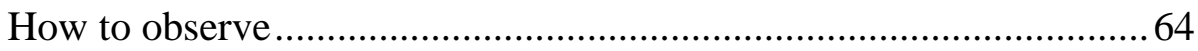

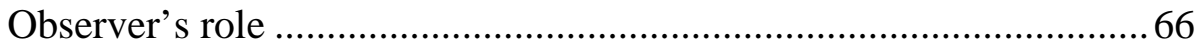

Why classroom observation was done before interview ……………....67

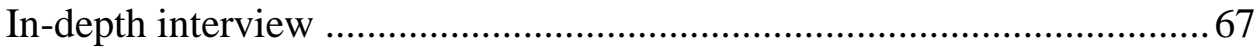

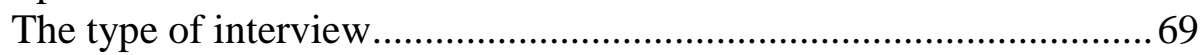

The Hows of the interview ………………………………………....... 70

Interview questions........................................................................... 72

Interview process .......................................................................... 76

Language used in the interviews ........................................................79

In-the-field insights (Patton, 2002).......................................................79

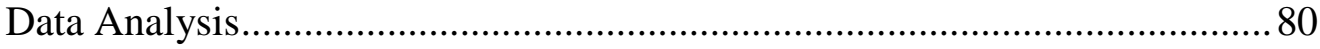

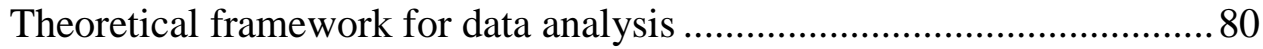

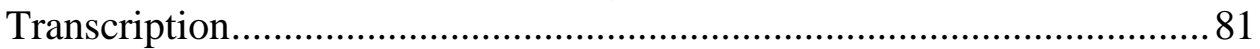

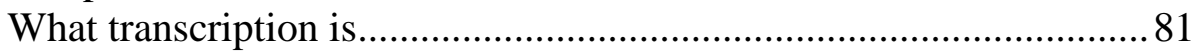

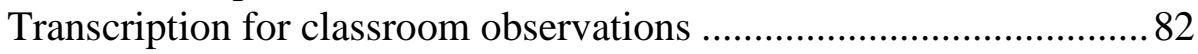

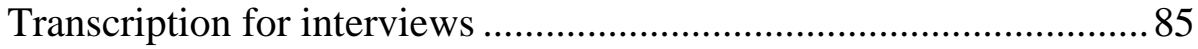

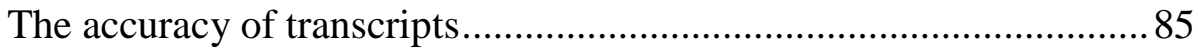

Capturing more details in the process of transcription ...........................8 85

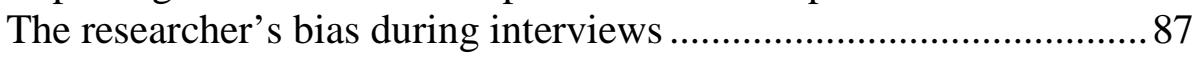

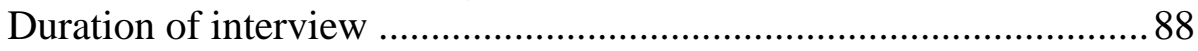

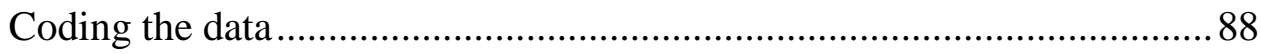

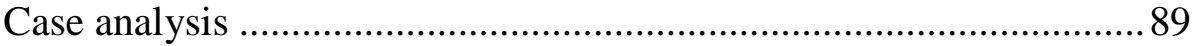

Preparing questions for second interviews .......................................90

Capture the "hows" in the process of coding...................................99

An emerging topic ............................................................................92

Un-responded "how" questions .......................................................92

Checking bias in questions for second interviews............................93

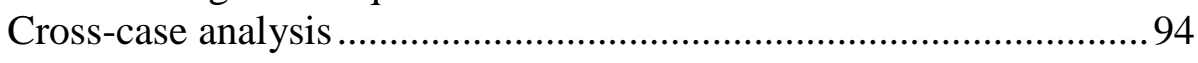




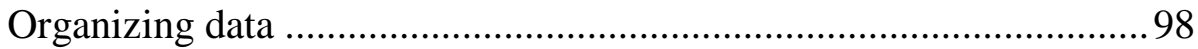

Writing analytic memos .................................................................... 99

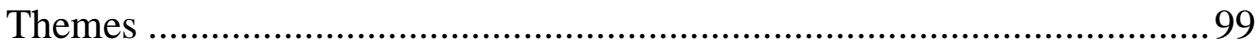

A key linkage (Erickson, 1986)........................................................ 100

Forming themes to answer the research questions ..............................102

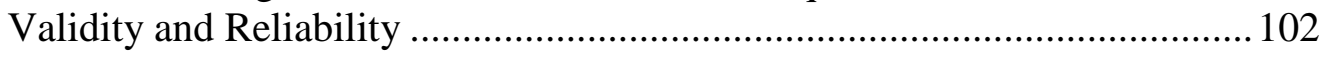

Internal validity ............................................................................... 103

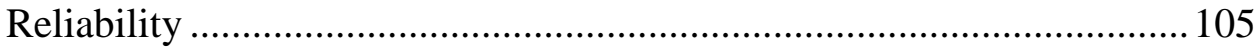

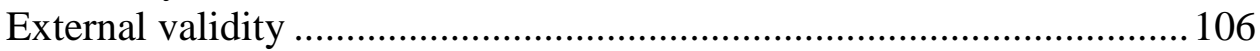

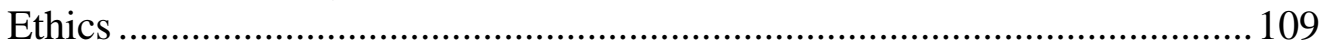

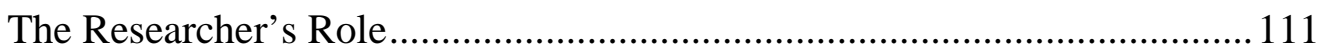

Chapter IV

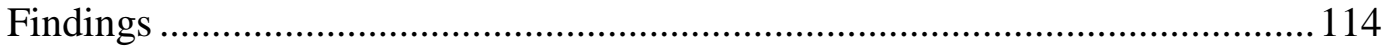

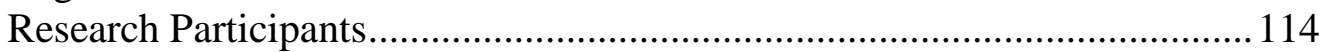

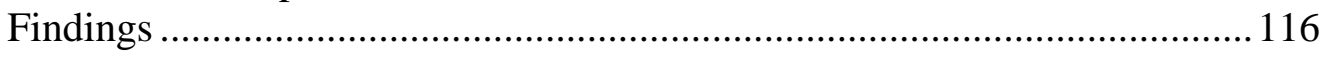

Findings from interviews.......................................................................117

Theme 1: Early formation of epistemological belief..........................118

Theme 2: Initial application of knowledge and skills ........................120

Theme 3: Refinement of pedagogical approaches in real world application ..........................................................................122

Theme 4: Reframing of pedagogical and epistemological beliefs ....123

Learning from co-teachers......................................................... 123

Learning from students ........................................................... 126

Theme 5: Communicative and cultural consideration.........................127

Theme 6: Student diversity context ................................................... 132

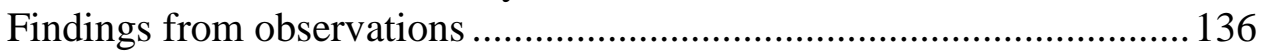

Theme 7: Reflective learning cycle ....................................................136

Wen's remarks on methods and approaches ..............................137

Summary of the classroom observations for Wen............137

An interesting way to teach speaking Chinese ..................138

Meeting students' needs - no textbooks..........................139

A brief discussion about Wen's views on methods and about her classroom teaching ............................................ 140

Ming's comments on methods and approaches...........................140

Students should be "put into the water to swim" .............141

Summary of the classroom observations for Ming...........142

A brief discussion about Ming's views on methods and about her classroom teaching ............................................. 144

Zhong's comments on methods and approaches ......................... 145

Summary of the classroom observations for Zhong.........146

A brief discussion about Zhong's views on methods and about his classroom teaching............................................. 147

Guo's views about methods and approaches............................... 148 
Summary of the classroom observations for Guo 149

A brief discussion about Guo's views on methods and about her classroom teaching ......................................... 150

Hua's remarks on methods and approaches ............................ 151

Helping students develop "A new habit” ........................ 152

Summary of the classroom observations for Hua............. 152

A brief discussion about Hua's views on methods and

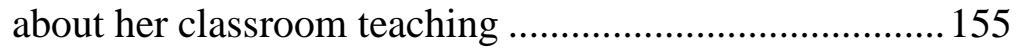

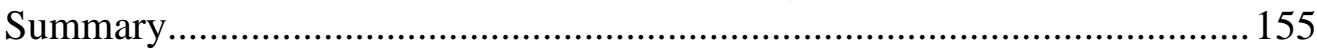

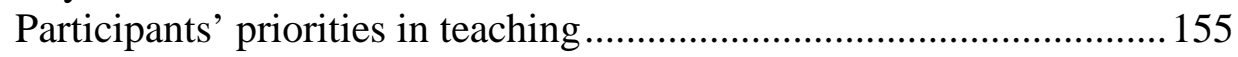

Transformative teaching ............................................................... 156

The Lin Transformational Teaching and Professional Development

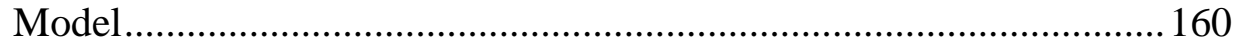

Chapter V

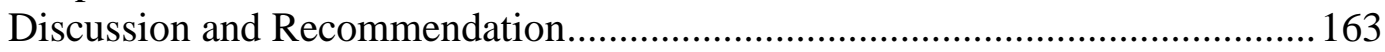

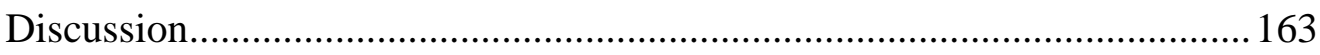

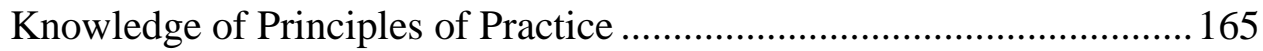

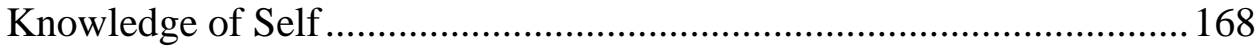

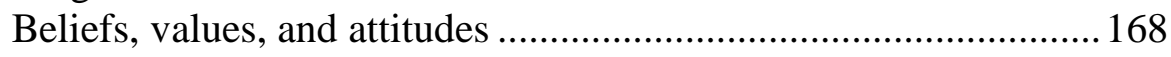

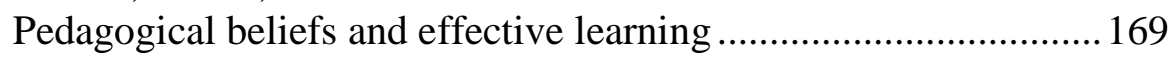

Epistemological beliefs ........................................................... 170

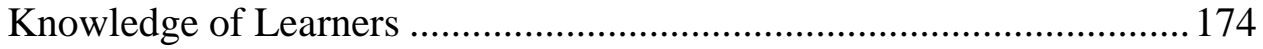

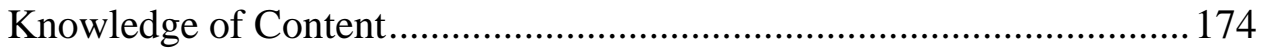

Culture in discourse and cultural competence................................176

Knowledge of Method .................................................................. 177

Communicative language teaching (CLT) and project-based

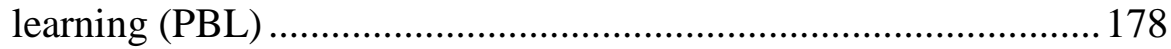

Grammar-translation, out of date? ................................................ 180

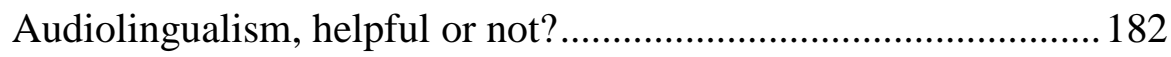

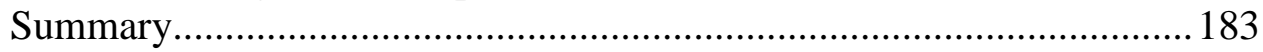

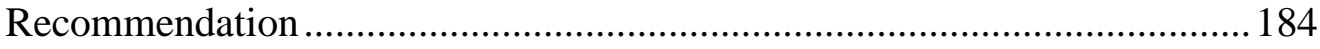

Individual professional development ............................................... 185

Teachers as learners of language teaching .................................... 187

Upgrading knowledge, and competence to apply the knowledge .. 188

Re-examining assumptions about students.................................. 189

Re-examining beliefs about content ........................................... 189

Upgrading assumptions about learning - constructivism............... 190

Collaborative professional development ........................................... 193

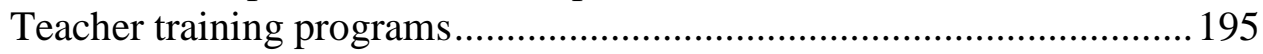

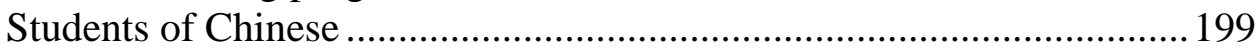

A more comprehensive goal for learning Chinese ........................ 200

Adjusting attitudes towards a Chinese teaching style ....................201

Assumptions and Limitations .............................................................. 202 


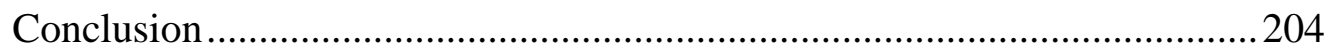

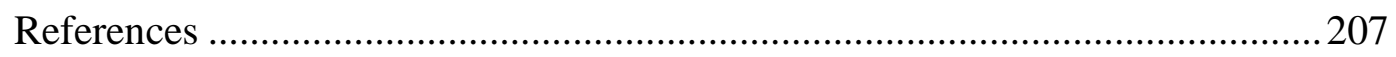

Appendices

A: Guidelines for Classroom Observation ................................................ 215

B: Fieldnotes for Classroom Observation ..................................................2 218

C-1: Questions for the First Interview ................................................... 219

C-2: Questions for the Second Interview .............................................. 220

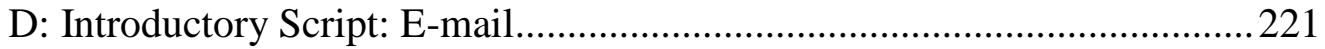

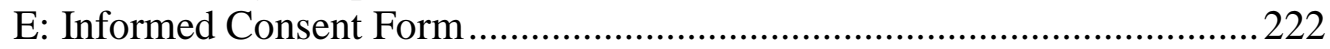


List of Tables

Table 1: Degrees Conferred by Degree-granting Institutions by Field of Study: 2003-04 6

Table 2: Degree Conferred by Degree-granting Institutions by Field of Study:

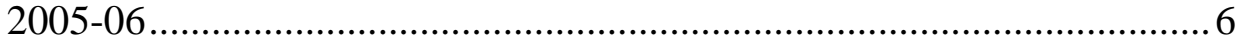

Table 3: Fall 2002 and 2006 Language Course Enrollments in U.S. Institutions of Higher Education......................................................................... 7 


\section{List of Figures}

Figure 1: Thorndike's Law of Effect.............................................................. 20

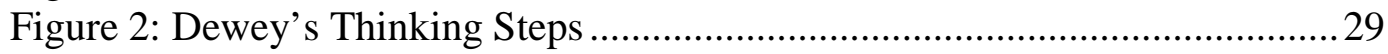

Figure 3: Kolb’s Experiential Learning Model ................................................. 29

Figure 4: Range of Contextual Support and Degree of Cognitive Involvement in

Communicative Activates ................................................................. 32

Figure 5: The Length of Time to Achieve Language Proficiency.......................... 34

Figure 6: The Potential Connections between Teachers’ Epistemological Beliefs and Language Teaching............................................................... 42

Figure 7: How $x$ Plays a Role in Causing y (Maxwell, 1996) ............................... 53

Figure 8: Transcription of Classroom Observations for One Participant...............82

Figure 9: Data Collection and Analysis go Hand in Hand (Patton, 2002) .............91

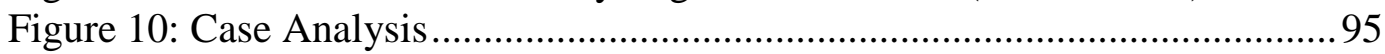

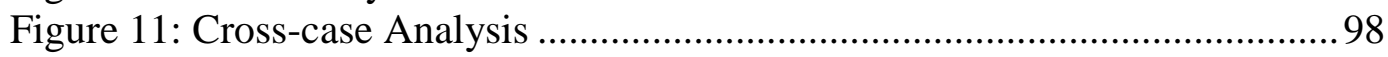

Figure 12: Seven Themes Respond to the Two Research Questions .................. 117

Figure 13: The Chinese Teachers’ Professional Development - Analyzed with Mesirow's (2000) 10 Phases of Transformation .............................. 159

Figure 14: The Lin Transformational Teaching and Professional Development

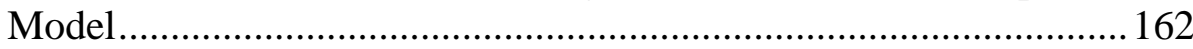

Figure 15: The Five Areas of Discussion ......................................................... 164

Figure 16: Changes in Beliefs about Foreign Language Teaching and Learning:

A Schematic Diagram.................................................................... 169

Figure 17: Suggestions for Four Areas.......................................................... 185

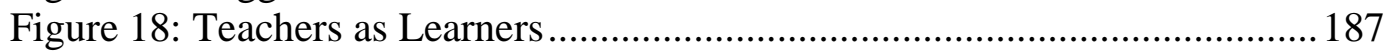

Figure 19: Seven Areas for Foreign Language Classroom Observation.............. 194

Figure 20: Six Independent Variables that Influence Language Teachers’ Pedagogical Beliefs about Teaching ............................................... 197

Figure 21: Two Dependent Variables Derived from Teachers’ Pedagogical Beliefs 198

Figure 22: Four Dimensions of Classroom Teaching........................................ 203 


\section{CHAPTER I \\ INTRODUCTION}

Teacher's Beliefs Impact Student Learning Outcomes

Traditionally, language has tended to be viewed more as a parallel to objects and phenomena of the physical world, rather than being seen as part of the social world (Hamp-Lyons \& Condon, 2000; Lange, 2003). This physical-world orientation for language leads to the assumption that the goal of language teaching is to teach knowledge about a language, not how to use the language (Freeman \& Johnson, 1998; Hamp-Lyons \& Condon, 2000; Lange, 2003). When government officials and business leaders feel increasingly concerned about a lack of international skills and foreign language proficiency among college graduates they hire (Bollag, 2006, 2007; Field, 2006; Liebowitz, 2006; Millman, 2007, Modern Language Association of America [MLA], 2007; Wasley, 2008), this fundamental concept of what language is can be a highly relevant issue, though often unspoken or misunderstood.

To improve the outcome of foreign language teaching, new curricula based on the Standards for Foreign Language Learning in the $21^{\text {st }}$ Century (National Standards, 2006) have been designed (Allen, 2002), and new approaches to language teaching have been introduced (Bollag, 2007; Freeman \& Freeman, 1994; Freeman \& Johnson, 1998; Hamp-Lyons \& Condon, 2000; Lange, 2003; Nieto, 2002; Seelye, 1993). However, these efforts have not been enough to ensure that students can learn to communicate in meaningfully appropriate ways.

It has been argued that teachers are the most powerful agent for modifying classroom practices (Prawat, Richard \& Anders, Tedick \& Walker, as cited in Allen, 
2002): "The only way to realize reform and pay attention to the new standards is by altering the way in which teachers think about teaching" (Glisan, as cited in Allen, 2002, p. 518).

Teacher belief, which "is a particularly provocative form of personal knowledge that is generally defined as pre- or inservice teachers' implicit assumptions about students, learning, classrooms, and the subject matter to be taught" (Kagan, 1992, p. 65-66), can be a measure of a teacher's professional growth. Key instructional activities are likely to become the vehicles that translate teacher beliefs into classroom instruction (Kagan). "In most current conceptions, the perceived relationship between beliefs and actions is interactive. Beliefs are thought to drive actions; however, experiences and reflection on action may lead to change in and/or addition to beliefs" (Richardson, 1996, p. 104). Kagan points out “ ... as we learn more about the forms and functions of teacher beliefs, we are likely to come a great deal closer to understanding how good teachers are made" (p. 85).

Previous research indicates that teachers change the way they teach when their beliefs about foreign language change (Freeman \& Freeman, 1994). However, inconsistencies can develop between teachers' beliefs and the nature of the new approaches that they have adopted (Allen, 2002; Beckett \& Miller, 2006). When teachers do not completely internalize the approaches they use, students are less likely to evidence learning gains. 
In order to facilitate effective language learning, this study focused on the relationship between foreign language teachers' pedagogical beliefs and classroom teaching. The following is the social context of the study.

\section{U.S. Need for Foreign Language Competence}

Following the September $11^{\text {th }}, 2001$ attacks, international education and foreign language learning in the U.S. become viewed as keys to securing America's future (Bollag, 2006, 2007; Field, 2006; Liebowitz, 2006; Millman, 2007, Modern Language Association of America [MLA], 2007; Wasley, 2008). Liebowitz (2006) reports that at the U.S. university presidents' Summit on International Education meeting, "Secretary of State Condoleezza Rice and Secretary of Education Margaret Spellings set out to make Americans' foreign-language competency a central component of U.S. national policy” (ף 1). Similarly, Dr. Rita Oleksak, president of the American Council on the Teaching of Foreign Languages (ACTFL), presented testimony before Congress on January 25, 2007:

The United States suffers from a "language deficit" because our country has failed to make language learning an important part of every child's education ... the goals of achieving language-trained military and language-qualified personnel in embassies around the world will fail unless strong support is provided to our nation's K-20 foreign language education infrastructure. (p. 5)

Wasley (2008) notes that, "National-security experts have unabashedly spoken of the shortfall in qualified teachers and linguists in Arabic and other languages now crucial to military, intelligence, and diplomacy, as a crisis” ( $₫ 1)$. The Modern Language Association of America (MLA) (2007) states that "The lack of foreign language competence is as much a fact within academic disciplines as in the society at 
large ... At the graduate level, language requirements are notoriously underenforced across the humanities and the social sciences ... Four-year language majors often graduate with disappointingly low levels of linguistic ability" (Strengthening the demand for language competence within the university section, $₫ 1$ ). For example, surveys of business leaders reveal that they are increasingly concerned about a lack of international skills and foreign language proficiency among college graduates they hire. Educators and policy makers have voiced concern that far too few students graduate from American institutions with the ability to work in foreign languages, and of those who do, many have only a shallow understanding of the culture of the target language. The U. S. government needs people who can conduct high-level negotiations in Chinese, Persian, Arabic, and other critical languages (Bollage, 2007; Fischer, 2007; Millman, 2007).

However, "Despite pressure from government and industry, universities do not produce enough graduates fluent in 'critical languages'... according to a recent report by the congressionally appointed Iraq Study Group, only six of the 1,000 U.S. embassy employees in Baghdad speak the language fluently. Mandarin is vital for representing American companies in China ... But in the 2003-4 academic year, the latest for which the U.S. Education department has figures, American institutions awarded only 15 master's degrees in Chinese, and five Ph. Ds" (Bollag, 2007, ๆ 1). Degrees Issued in Foreign Languages and Literatures

Data from the National Center for Education Statistics (NCES) shows that during 2003-2004, the total number of bachelor's degrees conferred by degree- 
granting institutions in foreign languages and literatures was 17,754; the total number of master's degrees was 3,214; and the total number of doctorates was 1,031 . During 2005-2006, the total number of bachelor's degrees rose to 19,410 ; the total number of master's degrees rose to 3,539; and the total number of doctorates remained about the same, 1,047. Called critical languages (Bollag, 2007), the eight languages identified with the most pressing deficits are Arabic, Chinese, Japanese, Korean, Russian, Hindi, Persian, and Turkish. Tables 1 and Table 2 compare the degrees conferred by degreegranting institutions in 2003-2004 and 2005-2006 for four of the eight critical languages. Although more degrees were issued during 2005-2006, the number is still small. These numbers seem to indicate that in the face of globalization, "The United States suffers from a language deficit" (Oleksak, 2007, p. 5). 
Table 1

Degrees Conferred by Degree-granting Institutions by Field of Study: 2003-04

\begin{tabular}{llll}
\hline Field of Study & Bachelor's & Master's & Doctoral \\
\hline Arabic & 13 & 3 & 1 \\
Chinese & 186 & 15 & 5 \\
Japanese & 381 & 24 & 8 \\
Russian & 301 & 21 & 3 \\
\hline
\end{tabular}

Entries in these columns are selected from National Center of Educational Statistics, Table 252.

Table 2

Degrees Conferred by Degree-granting Institutions by Field of Study: 2005-06

Field of Study Bachelor's Master's Doctoral

\begin{tabular}{llll}
- & & & \\
Arabic & 26 & 4 & 2 \\
Chinese & 241 & 20 & 10 \\
Japanese & 487 & 29 & 10 \\
Russian & 279 & 28 & 7 \\
\hline
\end{tabular}

Entries in these columns are selected from National Center of Educational Statistics, Table 252.

\section{Enrollments in Foreign Languages and Literatures}

According to reports from MLA $(2004,2007)$, in 2002 the proportion of 8.6 MFL (modern foreign language) enrollments per hundred institutional enrollments was the highest since 1972 (Welles, 2004). In 2002, overall enrollments in languages other than English were 1,397,253. In 2006, the overall enrollments were 1,577,810, up by $12.9 \%$. Although there is an enrollment growth in foreign languages, enrollment in 2006 was only half of that in 1960-65. In 1965, for every 100 college students, there 
were 16.5 enrollments in foreign languages (Howard, 2007; Welles, 2004). Table 3 shows an enrollment growth in four critical languages.

Table 3

Fall 2002 and 2006 Language Course Enrollments in U. S. Institutions of Higher Education

\begin{tabular}{llll}
\hline Languages & 2002 & 2006 & $\%$ Change \\
\hline Arabic & 10,584 & 23,974 & 126.5 \\
Chinese & 34,153 & 51,582 & 51.0 \\
Japanese & 52,238 & 66,605 & 27.5 \\
Russian & 23,921 & 24,845 & 3.9 \\
\hline
\end{tabular}

Entries in these columns are selected from The Modern Language Association of America, 2007.

Still, significant differences are observed between enrollments in lower-level and upper-level courses. For every eight enrollments in first- and second-year Arabic, there is only one enrollment in an advanced Arabic course. For Chinese, the ratio was 9 to 2. For Spanish and Japanese, the ratio was 5 to 1 (Howard, 2007; Redden, 2007). The MLA's executive director notes that the numbers do not reflect students who take advanced-level languages during study abroad (Redden, 2007). Furman, Goldberg, and Lusin (2007) argue that, "Retaining students in upper-level courses is a challenge many fields share and is made more acute by the growing curricular choices now offered to students in fields that did not exist a few decades ago" (p. 7). An even more serious problem is the shortage of qualified teachers. 
Shortage of Qualified Teachers of Critical Languages

Unlike many European and Asian countries, the United States has never made foreign language learning a priority at schools. Understandably, there is a shortage of Americans who can speak and teach the critical languages (Liebowitz, 2006). For example, enrollments for Arabic rose by $126.5 \%$ (MLA, 2007), but "the number of people available to undertake teaching (Arabic) has remained basically the same" (Howard, 2007, Shortage of teachers of Arabic section, \ 1). According to a report by the Asia Society (Liebowitz, 2006), the situation for Chinese is not much better. In 2006, the U.S. Government flew 10 Chinese teachers to Washington from China, which truly highlighting the urgency of establishing Chinese programs in U.S. schools and indicating the shortage of qualified teachers of Chinese (Aratani, 2006; Bollage, 2007; Fischer, 2007; Millman, 2007).

The need for more qualified professors of languages crucial to national security has been acknowledged by U.S. government and national-security experts (Wasley, 2008). Madeleine F. Green, vice president for international initiatives at the American Council on Education, suggests that attention should be paid to in-service teachers. She said, "I tell provosts that if they have $\$ 100$ to invest in internationalization, invest most of it in faculty development. If faculty are not engaged, it's not going to happen" (Fisher, 2006, \ 2). "In short, the U.S. has no large population of language educators at the Ph.D. level. University language departments are, by and large, departments of literature and culture" (Vantten, 1998, p. 931). Since the United States is unlikely to produce a new cadre of speakers of critical languages in a short period (Liebowitz, 
2006), it is time to begin changing the way teacher-educators and in-service teachers of foreign languages view the teaching and learning of foreign languages (Bollag, 2007; Freeman \& Johnson, 1998; MLA, 2007). A review of traditional curricular approaches follows.

Traditional Natural Science Oriented Curriculum, Instruction, and Assessment

Historically, language learning was conducted like learning natural science. Lange (2003) points out that, “...much of the foreign language literature on curriculum has been based on a technical orientation of curriculum, assessment, and instruction derived from the scientific nature of the area of study" (p. 286). Language has been viewed as parallel to objects and phenomena of the physical world instead of being seen as part of the social world (Hamp-lyons \& Condon, 2000; Lange, 2003). And much foreign language classroom teaching and assessment tends to stick to scientific-technical approaches (Lange, 2003). Knowledge about the target language (the foreign/ second language that is learned) is taught, but the cultural contexts in which the language occurs tend to be missing in the learning process. Fixed, normative phenomena of language use are taught without cross-cultural information (Cramsch, 2003). Grammar-translation and audio-lingual approaches are practiced in most classrooms. The instructor speaks in the first language and focuses on grammatical parsing (Celce-Murcia, 2001). The learning process is often set in a simple behaviorist framework (Chomsky, 2006). Language learning is limited to the "four skills": listening, speaking, reading, and writing. But, it is argued, this four-skill model of language use does not capture the interactive nature of communication (National 
Standards, 2006). Therefore, the result of such teaching is college graduates' lack of language proficiency (Bollag, 2007; Fischer, 2007; Millman, 2007; MLA, 2007).

New Challenges to Teachers of Foreign Languages

The MLA has called for the traditional foreign language teaching model (two or three years of vocabulary, grammar, and conversation, followed by literature courses) to be replaced by new approaches that incorporate more culture from the start (Bollag, 2007; MLA, 2007). This change might help improve the curriculum and governance structure of language departments and the connection between the language curriculum and the literature curriculum. Still, the question remains: How well do teachers understand the National Standards (2006) and new approaches (Allen, 2002; Sato \& Kleinsasser, 1999)? There is evidence that while the National Standards are recognized in theory as important to instruction, they are not being fully integrated into teaching practices (Wilbur, 2007). With the new requirements of the National Standards and demands from governments and business (Bollag, 2007; Liebowitz, 2006; MLA, 2007; Wasley, 2008), in-service teachers are facing challenges to acquire knowledge and competencies not required twenty years ago (Velez-Rendon, 2002).

Given these changes and pressures to be an effective foreign language teacher, one needs to re-examine his/her beliefs about language and language teaching (Allen, 2002; Freeman \& Freeman, 1994; Freeman \& Johnson, 1998; Freeman \& Richards, 1996). "The only way to realize reform and pay attention to the new standards is by altering the way in which teachers think about teaching" (Glisan, 1996, p. 158). 
Purpose and Significance of the Study

Since international education and foreign languages have become keys to securing America's future, foreign language enrollments rise every year, and institutions are facing the challenge to produce more graduates fluent in critical languages (Bollag, 2006, 2007; Field, 2006; Liebowitz, 2006; Millman, 2007) and familiar with the target culture, thus making it profoundly necessary to strengthen foreign language teaching.

Foreign language teachers' understandings of the National Standards (2006), and their pedagogical beliefs about language and classroom teaching, are two crucial factors that impact student learning outcomes (Freeman \& Freeman, 1994; Freeman \& Johnson, 1998; Glisan, 1996).

If the change of teacher pedagogical beliefs is a way to realize the reform advocated by the National Standards (Glisan,1996), and because "we lack direct evidence concerning the processes that effect change in teacher belief' (Kagan, 1992, p. 65), research into the development of foreign language teachers' pedagogical beliefs is needed. Results of the study would offer foreign language teachers, learners, or teacher training programs some potential factors, maybe previously less noticed, that are relevant to student learning outcomes.

This study investigated the relationship between Chinese teachers' pedagogical beliefs and their classroom instruction. The rationale for this study is: The United States must compete in a global market (Bollag, 2006, 2007; Field, 2006; Liebowitz, 2006; Millman, 2007, MLA, 2007; Oleksak, 2007; Wasley, 2008) and China is one of 
the key global markets. It is critical for universities to produce enough graduates with high level of Chinese proficiency and cultural competency for doing business in China (Bollage, 2007; Fischer, 2007; Millman, 2007). Because qualified teachers of Chinese are too few and the U.S. government is likely in future to hire Chinese-born teachers (Aratani, 2006; Bollage, 2007; Fischer, 2007; Millman, 2007), the target population of this study were teachers of Chinese, particularly teachers who came from China and taught in the U.S. colleges.

This study focused on the relationship between the Chinese teachers' beliefs and their decisions about classroom teaching. By exploring the early formation of their pedagogical and epistemological beliefs, the development of their pedagogical strategies, and the refinement of their teaching approaches, the results indicate some evidence concerning events that effect changes in these Chinese teacher's beliefs about foreign language teaching and learning. These beliefs can range from fundamental assumptions about the nature of language to concepts of what should be taught in classrooms, all the way down to details about behavior and reflection. All can be significant to how students learn.

The following chapter discusses related literature. 


\section{CHAPTER II \\ DISCUSSION OF RELATED LITERATURE}

This study was guided by theories and perspectives from two fields: foreign language teaching and adult education. These theories and perspectives informed the study from historical factors to current problems, and led to a potential change for teachers of Chinese and other foreign languages. The literature review centered around the theme of "shifting the conception of teaching from a behavioral view of what people do when they teach language to a constructivist view of how people learn to teach" (Freeman \& Johnson, 1998, p. 402). This chapter includes three sections: foreign language teaching, becoming an effective teacher of foreign language, and significance of this study and research questions.

\section{Foreign Language Teaching}

It has been recognized that much of what language teachers know about teaching comes from their memories as students, as language learners, and as students of language teaching. Teachers' beliefs about teachers and instruction are influential in shaping how they interpret what goes on in their classrooms. Teachers' beliefs and past experiences as learners tend to create ways of thinking about teaching (Freeman \& Freeman, 1994; Freeman \& Johnson, 1998; Kagan, 1992; Lortie, 1975; VelezRendon, 2002). These experiences hold true for all teaching as well as specifically for foreign language learning. The beliefs foreign language teachers hold and their experiences with language learning influence their own views of language acquisition.

Since approaches to foreign language teaching were developed based on linguists' and language educators' understanding about language, this section starts 
with traditional views and developing perspectives on language. A discussion of four approaches comes next: grammar-translation, audiolingualism, communicative language teaching, and project-based language learning. This is followed by a discussion of what counts as language proficiency. This section ends with a brief review of the attempts to improve the outcome of language learning.

\section{Traditional Views on Language}

Language is a defining property of humans, which is shared across all human communities and is manifested in no other species (Aronoff \& Rees-Miller, 2001). Chomsky (2006) states “... the nature of language... mirrors human mental processes or shapes the flow and character of thought ..." (p. 1), and "Language can serve as an instrument of thought and self-expression" (p. 11). To mirror or shape one's thought, one needs to achieve a high level of language proficiency (Discussion about language proficiency will be presented later in this section).

However, language was studied as a natural science for a long time. Traditional studies of language did not pay enough attention to the social interaction between language and humans. According to Aronoff and Rees-Miller (2001), the history of linguistics was mixed up with intellectual history in general. Early development in linguistics was regarded as part of philosophy, rhetoric, logic, psychology, biology, pedagogy, poetics, and religion. For example, Mas Mueller published his book The Science of Language in 1869. The first chapter of the book is entitled, "The science of language, one of the physical sciences" (as cited in Aronoff \& Rees-Miller, 2001, p. 
xiv). Another book, The Life and Growth of Language: An outline of Linguistic Science, written by William Whitney was published in 1875 .

When linguistics was conceived as a natural science, the historical dimension of language was conceptualized as the laws of sound change. Linguistics looked at language as a self-contained fixed structure, whose behavior can be predicted. Only those language phenomena that could be reduced to natural processes were regarded worthy of study. For a long time, language was grounded in the physical world of sound, and through the combination of sounds into words, and the combination of words into sentences. Operating on words and sentences, meaning came next. The core of linguistics was formed traditionally by these areas which deal with the formally structured aspects of language (Aronoff \& Rees-Miller, 2001).

However, as linguistic knowledge developed, it become clear that linguistic structure alone cannot answer satisfactorily the questions of why and how languages change. One must also look at language as it is used in society. Although social aspects of language often caught linguists' attention, their studies still focused on the physical world of language: phonetics (sound), phonology (the organization of sound in language), morphology (the combination of sounds into words), syntax (the combination of words into sentences), and semantics (meaning) (Aronoff \& ReesMiller, 2001). Based on this traditional view on language, the grammar-translation approach was developed (further discussion about this approach will be given later in this section). 


\section{Developing Perspectives on Language}

In the twentieth century, linguistics uncovered a great deal about language and how it is acquired and used (Aronoff \& Rees-Miller, 2001). The mainstream of linguistics has been greatly influenced by Noam Chomsky, the most famous theoretical linguist in our time, since 1957 . Chomsky points out that the primary task of a linguist should be to describe and explain the knowledge of the structure of the language which the native speaker has, instead of discovering the structure of the language from a body of recorded data (Campbell, 2001). Responding to Chomsky's (1965) characterization of the linguistic competence of ideal native speakers (individuals who know a language perfectly and use it appropriately in all social interactions) (Savignon, 2001), Hymes (1971) offers arguments on communicative competence. Although Hymes's arguments deal more with language as social behavior than with language learning, the social rules of language use reveal that language cannot be understood fully without looking at language use. And language cannot be truly learned without communicative competence. About twenty years later, according to Beckett (2006), Halliday and Mohan (as cited in Beckett) started to view language as a resource within a particular sociocultural context. This view of language is linked to the language socialization (Schieffelin \& Ochs, as cited in Beckett) that enlightens language learning: “... the language socialization view holds that language learning is the acquisition of linguistic as well as sociocultural knowledge" (Beckett, 2006, p. 6). Chomsky's later publications, Reflections on Language (1975) and Language and Mind $(1968,2006)$ further explore the social relationship between language and 
humans. Other studies on language (pragmatics, discourse, sociolinguistics, applied linguistics, etc.) and language acquisition have richly increased the knowledge of language.

However, according to Aronoff and Rees-Miller (2001), many of these advances and discoveries about language are still unknown outside a small group of practitioners. There are many reasons for this gap between academic and public thinking about language. The most commonly given reason is, "people have strong and sometimes erroneous views about language and have little interest in being disabused of their false beliefs; or that people are too close to language to be able to see that it has interesting and complex properties" (Aronoff \& Rees-Miller, p. xv). For example, Wilkerson (2008) states that faculty members outside linguistics and language departments generally believe that learning a second/foreign language means instruction in grammar and vocabulary. Many language teachers focus more on teaching behaviors and learner outcomes than on learning about the nature of language teaching (Freeman \& Johnson, 1998; Freeman \& Richards, 1996). This can be one of the factors behind the comment that "Four-year language majors often graduate with disappointingly low levels of linguistic ability" (MLA, 2007, Strengthening the demand for language competence within the university section, $\uparrow 1$ ).

\section{Foreign Language Teaching Methodology}

"Divergent views concerning language and its many functions are reflected in differing approaches to the study of language” (MLA, 2007, ๆ 2). To examine the relationship between foreign language teachers' pedagogical beliefs and the decisions 
they make about classroom teaching, it helps to be aware of the history behind various methodologies of foreign language teaching. This knowledge can help identify the advantages and disadvantages of adopting a specific approach in classroom activities. Heimlich and Norland (1994) state that the knowledge of method, "is not the what but the why" which allows the teacher "to bring personal beliefs, values, and philosophy of teaching and learning to the application of the method" (p. 163).

According to Celce-Murcia (2001), there are nine twentieth-century approaches to foreign language teaching: 1) Grammar-translation; 2) Direct; 3) Reading; 4) Audiolingualism (United States); 5) Oral-situational (Britain); 6) Cognitive; 7) Affective-humanistic; 8) Comprehension-based; and 9) Communicative. The discussion here focuses on three approaches that have been practiced in most classrooms: grammar-translation, audiolingualism, and communicative; followed by yet another approach that has received growing interest: Project-based second/foreign language learning.

\section{Grammar-translation}

American structural linguistics, founded mainly by Bloomfield (1887-1949), has had a great impact on grammar-translation. In the analytical Grammar-Translation Approach, instruction is given in the first language and focuses on grammatical parsing (Celce-Murcia, 2001). There is little use of the target language (the foreign language that is learned) in classroom activities. In the past, foreign language instruction focused primarily on the memorization of words and grammar rules (National Standards, 2006). Teachers are proficient only in the vocabulary and 
structures. Concomitantly, classroom teaching is teacher-centered. Students are guided to analyze sentences with elements of the sentence (subject, object, predicate, complement, adverbial, etc.) and parts of speech (noun, verb, adjective, conjunctions, etc.). Exercises of translating students' first language into the target language or the other way round are practiced in and out of class. The teacher acts as the knowledgegiver and students as knowledge-receivers. Little reflection or social interaction is involved.

\section{Audiolingualism}

According to Celce-Murcia (2001), audiolingualism can be regarded as a byproduct of World War II. The war pushed the U.S. military to quickly train people who could understand and speak foreign languages. The U.S. government hired linguists to help with the program. The audiolingual approach was built on structural linguistics (Bloomfield, 1933) and behavioral psychology (Skinner, 1957), and it worked arguably better than earlier methods. Before discussing more of this approach, a brief review on behaviorism is described.

In 1931, Watson claimed that the behaviorist view in psychology is a purely objective experimental branch of natural science. Its theoretical goal is the prediction and control of behavior. Behaviorists are interested in how new behavior is acquired, instead of how new knowledge is acquired. Learning can be described simply as the acquisition of new behavior without reference to mental events. To the behaviorists, learning was a process of expanding the behavioral repertoire, not a matter of expanding the ideas in the learner's mind (Phillips \& Soltis, 2004). 
According to Phillips and Soltis (2004), Thorndike (1874 - 1949) developed his "laws of learning" based on his study of the learning behavior of cats. A cat was imprisoned inside a box. Once the cat touched a lever set inside the box, it freed itself or got some fish as reward. Thorndike's "law of effect" can be diagramed as:

Figure 1 Thomdike's Law of Effect

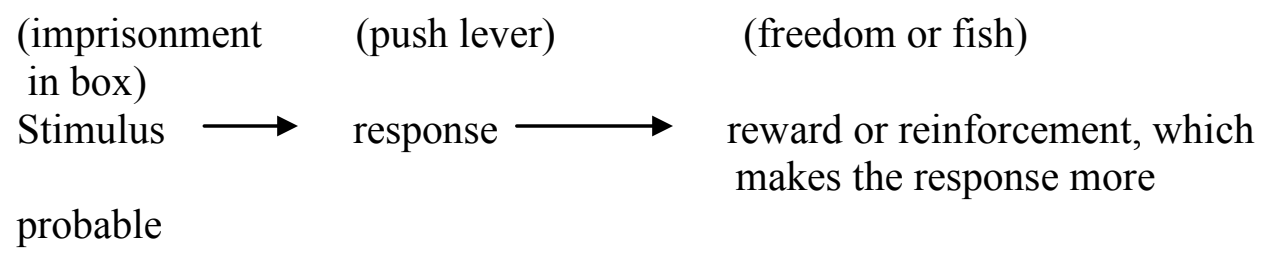

(Phillips \& Soltis, 2004, p. 26)

When this principle was applied to humans, Thorndike argued, people would repeat a behavior in order to get a reward. Thorndike believed the more behavior is practiced or exercised, the more strongly it will be learned.

Based on Thorndike's model and his own studies, Skinner (1904-1990) developed his Stimulus-Response (S-R) pattern: Changes in behavior are the result of an individual's response to events (stimuli) that occur in the environment. When a particular S-R pattern is rewarded (reinforced), the individual is conditioned to respond. In 1957, Skinner claimed to be able to explain language, based on his S-R model, as a set of habits gradually built up over the years. However, Skinner's Verbal Behavior was critiqued by Chomsky in 1959 (Campbell, 2001) and the field of stimulus-response psycholinguistics was rejected by Chomsky $(1968,2006)$ (further discussion will be in this chapter). 
Behaviorist psychology has had a great impact on the development of audiolingualism. In the audio-lingual approach, mimicry and memorization are used. Grammatical structures and rules are taught. Language is often manipulated without regard to meaning or context. Instructors must be proficient only in the structures and vocabulary (Celce-Murcia, 2001). Listening, speaking, reading, and writing are widely accepted as four skills for communication in the audio-lingual approach. Speaking and writing are assumed to be active skills, reading and listening as passive skills. It is believed that after the training, the learners should be able to make a response by using the sentence patterns/structures they have remembered when they hear or read something presented in the target language (as stimulus). What they need to do is to substitute one or two of the sentence elements.

Grammar-translation and Audiolingulism are based on the assumption that what people should learn is a set of words and the grammatical rules needed for comprehending and producing language with those words. These methods have the aim of helping students develop grammatical competence. However, grammatical competence is only one of the components of communicative competence (Kramsch, 2003; National Standards, 2006; Scarcella, Andersen, \& Krashen, 1990; Swain, 1984). Further discussion about communicative competence will be in the next section.

Current foreign language teachers, including teachers from China, have been largely trained through grammar-translation and audiolingualism, either in their teacher-training programs or as students of foreign languages. The idea that a language is best learned by repeating vocabulary and grammatical structures over and over until 
they are memorized was accepted up until the 1970s (Bollag, 2007). Even now, such ideas can still be seen in language textbooks and foreign language classroom activities.

" The problem was, while those who learned from that method might be able to read in a foreign language, they were often not very good at talking with native speakers" (Bollag, 2007, Changing lessons section 1). According to the comments on current foreign language learning outcomes (Bollage, 2007; Fischer, 2007; Millman, 2007; MLA, 2007), grammar-translation and audiolingulism are not sufficient enough to help learners acquire the ability to communicate in meaningful and appropriate ways with users of other languages. In this view, instead of being separated into the four skill areas (listening, speaking, reading, and writing), communication should be organized around a framework of interpersonal, interpretive, and presentational modes (The National Standards, 2006).

Freeman and Freeman (1994) state that a teacher's knowledge of language and theory of a foreign language help form the teacher's orientation toward teaching the language. Teachers' awareness of their own beliefs forms the basis for a philosophy or personal vision for teaching and learning (Freeman \& Johnson, 1998; Galbraith, 1998; Kangn, 1992; Velez-Rendon, 2002). The following studies are essential for understanding a reform of language teaching. Communicative Language Teaching (CLT)

Chomsky $(1968,2006)$ states that language plays an essential role in thinking and human interaction. The study of language relates to the study of human learning and behavior. "The normal use of language is a creative activity" (Chomsky, 2006, p. 
88). The philosophy or psychology of language is never as simple as Skinner's (1957) behaviorist framework describes. The structural linguistic methodology, the stimulusresponse psycholinguistics, or the automata-theoretic models for language use, each is “inadequate in a fundamental way" (Chomsky, 2006, p. 3). Chomsky points out that there is no direct relation between experience and action, between stimuli and responses. Furthermore, Chomsky argues that stimulus-response psycholinguistics limits itself to the concept of what is learned, missing how learning works. By diminishing the range and complexity of materials presented to the inquiring mind, by setting behavior in fixed patterns, these methods may harm and distort the normal development of creative abilities (Chomsky). Chomsky's theory of language brought about a revolution in linguistics. With new perspectives on language, CLT was progressively developed.

Communicative approach is regarded as a change in beliefs about language teaching and learning. The development of CLT reflects the increasing understanding of the nature of language and language teaching in the field. The development of CLT can be traced back to the 1970s in both Europe and North America. In Europe, to meet the language needs of a rapidly increasing group of immigrants and guest workers, the notional-functional concept of language was recognized, which focuses on what learners should be able to do with the language (Savignon, 2001). In North America, Hymes (1972) argues that the ability to speak competently not only entails knowing the grammatical rules of a language, but also knowing what to say to whom in what circumstances and how to say it. Swain (1984) states that communicative competence 
involves at least four areas of knowledge and skills: grammatical, sociolinguistic, discourse, and strategic. This view is supported by Scarcella, Andersen, and Krashen (1990), who state that language appropriateness relates to all four components of communicative competence. To reach a higher level of language proficiency, Kramsch (2003) claims that another competence is needed: cultural competence. Hymes's (1972) argument makes a great contribution to the development of sociolinguistics and foreign language learning. Several decades' hard work on language teaching and learning leads to the ten words that encompass all the linguistics and social knowledge required for effective human-human interaction: "Knowing how, when and why to say what to whom" (National Standards, 2006, p. 11). CLT tries to make it possible for learners of foreign languages to acquire this ability.

According to Savignon (2001), CLT derives from a multidisciplinary perspective that includes linguistics, psychology, philosophy, sociology, and educational research. It has been put forth as a new approach to foreign/second language teaching. In a CLT classroom, in which the target language is the language of instruction, there is an immediate and natural need for students to use the target language (Swain's input and output theory, 1995). Based on sociocultural theory (Vygotsky, 1978), the teacher acts as an expert to help students with the elements of a task that are beyond the students' ability (Krashen's Monitor Model, 1982) through negotiation. Savignon states that communication should be a collaborative activity like a football game: the interest of a football game lies not in the football, but in the moves and strategies of the players. Similarly, the interest of communication lies in the interpretation and 
negotiation of meaning between the participants. CLT plays a role to switch from the traditional teacher-centered class to a learner-centered class.

However, discussions of CLT frequently lead to questions of grammatical and formal accuracy (Savignon, 2001). To teachers who work with students for language testing (e.g. teachers in China), issues of grammar and accuracy are certainly serious problems that elicit sensitive feelings towards CLT.

Project-based Second/Foreign Language Learning (PBL)

Another approach to foreign language teaching that acts on the part of the learner is project-based second/foreign language learning $(\mathrm{PBL})$. The project method was Kilpatrick's construction of Dewey's problem method of teaching (Brubacher, as cited in Beckett, 2006). The method was introduced into the field of second language education about 20 years ago. According to Beckett, PBL takes a functional standpoint that views language as a resource within a particular sociocultural context (Halliday; Mohan, as cited in Beckett, 2006). This view of language is connected to the language socialization (Schieffelin \& Ochs, as cited in Beckett) that enlightens language learning. Instead of learning a set of rules for language learning, the language socialization perspective holds that language learning is the acquisition of linguistic and sociocultural knowledge together. From this perspective, language is a medium of "socialization through the use of language and socialization to use language" (Schieffelin, as cited in Beckett, 2006, p. 6). This theoretical framework "treats language as a focus of study as well as a medium of study" (Beckett, p. 6). The language socialization theory leads a teacher to see project-based instruction as an 
activity, and as a sociocultual context that provides opportunities for the teacher to teach the target language, school and social cultures, curriculum content, and various skills. Based on Beckett's arguments, PBL can be an activity or context in which foreign language teachers teach the target language functionally by requiring students to listen, speak, read, and write in the target language to learn content material.

Because it is a fairly new term in language teaching, PBL has been introduced in terms of a wide variety of other concepts. Its goal, in one of the explanations, is to provide students opportunities to "recycle known language and skills" in natural contexts (Haines, as cited in Beckett, 2006, p. 4). It has also been discussed within the theoretical frameworks of experimental learning, student-centered learning, learner autonomy, cooperative learning, and critical thinking (Fried-booth; Eyring; Hedge; Kohonen; Leguke \&Thomas; Van Lier; as cited in Beckett, 2006). It has been described as an approach to provide students with comprehensible input and output, with an emphasis on practicing listening and speaking skills, and as a content-based approach (Stroller, as cited in Beckett).

According to Beckett (2006), PBL has been adopted as a vehicle for fully integrated language and content learning, and a mechanism for cross-work. PBL has been connected with in-class group work, out-of-class activities, cooperative learning, and task-based instruction. Some project work involves fairly nonelaborated tasks, others require elaborate sets of sequenced tasks. For example, through projects such as getting-to-know-each-other multicultural parties or learning-about-other-cultures, students are working actively in information gathering, processing, and reporting, with 
the goal of increased content knowledge and language mastery (Beckett, 2006; Stoller, 2006).

Overall, project-based instruction is intended to create contexts for learning through language. By its nature this kind of goal can have trouble coexisting with conventional education methods. In particular, "Whenever high-stakes (standardized) tests rule the roost, project-based learning and similar initiatives tend to be pushed into the periphery of the educational landscape" (Lier, 2006, p. xii). Therefore, students have more opportunities to experience project based learning in earlier schooling, but the chances to do projects decrease as students move on into secondary and college preparatory years. When a student moves into a college or graduate level that does use a project-based method, he/she tends to forget how it felt to work on a project, and needs to make painful adjustments (Lier). For example, two research findings, one in 1989 and the other in 1999 , show that "... a considerable number of student participants did not endorse project-based English as a second language (ESL) learning, leaving their teacher frustrated and doubtful” (Beckett, 2006, p. 7). This leads to the issue of teachers and students conceiving of different models in the understanding of their teaching and learning. Further discussion about this issue will come in Chapter 5 of this paper.

But in the past ten years, there has been growing global interest in project-based foreign language education (Beckett, 2006). According to Lier (2006), PBL cannot be looked at as just another fashion. If we look past the conflicting terminology and observe PBL for what it is, we can see that under this approach there are deep 
foundations of educational thought, including Dewey's experimental and action based learning, and Piaget's and Vygotsky's modern educational theory. The following discussion focuses on Dewey's (1916) and Kolb's (1981) social and cognitive procedures for effective learning.

Learning through Experiences

Dewey (1916) and Kolb (1981) both emphasize that learning is a continuous process and learning from experiences helps adults construct knowledge. Dewey (1916) points out that the formation of habits can be translated into the power to learn from experience. Habits give control over the environment. Active habits involve thought, invention, and initiation in applying capacities to new aims. New aims create a desire to learn effectively. One cannot learn effectively without thinking. Thinking includes four steps: the sense of a problem, the observation of conditions, the formation and rational elaboration of a suggested conclusion, and active experimental testing. All thinking leads to knowledge, and the value of knowledge is decided by its use in thinking. Thinking is the method of an educative experience; the essentials of method are therefore identical with the essentials of reflection (Dewey).

About 80 years later, Kolb (1981) developed a learning model. Kolb (1981) describes learning as including four dimensions: experiences, reflection, abstraction, and experimentation. The premise of the model is "Knowledge results from the combination of grasping experience and transforming it" (Kolb, as cited in Tailor, Marienau, \& Fiddler, 2000, p. 24). When a learner takes in information through either one's sensory or conceptual faculties, the process is described as grasping. A learner 
also transforms what he/she has taken in through either reflection or action. In this way, a learner would go through all four dimensions: experience, reflection, abstraction, and experimentation (Tailor, Marienau, \& Fiddler, 2000).

When Dewey's thinking steps are put into Figure 2, and compared with Kolb's model (Figure 3), it is striking to see the similarity of the two arguments.

Figure 2 Dewey's Thinking Steps

The sense of a problem

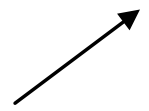

The active experimental testing

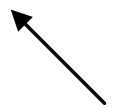

The formation and rational elaboration of a suggested conclusion

Figure 3 Kolb's Experiential Learning Model

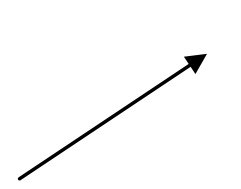

Active experimentation

(behavioral)

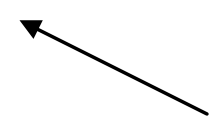

Concrete experience

(affective)

The observation of conditions

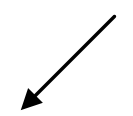

Abstract conceptualization

(symbolic)

Both Dewey's (1916) and Kolb's (1981) arguments explain procedures for effective learning. Dewey states that learning must grow from the individuals' own experience. Kolb (1981) asserts that learning cannot be achieved unless learners go through the four dimensions of the circle, and reconstruct their knowledge in order to 
guide new concrete experiences. This argument about learning is echoed by Mezirow (2000). He defines learning as “ $\ldots$ the process of using a prior interpretation to construe a new or revised interpretation of the meaning of one's experience as a guide to future action" (p. 5). Similarly, Taylor, Marienau, and Fiddler (2000) point out that experience, reflection, and meaning-making are three essential aspects of adult learning theory. It is important to explore one's past and current experiences through critical reflection while transforming one's way of knowing. Walker (2002) also points out that the process of coming to know is influenced and shaped by reflection, mediation, and social interactions.

Both PBL and CLT can be discussed within the theoretical framework of Dewey's (1916) and Kolb's (1981) social and cognitive procedures for effective learning. In a CLT class, students have a concrete experience in which messages are passed. When negotiation is needed to get the meaning of the messages, students use reflection to build concepts and generalizations. When the input (messages) leads to an output (response), this means that those concepts and generalizations are being tested for their implications. This process can then serve as a new guide to create new concrete experiences. Similarly, the in-class group work or out-of-class activities in PBL encourage students to work actively in information gathering, processing, and reporting. When a student decides to pursue the goal of increased content knowledge and language mastery set for the project, the process now includes the four dimensions of Dewey's (1916) and Kolb's (1981) social and cognitive procedures of effective learning, 
As stated at the beginning of this section, to examine the relationship between foreign language teachers' pedagogical beliefs and the decisions they make about classroom teaching, it helps to be aware of the history behind various methodologies of foreign language teaching. Another factor that influences teachers' decision-making about classroom teaching is the understanding of language proficiency.

\section{Language Proficiency}

According to Program Standards for the Preparation of Foreign Language Teachers (2002), the heart of language instruction is the ability to teach students to communicate. This can only be possible when teachers themselves have a high level of proficiency in the target language and keep strengthening their proficiency so as to be able to undergird effective implementation of the National Standards (2006). Teachers' language proficiency is a critical premise in teaching students to communicate. However, in-service teachers' understanding of the nature of language proficiency is also important when a foreign language is taught.

When discussing the nature of language proficiency, Cummins (1996) and a number of other language investigators suggest that it is necessary to fundamentally distinguish surface fluency (conversational fluency) and academic proficiency. The former needs basic interpersonal communicative skills (BICS), and the latter requires cognitive academic language proficiency (CALP). To help learners acquire both BICS and CALP simultaneously in classroom teaching is a challenge to a teacher. Classroom activities will more or less reveal the teacher's beliefs about language 
proficiency. Figure 4 is Cummins's framework for the cognitive and contextual demands of language proficiency.

Figure 4 Range of Contextual Support and Degree of Cognitive Involvement in Communicative Activities

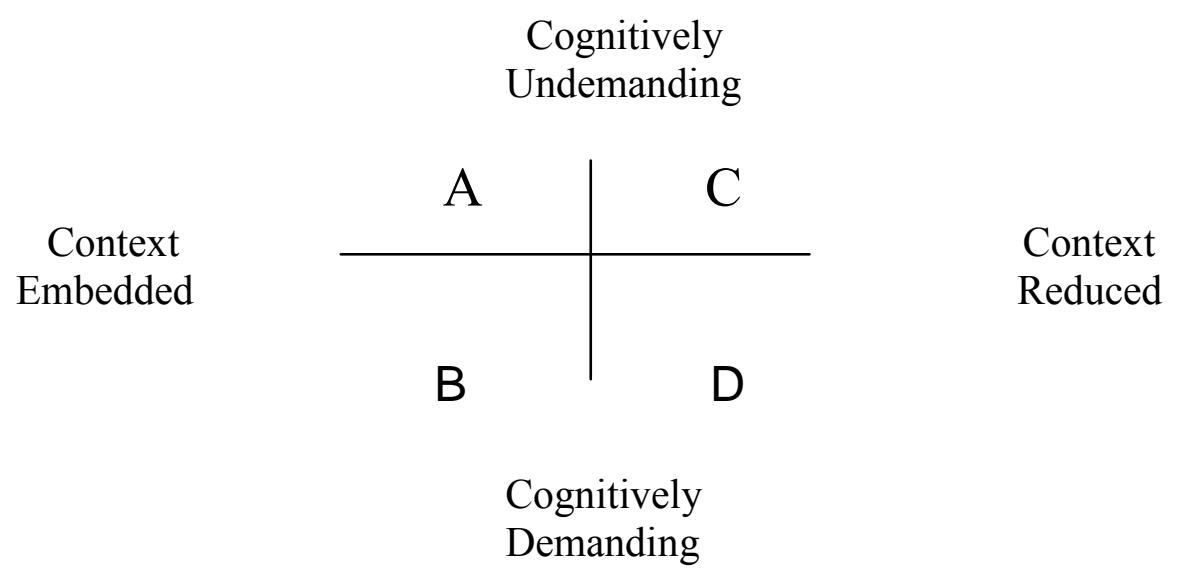

(Cummins, 1996, p. 57)

Quadrant A: A task such as a casual conversation is context embedded, and there is no cognitive challenge. Students are not pushed to go beyond what they already know and can accomplish the tasks. For example, questions like "What is your name?" and "Are you from New York?"

Quadrant B: Activities are context embedded and require active cognitive involvement. For example, an intense intellectual discussion with one or two other people. Classroom activities can provide cognitive, challenge and contextual support for students' academic progress, and explicitly focus on language awareness in order to assist students to develop strategies for picking up contextual clues embedded in both oral and written language itself. 
Quadrant C: No cognitive challenge and little context involvement, e.g. copying notes from the blackboard. Quadrant $\mathrm{C}$ activities are not very useful for promoting academic language acquisition or communication.

Quadrant D: Tasks, like academic reading and writing, require active and high levels of cognitive involvement for appropriate performance (Cummins, 1996).

Cummins (1996) argues that the distinctions incorporated into this framework have significant implications for instruction of English language learners. Cognitive challenge is essential for academic growth, and contextual support is necessary for students to meet that challenge. If we use this framework to analyze the four approaches discussed above, we shall see that CLT and PBL tend to help learners to obtain both BICS and CALP because a learning process in both approaches is context embedded and requires active cognitive involvement. On the other hand, grammartranslation, in its pure form, tend to be cognitively demanding but context involvement is rather limited; while audiolingualism, in its pure form, tends to be cognitively undemanding and involves little context.

According to the data collected from international students (from China, Cambodia, Korea, Laos, Japan, Indonesia, and Thailand) by the researcher of this study for her master's thesis, Quadrants C and D in Cummins's framework best describe the English teaching in these countries, where instruction is focused more on language analysis than proficiency. The results of such teaching is, after years of learning English, most students are not strong in BICS or CALP though they can achieve high scores in standardized tests, such as the TOEFL. Similar instruction 
occurs in the United States, according to the reports about the lack of foreign language proficiency among college graduates (Bollage, 2007; Fischer, 2007; Millman, 2007; MLA, 2007). Hence, teachers' understanding and beliefs about language proficiency will more or less impact student learning outcome.

Another issue is the length of time to achieve language proficiency. Usually, degrees require four or five years of study (MLA, 2006). Is this period of time enough to achieve language proficiency? Figure 5 shows the length of time required to achieve age-appropriate levels of conversational and academic language proficiency.

Figure 5 The length of Time to Achieve Language Proficiency

Native English speakers

English language learners
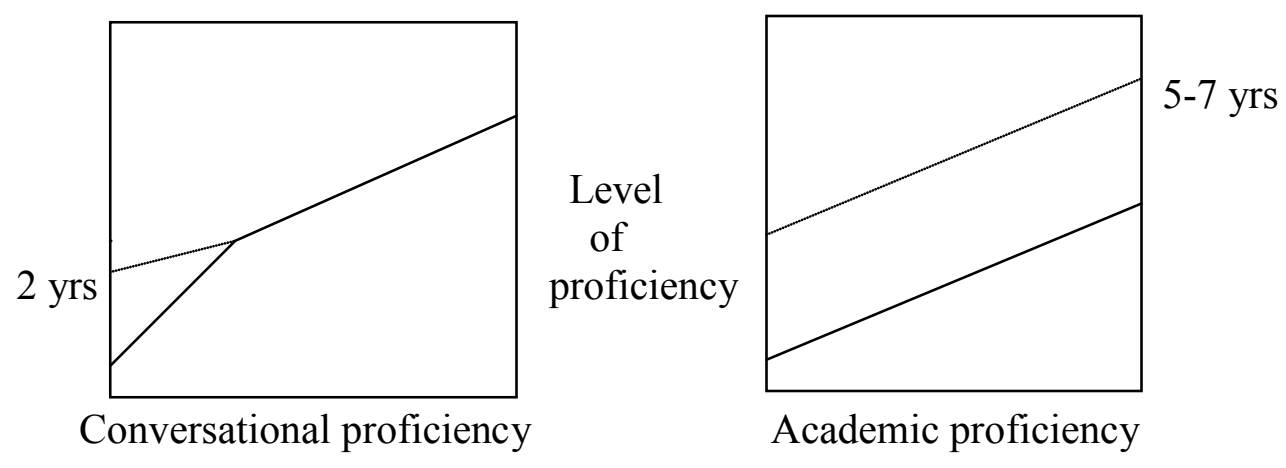

(Cummins, 1996, p. 62)

Cummins (1996) states that an English language learner needs two years of learning to obtain BICS and five to seven years to reach the level of CALP as English language speakers. He points out that students' surface fluency in a target language cannot be taken as indicative of their overall proficiency in the language. On the other hand, limited conversational proficiency should not be regarded as learning disabled. Unfortunately, such misconceptions remain rather common in schools. For example, 
an American student stayed in China for a few years and spoke Chinese without much difficulty. When he returned to the U.S., he was recommended to take the Chinese 203 class. However, he turned out to be unable to read or write at all.

In sum, a foreign language teacher's knowledge of language proficiency is essential for classroom teaching.

Attempts to Improve the Outcome of Language LearningIn the field of foreign language teaching and learning, efforts have been made to explain issues that interfere with success in foreign language learning. Various research studies have been done to shed light on these problems. Work has been done both in second language acquisition (SLA) research (Ellis, 1994, 1997; Krashen, 1982; Swain, 1995; Vygotsky, 1978, 1986) and in application of this research to classroom teaching practice (Celce-Murcia, 2001; Collentine \& Freed, 2004; Hymes, 1972; Omaggio Handley, 2001; Shrum \& Gilsan, 2006;). Studies have focused on culture (Kramsch, 1998, 2003; Lange, 2003;

Nieto, 2002; Seelye, 1993). New arguments about language and the mind have emerged (Chomsky, 1968, 2006; Kennedy, 2006). Other elements that might cause language learning difficulties have been explored. For example, ever since Krashen's (1982) affective filter hypothesis, anxiety has been considered as a byproduct of language learning deficits. Dinklage (1971) identifies that the anxiety present in students who have difficulty with foreign language was not the cause, but rather the result of failure in learning a foreign language. Another element studied is learning style. For instance, Ehrman (1996), Castro and Peck (2005) state that a student's preferred learning style is another component of language learning difficulties. All 
these and other studies have significantly contributed to foreign language teaching and learning. However, fewer studies focus on language teachers and teacher education (Freeman \& Johnson, 1998; Schulz, 2000) and their attendant beliefs about the language teaching and learning process (Freeman \& Freeman, 1994; Freeman \& Johnson, 1998; Freeman \& Richards, 1996; Velez-Rendon, 2002). Schulz (2000) states that many issues about foreign language teacher education have remained unsolved for more than 80 years. One of the issues is the lack of communication and cooperation between foreign language departments and the education departments responsible for language-teacher education. Schulz suggests that the significant relationship between foreign languages and education should receive more serious attention. Indeed, the demand for critical languages by government and business has brought new challenges to teachers of foreign languages (Bollag, 2006, 2007; Field, 2006; Liebowitz, 2006; MLA, 2007; Millman, 2007; Oleksak, 2007; Wasley, 2008). To meet these new challenges, it is crucial for teachers to upgrade their knowledge and competence in foreign language teaching and learning. Becoming an Effective Teacher of Foreign Language

Galbraith (1998) states that most teachers of adult education programs are expert in the content they teach. However, they usually have little preparation in the process of helping adults learn. He points out that becoming an effective teacher of adults depends on understanding what composes the development of a teaching style and how to connect that framework of ideas to practice in a meaningful and constructive manner. Galbraith offers a model of developing a teaching style which consists of five 
knowledge areas: knowledge of principles of practice, knowledge of self, knowledge of learners, knowledge of content, and knowledge of methods. These knowledge areas are essential for teachers of foreign languages, including teachers from China, in the development of a more effective teaching style.

\section{Knowledge of Principles of Practice}

As Galbraith (1998) suggests, teachers of foreign languages should examine their own practice and compare what they do with what the literature has presented as principles of effective practice. Galbraith's 10 principles of effective practice are:

(1) An appropriate philosophy should guide the educational encounter.

(2) Understanding the variability and diversity of adult learners is vital to good practice.

(3) A conducive psychosocial climate for learning should be created.

(4) It is important to reduce physical, social, and psychological behaviors or actions on the part of the teacher that produce resistance.

(5) Challenging teaching and learning interactions should occur that present learners with opportunities to scrutinize, question, and develop alternative ways of thinking and acting.

(6) Praxis should be fostered that enhances critical thinking and reflection.

(7) A rationale and vision for conducting the educational process should be apparent.

(8) Authenticity and credibility should be essential elements of the educational encounter. 
(9) It is important to attend to how learners experience learning.

(10) Independence should be fostered in an effort to encourage autonomy, empowerment, and self-direction. (pp. 8-9)

These principles can serve as a framework for teachers to realize a meaningful teaching and learning encounter.

\section{Knowledge of Self}

Galbraith (1998) points out that it is critical for teachers to be aware of their own beliefs, values, and attitudes with regard to teaching and learning. The combination of these beliefs, values, and attitudes shapes the basis for a philosophy or personal vision for teaching.

Beliefs, Values, and Attitudes

This knowledge of self is particularly essential to teachers of foreign languages. For example, most teachers of foreign languages grew up in a home culture which is more or less different from that of the target country (the country where the foreign language is the first language). What they believe as truth might not be necessarily accepted by people from other countries. Since value is guided by a set of beliefs (Galbraith, 1998), what is valued in one country can be devalued or denied by people who hold different beliefs in another country. For example, the traditional Chinese saying “严师出高徒 yan shi chu gaotu” (“Excellent students come from a strict teacher") is still acceptable in China. However, it is likely to be rejected by American students. As culture is critical to foreign language learning and is one of the five components of communicative competence (Kramsch, 2003; Lange, 2003; National 
Standards, 2006; Nieto, 2002; Seelye, 1993), foreign language teachers' beliefs, values, and attitudes play a critical role in their teaching.

\section{Pedagogical Beliefs}

For pedagogical beliefs, the first section of this chapter has discussed the knowledge that tends to shape the way in which language teachers think about teaching. The following statement by Freeman and Johnson (1998) highlights this issue:

... The predominant view of language teaching had traditionally been based on a scientifically derived conception of teaching supported by empirical investigations that either operationalize learning principles, rely on tested models of specific teaching skills, or model effective teaching behaviors. Moreover, the assumptions that have underlain the practice of language teacher education have focused more on what teachers needed to know and how they could be trained than on what they actually knew, how this knowledge shaped what they did, or what the natural course of their professional development was over time. (p. 398)

In the past century, the traditional scientific orientation toward language has had a strong influence in foreign language teaching and learning. Most teachers of Chinese and other foreign languages tended to believe foreign language teaching means introducing knowledge about the target language. Actual use of the language has not received enough attention. Thus, "the lack of foreign language competence is as much a fact within academic disciplines as in the society at large..." (MLA, 2007, Strengthening the demand for language competence within the university, 91 ).

Kagan (1992) states:

... a teacher's beliefs usually reflect the actual nature of the instruction the teacher provides to students .... teacher belief may be mediated by epistemological differences inherent in respective content areas or by the kinds of instructional materials that happen to be available (Wood, et al., 1990). (p. 73) 
Similarly, Freeman and Freeman (1994), and Freeman and Johnson (1998) call for a broader epistemological view of language teaching, it is necessary to examine how language teachers' beliefs about language connect to their epistemological beliefs. Epistemological Beliefs

"Epistemological beliefs, as they have been assessed by educational psychologists, are beliefs about the nature of knowledge and learning but not in a strict philosophical sense" (Schommer, 1998, p. 129). Schommer states that the influence of epistemological beliefs is subtle and tends to have more indirect effects than direct effects. Different beliefs about the organization and certainty of knowledge will lead to different attitudes and behaviors toward learning. When individuals believe that knowledge is isolated bits to be discovered, they will try ways and strategies to recall and remember these isolated bits. However, they will struggle when they are required to transfer or apply the information. On the other hand, when individuals believe that knowledge is a complex and interrelated network, they will study how to integrate and elaborate the information so as to be able to perform well on application (Schommer).

If a teacher of foreign language believes language is parallel to objects and phenomena of the physical world (Hamp-Lyons \& Condon, 2000; Lange, 2003), he/she will tend to follow a technical orientation of curriculum, instruction and assessment. Language teaching is likely to be broken into isolated bits: parts of speech (noun, verb, adjective, adverb, conjunction, etc.), elements of sentence (subject, object, predicate, complement, adverbial, etc.), and sentence patterns, etc. Assessment will focus on testing learners' knowledge about a language. Once a teacher of foreign 
language believes that language is a part of the social world (Hamp-lyons \& Condon, 2000; Hymes, 1972; Schieffelin \& Ochs, as cited in Mecken \& Miller, 2006) and the nature of language is a complex, interrelated network that connects human-human interactions in society (Chomsky, 2006, National Standards, 1999, 2006), the teacher is more likely to reach the deeper layer of the five C's ( Communication, Culture, Connections, Comparisons, and Communities) for language learning that are stated in the National Standards $(1999,2006)$. Figure 6 shows the potential connections between teachers' epistemological beliefs and their classroom teaching. 


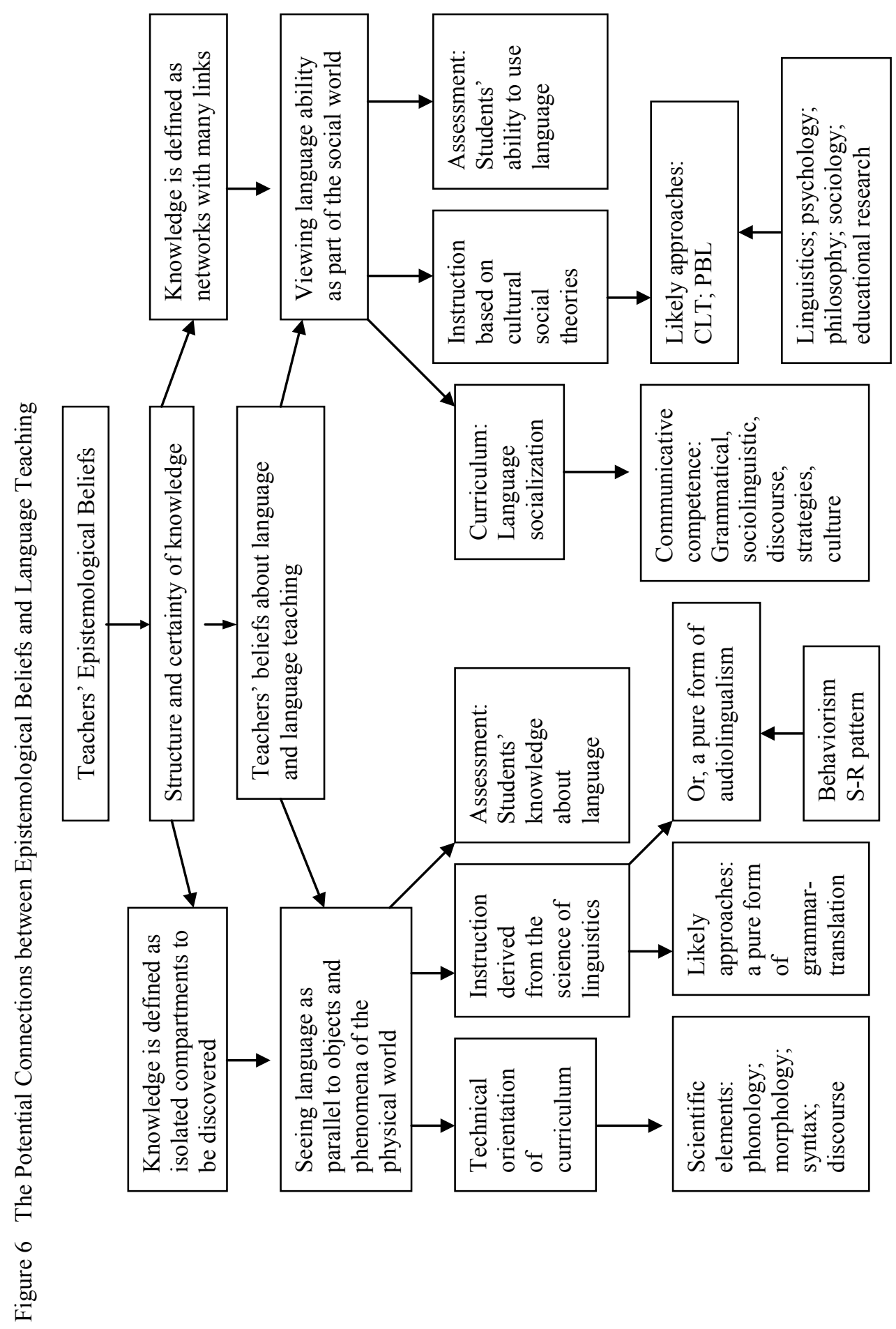


Knowledge of epistemological beliefs is helpful for understanding the nature of different approaches to foreign language teaching. For example, research shows that teachers felt somewhat familiar with the National Standards (Allen, 2006). However, inconsistencies tend to appear between teachers' beliefs and actions. Participants in a study claimed to believe in and use Communicative Language Teaching (CLT), however, no evidence of CLT was observed in their classroom teaching (Allen). This phenomenon indicates there is a gap between the teachers' beliefs and their action. Epistemological beliefs can be a starting point to explore what causes the gap: examining the nature of CLT and the nature of language learning.

Knowledge of self (Galbraith, 1998) is essential for teachers from China. A deeper understanding of learners is important as well.

\section{Knowledge of Learners}

To understand more and deeper about learners, Galbraith (1998) suggests that teachers first review their experiences as learners, and then explore the multifaceted physiological, psychological, sociological and developmental aspects of adults. The following is a summary of Galbraith's three suggestions:

(1) Acknowledge that adult learners bring a diversity of prior experiences and preset ideas which form the basis of beliefs and actions that guide them and influence teachers' teaching styles.

(2) Understand the multifaceted aspects of adult development. Adult learners are varied in their physical, social, psychological, ego, moral, and developmental learning directions. The diversity of individual learning styles should also be recognized.

(3) Be concerned with adult learners' emotion and self-esteem.

Culturally diverse learners (Lasley \& Matczynsk, 1997) are a challenge to all teachers, especially to teachers from China. Knowledge of learners is a complex and 
demanding process for teachers of adults (Galbraith, 1998). Baxter Magolda (2001), Brookfield (1990), and Galbraith (1998) all have discussions on principles of adult learning. The following are key principles drawn from their discussions: 1)

Acknowledge the experience of learners and value the learners as knowers; 2) Make the learning meaningful; and 3) Help learners construct knowledge (Cress, 2005).

Another area that closely connects to teachers is knowledge of content.

\section{Knowledge of Content}

"Content-specific beliefs have been found to correlate with a wide variety of instructional and noninstructional variables" (Kagan, 1992). Content is generally referred to as curriculum, subject matter, or what is taught. Galbraith (1998) identifies content as more than just what we teach. It serves as a mechanism for defining and developing a portion of teaching style. He states:

Content incorporates identifying certain knowledge, skill, or attitudes to learners that result in learning outcome. Content dictates appropriate teaching strategies, fosters standards against which to compare proficiency, promotes dialogue, provides flexibility and responsiveness, fosters the implicit intent to change, and involves the administration, organization, and functioning of the group itself. (p. 15)

Newcomb, McCracken, and Warmbrod (as cited in Galbraith, 1998) suggest that teachers' teaching style and decisions about content are impacted by various factors such as their educational philosophy or vision, the philosophy of the organization or agency, established program objectives, teacher's expertise level, available educational facilities and equipment, and allocated financial resources. These factors impact how teaching style, its development, and knowledge of content work together. Therefore, content is involved with the concepts of individual and the environment. 
Newcomb, McCracken, and Warmbrod's (as cited in Galbraith, 1998) and Galbraith's (1998) statements on knowledge of content support the discussion of language teaching in the first section of this chapter (the nature of language, the scientific elements of language, the development of the understanding of language and language teaching, strategies of classroom teaching, the potential for change, etc.). Foreign language teaching arguably belongs to the field of social science. Language itself is changing with the development of the society. It is essential for teachers from China to learn about this wide variety of instructional and noninstructional variables that relate to content (Kagan, 1992; Galbraith, 1998).

\section{Knowledge of Method}

Galbraith (1998) states that methods are the tools to use within the instructional process to improve teaching and learning. Knowledge of methods is important in the development of teaching style because it combines the other four knowledge areas (principles of practice, self, learners, and content) and gives a rational and systematic viewpoint for the instructional process. According to Heimlich and Norland (as cited in Galbraith, 1998), knowledge of method lets teachers present personal beliefs, values, and philosophy of teaching and learning through the application of the method. Galbraith points out that knowledge of method can assist teachers in identifying the purpose and the rationale for the educational encounter, and learn how to select the appropriate method for the already established teaching and learning purpose.

In the field of foreign language teaching, a method or an approach that a teacher applies will reveal his/her beliefs, values, and philosophy of teaching. When an 
inconsistency occurs between teachers' beliefs and the methods they adopt, the inconsistency can serve as a clue that there is a gap between the teachers' understanding about the method and the nature of the method. For example, when a teacher is unable to catch the core of CLT, what he/she does is just follow the form of the approach (Allen, 2002). Findings in another research show that teachers added extra goals, which are beyond PBL, for students to reach when the approach was adopted (Beckett $\&$ Miller, 2006). Clearly, a deep knowledge of methods is critical in the development of teaching style (Galbraith, 1998).

The following section is the significance of the study.

Significance of the Study

There are three parts in this section: 1) Summary and research gap; 2) This study; and 3) Context of this study and research questions.

\section{Summary and Research Gap}

This chapter starts with the traditional views and current studies on language and linguistics, and how these perspectives have impacted the development of foreign language teaching methodology.

Since much of what language teachers know about teaching comes from their memories as language learners or as students of language teaching (Freeman \& Freeman, 1994; Freeman \& Johnson, 1998; Lortie, 1975; Velez-Rendon, 2002), the literature review explores the concepts and knowledge about language and language teaching. The discussion shows a shift from the traditional views of language (as a domain of natural science: separated elements of language) to current studies on 
language (as a field of social science, meaningful communication) and how these perspectives impact the development of approaches to language teaching, from the traditional beliefs (grammar-translation) and the behavioral concept (audiolingualism) to a constructivist view (CLT and PBL). Analysis of these approaches is presented and the potential results are introduced. What counts as language proficiency is discussed. In the field of foreign language teaching, efforts have been made to identify the problems that impact teaching and learning. It becomes clear that the significant relationship between foreign language and education has received little attention (Schulz, 2000).

Many language teacher education programs still focus on knowledge about language and teaching practices or methodologies (Freeman \& Johnson, 1998). Researchers who seek to improve the scientific respectability of their work tend to view teaching as separated behaviors, distance their conclusions about teaching from the contexts, and ignore the perspectives and understanding of the teachers whose teaching is studied (Erickson, 1986; Freeman \& Johnson, 1998; Woods, 1987). In-service teachers' perspectives and understanding of teaching tend to be ignored in research on language teaching.

Studies on language teacher education are strikingly few compared with the large amount of literature on general teacher education (Bernhardt \& Hammadou, 1987; Freeman \& Johnson, 1998; Houston, 1990; Schulz, 2000; Velez-Rendon, 2002). Foreign languages are excluded from the Handbook of Research on Teacher Education (Houston, 1990) which includes 11 specific curricular areas. A review of literature on 
foreign language teacher education covering the years 1977 to 1987 shows only eight articles to be research-based studies (Bernhardt \& Hammadou, 1987). Freeman and Johnson (1998) reveal that only 9\% of the articles published in TESOL Quarterly between 1980 and 1997 are relevant to the topic of language teacher preparation. A search of the Foreign Language Annals cumulative indexes from 2000 to 2008 reveals that about $6 \%$ of the articles are listed under the topic of "teacher preparation and teacher beliefs." No discussions about Chinese teachers' beliefs are found in publications on foreign language teaching. According to Freeman and Johnson (1998), the low numbers in these journals in the field of language teaching are "evidence of problems not of access but of emphasis in what are considered critical understandings in this field" (p. 398).

\section{This Study}

The ultimate goal of today's foreign language learning is the development of the ability to communicate in meaningful and appropriate ways with users of other languages (National Standards, 2006). Institutions are facing the challenge to produce more graduates fluent in critical languages (Bollag, 2006, 2007; Field, 2006; Liebowitz, 2006; Millman, 2007). Strengthening foreign language teaching is a necessity. The literature review shows foreign language teachers' pedagogical beliefs about language and classroom teaching are crucial factors that influence student learning outcomes (Freeman \& Freeman, 1994; Gilsan, 1996; Freeman \& Johnson, 1998; Vantten, 1998). However, few studies focus on analyses of language teaching activity as it is practiced in classrooms and how teacher beliefs connect to classroom activities (Allen, 2002; 
Freeman \& Johnson, 1998). There is also evidence that while the National Standards $(1999,2006)$ are recognized in theory as important to instruction, they are not being fully integrated into teaching practices (Wilbur, 2007). "While it is true that many second language teacher educators are seasoned and reflective thinkers, it is also true that many need to rethink their roles and renew their practices" (Velez-Rendon, 2002, p. 464).

This study intended to reveal where language teachers' beliefs and assumptions came from and how these beliefs and assumptions influenced their decisions of classroom teaching. The following is the context of this study and research questions.

\section{Context of This Study and Research Questions}

In the United States, baccalaureate, master's, and doctoral's degrees are conferred in at least 22 foreign languages. The languages identified with the most pressing deficits are Arabic, Chinese, Japanese, Korean, Persian, Hindi, Turkish, and Russian (Bollag, 2007; Fischer, 2007; Millman, 2007). This study focused on teachers of Chinese, particularly teachers from China who came to the United States to teach Chinese at a college level. The following was the rationale for focusing on this particular context.

(1) Chinese is one of the eight critical languages.

(2) Enrollment in Chinese increased 51\% from 1995 to 2006 (MLA, 2006).

(3) There is a rising tendency for American schools to hire more Chinese speakers to teach Chinese. Qualified teachers of Chinese are needed (Aratani, 2006; Bollage, 2007; Fischer, 2007; Millman, 2007). 
(4) The researcher of this study has found little literature about teachers of Chinese in the United States.

(5) Most teachers from China who teach at the college level in the United States used to be English teachers in China. They have been largely exposed to traditional views on language and language teaching, as learners and students of English language teaching.

(6) Chinese teachers' beliefs will offer information about Chinese culture.

(7) To become qualified teachers of foreign language in the United States, teachers from China need to re-examine and analyze their beliefs, assumptions, and attitudes toward language and language teaching. Results of this study will help teachers from China with the challenges they face while teaching in the United States.

This investigation of the relationship between teachers' pedagogical beliefs and classroom teaching was guided by two research questions:

(1) What serves as the foundation for Chinese teachers' pedagogical beliefs about teaching?

(2) How do Chinese teachers' pedagogical beliefs relate to their classroom teaching, and what characterizes this relationship? 


\section{CHAPTER III METHODOLOGY}

This chapter addresses several components of the dissertation's methodology, beginning with a restatement of the purpose and research questions. The research design comes next: Rationale for the research design, the research site, research population, a discussion of data collection and analysis. This is followed by validity, reliability, ethics issues, and the researcher's role.

Purpose and Research Questions Restated

International education and foreign languages have become keys to securing America's future. Institutions are facing the challenge to produce more graduates fluent in critical languages (Bollag, 2006, 2007; Field, 2006; Liebowitz, 2006; Millman, 2007). Foreign language teachers' pedagogical beliefs about language learning have become one of the crucial factors that impact student learning outcomes (Allen, 2002; Freeman \& Freeman, 1994; Freeman \& Johnson, 1998, Gilsan, 1996; Velez-Rendon, 2002). This study focused on the relationship between foreign language teachers' (especially Chinese teachers') beliefs and their classroom teaching. Results of the study will offer foreign language educators, teachers, and learners some potential factors, previously less noticed, that impact the outcome of language teaching and learning. The research questions grew out of the purpose of this study, and derive from the theoretical literature in Chapter Two:

(1) What serves as the foundation for Chinese teachers' pedagogical beliefs about teaching? 
(2) How do Chinese teachers' pedagogical beliefs relate to their classroom teaching, and what characterizes this relationship?

\section{Research Design}

To gain insight into the pedagogical beliefs of Chinese teachers and how these beliefs impacted their teaching decisions, the study used a qualitative design taking the case-study method as its research strategy.

According to Maxwell (1996), the four strengths of qualitative research are:

1) Understanding meaning; 2) Understanding the particular context within which the participants act, and the influence that this context has on their actions; 3 ) Identifying unanticipated phenomena and influences, and generating new grounded theories about the latter; and 4) Understanding the process by which events and actions take place. (p. 17-19)

Maxwell (1996) further states that "Quantitative researchers tend to be interested in whether and to what extent variance in $x$ causes variance in $y$. Qualitative researchers tend to ask how $x$ plays a role in causing $y$. What the process is that connects $x$ and $y$ " (p. 20). In this study: $x$ is teachers' pedagogical beliefs; $y$ is classroom activities (See Figure 7).

Figure 7 How $x$ Plays a Role in Causing $y$ (Maxwell, 1996)

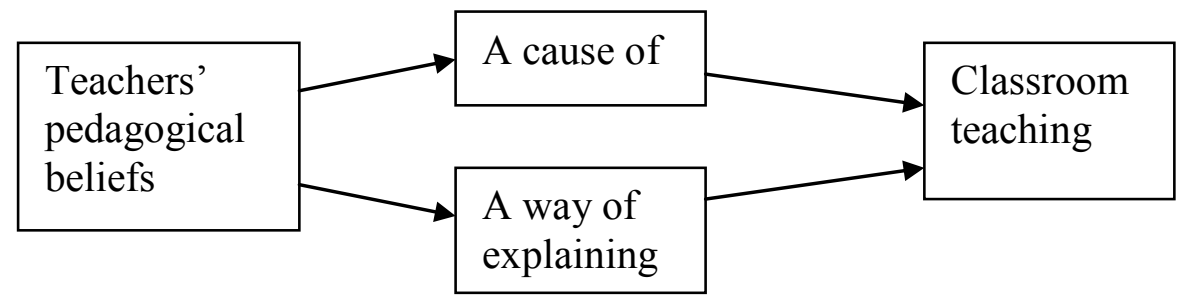

This study intended to investigate the relationship between foreign language teachers' pedagogical beliefs and their classroom teaching. It was unlikely that the 
researcher could fully understand a language class without considering the teacher's pedagogical beliefs, both as a cause of what happened in the class and as a way of explaining it. The approach and the method that the teacher adopts, and the design of the teaching process all reflect the teacher's beliefs and values about language teaching. The significance of teachers' beliefs, values, and assumptions as a way of understanding and explaining the challenge and complexity of classroom language teaching has been acknowledged by Freeman and Johnson (1998).

Therefore, the arguments for the choice of this study's methodology are: 1) Chinese teachers' beliefs in teaching are complex, and take shape through a complicated process; 2) Relevant variables, such as unanticipated phenomena and influences, have yet to be identified; 3) Classroom teaching is significantly influenced by its setting and it should be studied in real-life situations; and 4) Teachers' classroom practices should be studied in terms of meaning instead of behavior (Erickson, 1986).

Yin (1984) states that "case studies are the preferred strategy when 'how' or 'why' questions are being posed, when the investigator has little control over events, and when the focus is on a contemporary phenomenon within some real-life context" (p. 13). According to Stake (2000), "case study is not a methodological choice but a choice of what is to be studied ... while we are studying it, our meager resources are concentrated on trying to understand its complexities" (pp. 435-436). Wolcott (as cited in Merriam, 1998) regards case study as "an end-product of field-oriented research" (p. 26). However, Patton (2002) states that "the term case study can refer to either the process of 
analysis or the product of analysis, or both" (p. 447). For this investigation, "case study" refers to the process of analysis.

The researcher of this study was interested in the relationship between foreign language teachers' pedagogical beliefs and their classroom teaching: This meant that through the phenomenon of classroom teaching, the researcher must examine the teachers' beliefs, assumptions, and behaviors in both teaching and learning. The study focused on how the Chinese teachers understood foreign language teaching, and why they adopted certain approaches. According to Marshall and Rossman (1999), a case study researcher would see both what is common and what is particular about the case, but the results eventually reveal something uncommon by gathering data from the following:

1) The nature of the case; 2) The case's historical background; 3) The physical setting; 4) Other contexts; 5) Other cases through which the case is recognized; and 6) Those informants through whom the case can be known. (Marshall \& Rossman, 1999, p. 438)

For this study, the researcher followed Marshall and Rossman's (1999) suggestion and studied both the common and the particular about Chinese teaching.

\section{Site Selection}

Chinese sections in foreign language departments are relatively small. Data collected from a single department will therefore always be limited. The sites for this study were four departments at two institutions: The Department of Foreign Languages and Literatures (FLL) at the Urban University (UU), Business School at UU, the C Institute at UU, and the Department of Language and Culture at the Urban College (UC). The rationale for these choices was: a) there was at least one teacher from China in each 
unit; b) the teachers had at least five years of teaching experience; c) the teachers had been exposed to traditional views on language and language teaching as learners of English or of English language teaching methodology; d) since the participants were working in a variety of organizations, this would broaden the findings and recommendations for teachers of foreign languages; and e) these sites were accessible to the researcher of this study.

UU served 25,000 undergraduate and graduate students in the 2007-2008 academic year. There were 141 degree programs at the university (67 bachelor's, 61 master's, and 13 doctorate). There were 3,503 part-time and full-time employees, among them 1,303 faculty.

FLL offered 28 different languages and allowed students to take specialized degrees in 16 languages. 3,905 students enrolled in Fall 2009, total credit hours were 15,528. There were 44 full-time faculty, 42 part-time faculty, and 45 graduate teaching assistants (TA) working in the department. The Chinese section offered five courses per quarter in language and literature; 21 separate quarter courses in regular rotation. Two full professors were leading an instructor and two TAs to work with their students in Chinese language and culture.

The Business School at UU was the state's largest business school, with about 2,000 undergraduate and graduate students. One of the programs in the school prepared students for careers focused on the markets of Asia's Pacific Rim. Intensive Chinese language and culture study was offered as part of the program. One professor and a TA taught Chinese at three different levels: beginning, intermediate, and advanced. 
The C Institute at UU opened in May 2007. The mission of the institute was to promote educational exchange and cooperation between the United States and the People's Republic of China. The institute shared some academic programs with their partner institution, S University in China. The institute focused on the development of non-degree China area studies and a Chinese language program. It offered short-term courses and seminars for travel, business, and tourism at all levels. Three instructors were working at the institute. One of them was from S University.

UC was the largest institution of higher learning in the state. In the 2007-2008 academic year, UC had 1,676 faculty (438 full-time, 1238 part-time). It served over 86,000 full-and part-time students. UC's Department of Language and Culture offered 22 different languages, including Chinese conversation and Continuing Chinese classes. Now students can learn "Chinese for Travelers" and "Chinese for Those Doing Business in China." Many of the instructors in the language and culture department were native speakers, including the two teachers of Chinese.

\section{Population Selection}

Based on the nature of the study and to collect specific data, sampling was purpose-oriented. Patton (2002) states that "the logic and power of purposeful sampling lies in selecting information-rich cases for study in depth. Information-rich cases are those from which one can learn a great deal about issues of central importance to the purpose of the inquiry, thus the term purposeful sampling. Studying information-rich cases yields insights and in-depth understanding rather than empirical generalizations" (p. 230). Maxwell (1996) states that there are four possible goals for purposeful 
sampling: 1) The first is achieving representativeness or typicality of the settings, individuals, or activities selected; 2) Purposeful sampling can achieve the opposite of the first --- to adequately capture the heterogeneity in the population; 3) To select your sample to deliberately examine cases that are critical for the theories that you began the study with, or that you have subsequently developed; and 4) To establish particular comparisons to illuminate the reasons for differences between settings or individuals.

For this study, the first common characteristic of the participants was that they came from China and were teaching at the college level in the United States. Since Chinese sections in foreign language departments are relatively small, and most teachers from China in the research sites listed above were female, the participants numbered one male and four females. They came from widely varying regions of China.

The second characteristic of the participants was that they had at least five years of college teaching experience. This level of accumulated experience has offered rich information and deep reflections on teaching.

The third characteristic was that the participants had English proficiency. Having spent long years of learning English, they could reflect broadly about language teaching methodology as well as learning strategies.

It was originally planned that the fourth characteristic would be teachers who hold a masters' or doctorate degree. Former schooling is one of the important factors that shape teachers' views on teaching (Freeman \& Johnson, 1998; Galbraith, 1998; Lortie, 1975). With a higher educational level, the participants' perspectives and reflection could reveal a relatively thorough impact from their former schooling. However, while 
selecting participants, the researcher found that among the teachers who were interested in the study, there was one who held only a bachelor's degree but had been teaching Chinese at the college level in the United States for over twenty years. She was included because her experience of foreign language learning and teaching could bring diverse and valuable information to the study. Therefore, instead of four participants as originally planned, five teachers of Chinese were selected from the research settings listed above. Issues about working with the participants will be discussed in the ethics section. The next section examines data collection.

\section{Data Collection}

It has been recognized that teachers are central to understanding and improving language teaching. Teachers enter their classrooms with prior experiences, personal values, and beliefs that inform their knowledge about teaching and shape what they do in their classrooms (Freeman \& Johnson, 1998; Freeman \& Richards, 1996; Galbraith, 1998). To investigate the real foundations of the teachers' pedagogical beliefs, and how these beliefs connected to their classroom teaching, the researcher used classroom observations and in-depth interviews as the primary sources of data collection, based on two arguments:

1) ... research that examines only what university teachers say about their practice and does not directly observe what they do is at risk of telling half the story". (Kane, Sandretto, \& Heath, 2002, p. 177)

2) Beliefs cannot be inferred directly from teacher behavior, because teachers can follow similar practices for very different reasons. Moreover, much of what teachers know or believe about their craft is tacit: For example, teachers often unaware of their own beliefs, they do not always possess language with which to describe and label their beliefs, and they may be reluctant to espouse them publicly (Cooney, 1983; Thompson, 1984). (Kagan, 1992, p. 66) 
Audio-recording was employed during all the classroom observations and interviews, and field-notes were taken when data were collected. Classroom observation was conducted first, followed by in-depth interviews. The rationale for this order will be given in the next section. Observation of the same participant was conducted three times except for one participant, who was observed five times (Further information will be offered in the following section). As originally planned, two 60-90 minute interviews were planned for each participant. However, one interview lasted only 36 minutes because the participant had a meeting to attend (Further information will be offered in the following section). The second classroom observation and interview were done at least one week after the first. To clarify some details about participants' experiences or statements, two telephone calls were made; each call lasted about 5 minutes. English was the language for all the interviews. Further discussion about observations and interviews is as follows.

\section{Classroom Observation}

There are six parts in this section: 1) Rationale for observation; 2) Settings, duration, and occurrence of observation; 3) What to observe; 4) How to observe; 5) Observer's role; and 6) Why classroom observation is done before the interview.

\section{Rationale for Observation}

Classroom observation followed criteria and frameworks based on statements made by several writers: Patton (1985, 2002), Angrosino and Mays de Perez (2000), Marshall and Rossman (2006), Maxwell (1996), Merriam (1998), and Creswell (2008). 
Observation has been characterized as "the fundamental base of all research methods" in the social and behavioral sciences. Observation can be conducted in a lab or clinic, in which case the activity may be the result of a controlled experiment. Observation can also be conducted in a setting that is the "natural" place for those activities (Angrosino \& Mays de Perez, 2000). However, Freeman and Johnson (1998) state that very few studies that analyze teaching start with the activity as it is practiced in classrooms. "We believe it has to do primarily with the challenge and complexity of studying classroom language teaching and learning as it is actually lived and experienced by its protagonists" (Freeman \& Johnson, 1998, p. 410). Indeed, it was a challenge for the researcher of this study to explore this complexity of Chinese teaching in natural settings, but it was precisely through classroom observation that the researcher could trace how participants' pedagogical beliefs connected to their teaching. According to Merriam (1998) and Creswell (2008), classroom observations offer the opportunity to notice things that have become routine to the observed themselves, to see things that may lead to understanding the context, and to record behaviors as they are happening. "Another reason to conduct observations is to provide some knowledge of the context or to provide specific incidents, behaviors, and so on that can be used as reference points for subsequent interviews. This is a particularly helpful strategy for understanding ill-defined phenomena" (Merriam, 1998, p. 96). It was true that through classroom observations, the researcher of this study found a new understanding and application about two approaches to language teaching: grammar-translation and 
audiolingulism, both of which are regarded as out of date by many language teachers. Further discussion about this issue will be in Knowledge of Method in this paper. Settings, duration, and occurrence of observation

The observation for this study took place in natural settings: foreign language classrooms in a college and in a university.

The originally planned time for each observation was 50 minutes, a normal length for a foreign language class period. However, the classes observed included credit classes, non-credit-classes, and a class in a graduate program. The students in the latter class were graduate students but the language level was beginning. Because the observations were done in summer term and fall term, the time for an actual class meeting ranged from 50 minutes to four hours.

According to Richard (1990), an observer should try to "capture the essence or spirit of what was going on during the observer's presences and is especially useful when the observer wants to capture a broad picture of a lesson rather than focus on a particular aspect of it" (p. 44). Therefore, this study planned on observing the whole process of each class meeting. When the researcher talked to participants about the duration for the observations, most participants preferred the researcher to observe the whole process of a class meeting. Therefore, the actual observations ranged from 50 minutes to 120 minutes, as did the classes.

The researcher observed the classes conducted by each participant three times except for one, who was observed five times. The reason for the two extra observations was: The first three observations were done during the summer term in a 200 -level 
classroom, after which the participant stated that the researcher was welcome to observe her teaching at 100-level in the fall term. Therefore, to learn more accurately about this participant's design for the teaching process, the researcher observed two more class meetings taught by her in the fall.

What to Observe

Merriam (1998) states that the choice of what to observe is determined by the conceptual framework, the problem, and the questions of interest. For this study, guidelines for classroom observation were developed based on the research questions and derived from the research and theoretical literature highlighted in Chapter Two, including Allen (2002), Celce-Murcia (2001), Cummins (2001), Dewey (1916), Ellis (1997), Freeman and Freeman (1994), Freeman and Richards (1996), Freeman and Johnson (1998), Galbraith (1998), Kolb (1981), Kramsch (2003), Krashen (1982), Laskey and Matezynsk (1997), Schommer (1998); Shcommer-Aikins (2004), Swain (1995), the National Standards (2006), Velez-Rendon (2002), Vygotsky (1978, 1986), Walker (2002), and Zinn (as cited in Galbraith, 1998).

Observation focused on the teacher. The areas to be probed included teaching and learning methods in two fields: foreign language teaching and adult education. Attention was paid to seven areas:

1) Content delivered: What was taught/introduced in class? How was knowledge defined? Was knowledge defined as isolated compartments to be discovered or viewed as networks with many links (Pratt, 1998; Schommer-Aikins, 2004)? Was knowledge about the Chinese language taught? Was language use given a 
cultural context (Hamp-lyons \& Condon, 2000; Kramsch, 2003; Lange, 2003; National Standards, 2006)?

2) Instruction conducted: Was knowledge broken into isolated facts? Or was it organized as highly interrelated concepts (Belenky et. al. 1986; Pratt, 1998; Schommer-Aikins, 2004)? Did instruction focus on vocabulary and grammar rules, or on the cultural background and contexts of words and expressions introduced (National Standards, 2006)?

3) Classroom assessment: Were students required to recall facts without synthesis/application, or were they encouraged to synthesize knowledge and apply the knowledge to a challenging task (Schommer-Aikins, 2004)? Was a paper-and-pencil quiz for specifications about grammar-translation employed, or was a mini-sociocultural project for application of language required (Hamplyons \& Condon, 2000)?

4) Methods/teaching strategies: Were lectures, programmed instruction, practice and reinforcement, and study groups adopted? Or were instructional scaffolding, problem-solving, individual tasks, group learning, dialogue, and communicative discourse involved? Which approaches to foreign language teaching were adopted: grammar-translation, audiolingualism, CLT, or other approaches and methods (Anton, 1999; Celce-Murcia, 2001; Collentine \& Freed, 2004; Hymes, 1972; Omaggio Handley, 2001; Savignon, 2001; Shrum \& Gilsan, 2006)? Did any activities involve learning through experiences (Dewey, 1916; Galbraith, 1998; Kolb, 1981; Taylor, Marienau \& Fiddler, 2000)? 
5) Role of teacher: Did the teacher work as expert, controller, and manager, or as facilitator, helper, partner, organizer, and coordinator (Elias \& Merriam, 1995; Freeman \& Johnson, 1998; Pratt, 1998)?

6) Language used: Which language was more used in class, Chinese or English? How did the teacher understand second/foreign language acquisition and language learning (Ellis, 1994, 1997; Freeman \& Freeman, 1994; Krashen, 1982; Swain, 1995; Vygotsky, 1978, 1986)?

7) Meeting student needs: Did the teacher notice that culturally and cognitively diverse students have different needs? Did the teacher adjust specific content taught in class according to responses from students? Did the teacher modify instructional strategies or activities when things did not go smoothly? Was an assessment strategy changed when it did not fit students' level? (Galbraith, 1998; Kramsch, 2003; Lasley \& Matezynsk, 1997; Nieto, 2002; Seelye, 1993).

The related literature for these seven areas was used as a guideline for classroom observation (see Appendix A).

\section{How to Observe}

Patton (1990) states techniques that a skilled observer should have, including "learning how to write descriptively; practicing the disciplined recording of field notes; knowing how to separate detail from trivial ... and using rigorous methods to validate observations" (Patton, 1990, p. 201). 
After participants accepted the researcher's request for classroom observation, the process of observing went as follows, according to the suggestions of Creswell (2008), Marshall and Rossman (2006), and Maxwell (1996):

(1) Contacted the instructor for: a) The time for observing; b) The duration for observing; c) The researcher's role of observation; and d) Means for recording notes during the observation.

(2) Went to the classroom at least five minutes early, getting a general sense of the site; selected a seat that could help the researcher best understand the central phenomena; and took limited notes initially.

(3) Took notes on the classroom and students.

(4) Originally, the researcher planned to make herself known but remain lowprofile. However, two participants seemed to prefer the researcher to be unnoticed. Therefore, the researcher did not make herself known and remained silent while observing their classroom teaching.

(5) The note-taking was divided into three columns: time, descriptive fieldnotes, and reflective fieldnotes (see Appendix B). In the descriptive fieldnotes, the researcher recorded a description of the events, activities, and what had happened in class, focusing on the instructor. In the reflective fieldnotes, the researcher jotted down her thoughts and reflections on what she saw and heard during the observation.

(6) Careful attention was paid to visual details, including body language and other gestural cues that linked to the words of the instructor and students. 
(7) After observing, the researcher thanked the instructor and students when there was an opportunity to do so before leaving. Otherwise, she sent an email to thank the instructor.

\section{Observer's Role}

Creswell (2008) suggests that a researcher can choose from three observational roles: participant observer, nonparticipant observer, and changing observational roles. The researcher of this study originally planned that if the participants agreed, she would take the changing observational roles according to the following.

Angrosino and Mays de Perez (2000) point out that "Most social scientists have long recognized the possibility of the observer's affecting what he or she observes, but careful researchers are nonetheless supposed to adhere to rigorous standards of objective reporting designed to overcome that potential bias" (p. 674). Angrosino and Mays de Perez suggest that researchers rethink their received notions about observation: what observation is, how it is done, what role it plays in the traditional notion of objectivity and in the postmodernist turn in contemporary studies of society and culture. They point out "In effect, objective truth about a society or a culture cannot be established, because there are inevitably going to be conflicting versions of what happens" (p. 675). Based on arguments made by Wolf (1996), Matsumoto (1996), and Kuhlmann (1992), Angrosino and Mays de Perez suggest that “... it might be useful to shift from a concentration on observation as a "method" per se to a perspective that emphasizes observation as a context for interaction among those involved in the research collaboration" (p. 676). 
The role shift from that of inquirer to that of participant would help with describing the culture in terms of the meanings specific to the instructors and students in a Chinese classroom. For example, participation in classroom activities allows the researcher to be involved with students and to experience student practices guided by the instructor under observation.

However, there were few opportunities for the researcher of this study to adopt those kinds of changing observational roles. During all the classroom observations, she remained a nonparticipant observer. Only once when observing a class: during the discussion about a question of grammar, the teacher asked the researcher to give her opinion about the question. The researcher gave her comment about the question briefly, but then agreed with the teacher when he gave a different opinion.

\section{Why Classroom Observation Was Done before the Interview}

Merriam (1998) states that observational data represent a firsthand encounter with the phenomenon of interest, while a secondhand account of the world is obtained in an interview. Clearly, both firsthand evidence and secondhand reflections can be useful.

For this study, observation was the first step for the researcher to get to learn about a participant's pedagogical beliefs. According to Richardson (1996), "Beliefs are thought to drive actions; However, experiences and reflection on action may lead to change in and/or addition to beliefs" (p. 104). It was expected that classroom activities would reveal teachers' beliefs and assumptions. For example, if students of a Chinese language class are asked to translate the Chinese text into English in class, this shows that the teacher tends to rely on translation to make sure the students understand the text. 
The observer's record of this activity can serve as a reference point during the subsequent interview. If grammar-translation has become routine to the teacher, he or she might not have questioned what factors shape his/her thinking or form the basis of his/her reasoning about teaching in this way. But questions in the interviews may lead teachers to reflect on the teaching they have done, or reexamine their philosophy.

The subsequent interview would directly collect information on the research question: What serves as the foundation for Chinese teachers' pedagogical beliefs about teaching? Activities practiced in class, such as translation, could also serve as information about teachers' beliefs, though any assumptions about those activities needed to be clarified in the subsequent interview. Information collected from interviews was further instrumental in revealing the teacher's beliefs about making decisions for classroom teaching.

The above is the rationale for the original decision to observe first and interview second. And in fact, the choice worked. For example, it was observed that every student in one of the classes was required to give a one-minute presentation in each class meeting; it was also observed that the students' motivation to learn was high. This showed that the teacher tended to believe that presentation was a good instrument to assess students' learning, and that it was also a good strategy to stimulate the students' motivation to learn. The record of this activity during the observations was used as a reference point to raise a question during the interview ("I noticed that every student in your class was so active, they were so ready to learn. Could you please talk about where does the dynamic come from?"). Data collected from the interviews showed that the 
participant's decision-making for classroom teaching happened as Richardson's (1996) statement quoted at the beginning of this section: the participant's experiences and reflections on her English learning had led her to change her beliefs about foreign language learning and teaching, and these beliefs drove her to take action in her current

teaching. Further discussion about the connections between that participant's beliefs and her classroom teaching will come in Chapter Four.

\section{In-depth Interview}

There are five parts in this section: 1) The type of interview; 2) The hows of the interview; 3) Interview questions; 4) Interview process; and 5) Language used in the interviews.

\section{The Type of Interview}

Merriam (1998) states that there are three types of interviews: 1) Highly structured/standardized, 2) semistructured, and 3) Unstructured/informal. The most highly structured interview would be an oral form of a written survey; a totally unstructured interview is seldom used as the sole way of collecting data in qualitative research (Merriam). In semistructured interviews, questions are flexibly worded, but the bulk of the interview is guided by a specific list of questions to be explored. The exact wording and the order of the questions are not determined ahead of time (Merriam). For this study, semistructured interviews were adopted.

Following the suggestion by Patton (1990), the researcher of this study tried to use "words that make sense to the interviewee", because "words that reflect the respondent's world view, will improve the quality of data obtained during the interview. 
Without sensitivity to the impact of particular words on the person being interviewed, the answer may make no sense at all - or there may be no answer" (p. 312). What was more, the researcher paid attention to the hows of interviews, as Holstein and Gubrium (1995) suggest.

\section{The Hows of the Interview}

It has been said that people are now living in an "interview society" because the use of interviewing to acquire information is ubiquitous (Atkinson \& Silverman, 1997; Silverman, 1993). It seems that everyone relies on the interview as a source of information, with the assumption that interviewing results in true and accurate pictures of respondents' self and lives. The interviewer is taught to remain as passive as possible, so as to reduce his or her influence. The scope of the interviewer's function is to take respondents' answers. The rationale for this type of interviewing assumes that there is an objective knowledge out there and that if one is skilled enough one can gain access to the knowledge (Fontana \& Hrey, 2000).

However, Fontana and Hrey (2000) deconstruct these notions as they frame the interview as an active, emergent process. They state that qualitative researchers increasingly have realized that interviews are not neutral instruments of data gathering but active encounters between two or more people, leading to negotiated, contextually based results (Fontana \& Frey). "Every interview ... is an interpersonal drama with a developing plot" (Pool, as quoted in Fontana \& Frey, 2000, p. 663). Holstein and Gubrium (1995) state that so far people have focused on the whats of the interview, the substantive findings. Now it is time that we pay attention to the hows of the interview - 
the contexts, particular situations, nuances, manners, people involved, and so on. Holstein and Gubrium (1995) point out: "To say that the interview is an interpersonal drama with a developing plot is part of a broader claim that reality is an ongoing, interpretive accomplishment" (p. 16).

According to the above arguments, the focus of the interviews for this study included the hows (the constructive work involved in the Chinese instructors' beliefs and classroom teaching) as well as the traditional whats (their beliefs and assumptions about language and language teaching).

Beliefs are best accessed indirectly from what individuals say and do (Kagan, 1990; Woods, 1996). Marshall and Rossman (2006) state that participants' frames of reference matter in qualitative studies, and that human actions cannot be understood unless the meaning that humans assign to them is understood. Berg (2004) points out that in the life-worlds, researchers should focus on naturally emerging languages and the meanings individuals assign to experiences. Life-world includes emotions, motivations, symbols and their meanings, empathy, and other subjective aspects associated with naturally evolving lives of individuals and groups (Berg; Marshall and Rossman).

To sum up the hows: Foreign language teachers' classroom teaching involves thoughts, feelings, beliefs, values, and assumptions. It was through face-to-face interaction that the researcher was able to access useful information that could not be directly observed in classrooms (Creswell, 2008), and to capture and understand the Chinese instructors' deeper perspectives. Also, the interviews offered opportunities for 
participants to describe detailed personal information (Creswell), and for the researcher to dig out the sources of the participants' beliefs and assumptions, to discuss the challenges in detail, and to trace the triggers and preconditions by which the participants changed their beliefs about language teaching. By connecting the whats to the hows (Fountana \& Hrey, 2000; Holstein \& Gubrium, 1995), the researcher was able to collect more accurate information to answer the research questions.

\section{Interview Questions}

Freeman and Freeman (1994) state that teachers have a theory about learning. Brookfield (2005) states that each person is a theorist. Similarly, Marshall and Rossman (2006) state that "people develop personal theories about events as ways to reduce ambiguity and explain paradox" (p. 31). Further, it is claimed that these personal theories are developed based on beliefs, assumptions, and experiences. Freeman and Johnson (1998) "believe that teachers must understand their own beliefs and knowledge about learning and teaching and be thoroughly aware of the certain impact of such knowledge and beliefs on their classrooms and the language learners in them" (p. 412). The interview questions should be able to elicit the participant's beliefs, assumptions, and knowledge; and to discover connections between their beliefs and their teaching.

A brief introduction and twelve questions were prepared for the first interview of this study (see Appendix C). The introduction was to inform the participants about what the interviewer intended to do. It took approximately the following form, with an introduction at the beginning: 
Several writers (Brookfield, 2005; Freeman \& Freeman, 1994; Marshall \& Rossman; 2006) state that each teacher is a theorist. Teachers build up personal theories about events as ways to reduce ambiguity and explain paradox. Professional teachers tend to explore the most effective ways to encourage learning for their students. Our interview will focus on how you develop your theories on foreign language classroom teaching, and how you put your theories into practice. We shall talk about this step by step. Shall we start with the first question?

Question 1 (“Could you please talk about how you learned to teach Chinese?”) was to elicit information about interviewees' former schooling and experiences with foreign language learning, and to learn what contributed to the development of their teaching style (Freeman \& Johnson, 1998, Galbraith, 1998; Freeman \& Richards, 1996; Lortie, 1975; Velez-Rendon, 2002 ).

Question 2 ("What knowledge prepared you to be a teacher of Chinese ?") intended to elicit information about interviewees' general orientation toward language teaching (Freeman \& Johnson; 1998; Hamp-Lyons \& Condon, 2000; Lange, 2003) and their epistemic beliefs/philosophy of knowledge (Galbraith, 1998; Pratt, 1998; Schommer-Aikins, 2004).

Question 3 (“How did you attain this knowledge?") intended to identify and understand interviewees' perspectives about foreign language teaching and how they are linked to their beliefs in the organization and certainty of knowledge (Belenky et al., 1986; Schommer, 1998; Schommer-Aikins, 2004). 
Question 4 ("Does what you learned from your former schooling help with your current teaching? And how?") was to elicit information about how the interviewees' early pedagogical frameworks were transformed in their current classroom teaching, including the cultural transformation from what they had learned in China to how they taught in the United States.

Question 5 ("What should be introduced and how to teach in Chinese language classes?") and 6 (“What counts as language proficiency?") intended to elicit interviewees' views about the nature of language, language teaching, and their understanding about the goal of foreign language learning (Chomsky, 1968, 2006; Cummins, 1996; Ellis, 1994, 1997; Freeman \& Freeman, 1994; Krashen, 1982; National Standards, 2006; Swain, 1995; Vygotsky, 1978, 1986). Data collected from the interviews showed that responses to these two questions offered information about interviewees' assumptions and beliefs about the organization/structure of knowledge (Schommer, 1998; Schommer-Aikins, 2004) and their "knowledge of content" (Galbraith, 1998, p. 14).

Question 7 (“How do students learn Chinese?”) intended to elicit interviewees’ orientation with regard to instruction, their roles as teachers, their understanding about student learning, and their philosophy of adult education. Did they keep a hierarchical relationship with their students and believe knowledge could be handed down? Or did they believe that learners were cable of pursuing knowledge which came from empirical evidence and reason (Belenky et al., 1986; Schommer, 1998; Schommer-Aikins, 2004)? What were their views about effective learning (Dewey, 1916; Galbraith, 1998; Kolb, 
1981; Mezirow, 2000; Schommer, 1998; Schommer-Aikins, 2004; Taylor, Marienau \& Fiddler, 2000; Walker, 2002)?

Question 8 ("Some writers state that student needs and past experiential development affect how teachers teach, what would you say?") was to elicit interviewees' knowledge of learners and their understanding about culturally and cognitively diverse students, their decision-making about classroom teaching, and how they met the students' needs (Galbraith, 1998; Kramsch, 2003; Lasley \& Matezynsk, 1997; Nieto, 2002; Seelye, 1993).

Question 9 (“Could you please explain why you ask your students to do ... in class?") asked for interviewees' decision-making about specific activities in class. Data from the interviews showed that responses to this question offered information about the interviewees' understanding of approaches to foreign language teaching (Cummins, 1996; Freeman \& Freeman, 1994; Freeman \& Johnson, 1998; Hymes, 1972; Krashen, 1982; Swain, 1995; Vygotsky, 1978) and their "knowledge of method" (Galbraith, 1998, p. 16).

Up through Question 9, interviewees had offered information on their beliefs about classroom teaching; beliefs from which they developed their personal teaching theories. By this time, interviewees had learned what "personal theories" refer to. Thus, Question 10 ("So far, you have offered important information. Thanks so much. Could you please sum up your ideas, theories, philosophies, and methods about Chinese language teaching?") planned to offer the interviewees an opportunity to review their beliefs, assumptions, and values about classroom teaching. However, two participants 
remarked that it was tough to make the summary right on the spot. The researcher agreed with them.

Question 11 ("Could you please talk about how you put your theories into practice?') led us to see the connection between the interviewees' beliefs and their decision-making about classroom teaching.

Question 12 ("How familiar are you with the Standards for Foreign Language Learning in the $21^{\text {st }}$ Century?") intended to elicit interviewees' understanding about the philosophy, goal, contents, and methods stated in the National Standards (2006). The reason for placing this question at the end of the interview was not to confuse or embarrass interviewees, and to let them feel free to voice their own perspectives. Data collected from the interviews proved that this was a right decision.

To sum up this section, Interview Questions 1- 8 and 12 collected data for Research Question 1 (What serves as the foundation for Chinese teachers' pedagogical beliefs about teaching?); and Interview Questions 9, 10, and 11 collected data for Research Question 2 (How do Chinese teachers' pedagogical beliefs connect to their classroom teaching and what characterizes this relationship?). Data collected from the first interview were transcribed as quickly as possible so that the transcriptions could be shared with the interviewee before the second interview. The preparation of questions for second interviews will be discussed in the next section, Data Analysis.

\section{Interview Process}

The researcher of this study originally planned that two interviews would be conducted with each participant, and each interview would last about 60 to 90 minutes. 
However, Participant A, had three interviews; and the first interview for Participant B, lasted shorter than 60 minutes. The first interview with $\mathrm{A}$ in her office was not taken during her working hours. However, unexpectedly, a middle-aged student knocked at the door and wanted to talk to A. The researcher and A both decided to stop the interview (it lasted 28 minutes) and let the student have his visit. As A suggested, the interview was continued the next day, and this became her second interview which lasted 45 minutes. B received a last-minute notice about a meeting at the time set for her first interview. However, there was no time for her to inform the researcher. Therefore, the first interview was done before her meeting in only 36 minutes, though she responded to all the questions and offered information comparable to what other participants offered in an hour. (Further discussion about the duration of interviews will come in the transcription section.) The second interview for B lasted 82 minutes.

Each person's second interview, except for Participant A's, was taken after the first one had been transcribed and questions for the second interview were wellprepared. In the process of coding the data, the researcher made two telephone calls with two participants in order to clarify some details about the participants' experiences or statements; each call lasted about 5 minutes.

During interviewing, the researcher used observational techniques to note body language and other gastrula cues that lent meaning to the words of the participants being interviewed, as Angrosino and Mays de Perez (2000) suggest. However, sometimes the researcher had to stop taking notes because she noticed that participants looked 
uncomfortable when she was writing while they were speaking. (Information about supplementing such information will be in the Data Analysis section.)

According to Creswell's (2008) and Fountana and Hrey's (2000) suggestion, steps conducted in interviews for this study were:

(1) Obtained consent from the interviewee for conducting the interview.

(2) Made a flexible plan for each interview.

(3) Located a quiet, suitable place for the interview.

(4) Prepared equipment for collecting data (digital-recorder, pencil and notebook).

(5) Decided how to present the interviewer herself (This decision was important. According to Fountana and Hrey's (2000), the interviewer's presentational self would leave an impression on the respondent that could have an influence over the success of the study).

(6) Took brief notes during the interview; used probes to obtain additional information.

(7) Noted body language and other gastrula cues that lent meaning to the words of the teacher being interviewed (Angrosino \& Mays de Perez, 2000).

(8) Completed the interview by thanking the interviewee, assuring him or her of the confidentiality of the responses, and asking if he or she would like a summary of the results of the study. 


\section{Language Used in the Interviews}

According to Banks and Banks (1991), a translator acts as a mediator; he or she may be unconscious of his or her own ideology and influences on the translated text. Banks and Banks argue:

... the process of translation acts as an intervening variable in intercultural interaction and research. As such, the process should be considered a threat to the reliability and validity of data gleaned from material that has been translated. ( $p$. 182)

To reduce a threat to the reliability and validity of data collected for this study, English was the language for all the interviews. Since all the participants were teaching at the college level, and most of them had been English teachers before they came to the United States, English was not very problematic for communication between the researcher and the participants. Although three participants spoke more fluently and two spoke a little slower, all participants were able to express their thoughts in English. In-the-field Insights (Patton, 2002)

During the process of classroom observation and interviewing, reflections and remarks kept occurring in the researcher's mind, though she knew that it was too early and not appropriate to make any comments or analysis of what she saw and heard. However, she kept a memo according to Patton's (2002) suggestion:

Recording and tracking analytical insights that occur during data collection are part of fieldwork and the beginning of qualitative analysis. I've heard graduate students instructed to repress all analytical thoughts while in the field and concentrate on data collection. Such advice ignores the emergent nature of qualitative designs and the power of field-based analytical insights. Certainly, this can be overdone. Too much focus on analysis while fieldwork is still going on can interfere with the openness of naturalistic inquiry, which is its strength. Rushing to premature conclusions should be avoided. But repressing analytical insights may mean losing them forever, for there's no guarantee they'll return. And repressing 
in-the-field insights removes the opportunity to deepen data collection that would test the authenticity of those insights while still in the field and fails to acknowledge the confirmatory possibilities of the closing stages of fieldwork. ( $p$. 436)

Indeed, for this study, the researcher's "in-the-field insights" (Patton, 2002, p. 436) did help her "deepen data collection" (p. 436), prepare questions for second interviews, and draw themes from codes.

\section{Data Analysis}

This section is composed of four parts: 1) Theoretical framework for data analysis;

2) Transcription; 3) Coding the data; and 4) Themes.

\section{Theoretical Framework for Data Analysis}

According to Patton (2002),

The challenge of qualitative analysis lies in making sense of massive amounts of data. This involves reducing the volume of raw information, sifting trivia from significance, identifying significant patterns, and constructing a framework for communicating the essence of what the data reveal .... No ways exist of perfectly replicating the researcher's analytical thought processes. No straightforward tests can be applied for reliability and validity. In short, no absolute rules exist except perhaps this: Do your very best with your full intellect to fairly represent the data and communicate what the data reveal given the purpose of the study. (p. 432-433)

Similarly, Marshall and Rossman (1999) state that data analysis is the process of

bringing order, structure, and interpretation to a mass of collected data:

In qualitative research, data collection and analysis typically go hand in hand to build a coherent interpretation of the data. The researcher is guided by initial concepts and developing understandings by shifts or modifies themes she collects and analyzes the data. Her overall strategy, thus, rests more toward the interpretive/subjectivist end of the continuum than the technical/objectivist end. ( $p$. 151)

Marshall and Rossman suggest researchers should use the research questions and related literature developed earlier to guide their data analysis. Similarly, Patton (2002) 
suggests, "The theoretical framework within which the study is conducted will heavily shape the analysis" (p. 434).

For this study, data analysis was guided by the research questions and the research and theoretical literature highlighted in Chapter Two: traditional beliefs about language and language teaching; current perspectives on language learning; the development of personal epistemology; learning through sociocultural context and experience, philosophy of adult education, etc. Indeed, data collection and analysis went hand in hand for this study in order to build a coherent interpretation of the data as Patton (2002), and Marshall and Rossman (1999) state. The process of data analysis for this study began with transcription.

\section{Transcription}

This section is comprised of four parts: 1) What transcription is; 2) Transcription for Classroom Observations; 3) Transcription for Interviews; and 4) Attention paid to accuracy of transcripts.

What Transcription Is

According to Creswell (2008), "Transcription is the process of converting audiotape recordings or fieldnotes into text data" (p. 246). "You obtain words through interviewing participants or by writing fieldnotes during observation; you need to convert those words to a computer file for analysis. Alternative, you might listen to the tapes or read your fieldnote to begin the process of analysis. .. the most complete procedure is to have all interviews and all observation notes transcribed ... it takes approximately 4 hours to transcribe 1 hour of tape" (p. 243). 
However, it took the researcher of this study approximately one hour to transcribe ten minutes of the recordings for the interviews. It took a longer time to transcribe the recordings of classroom observations, because typing Chinese characters is more complicated than typing English. All interview and observation recordings and notes for this study were carefully transcribed by the researcher herself.

\section{Transcription for Classroom Observations}

Figure 8 Transcription of Classroom observations for One Participant

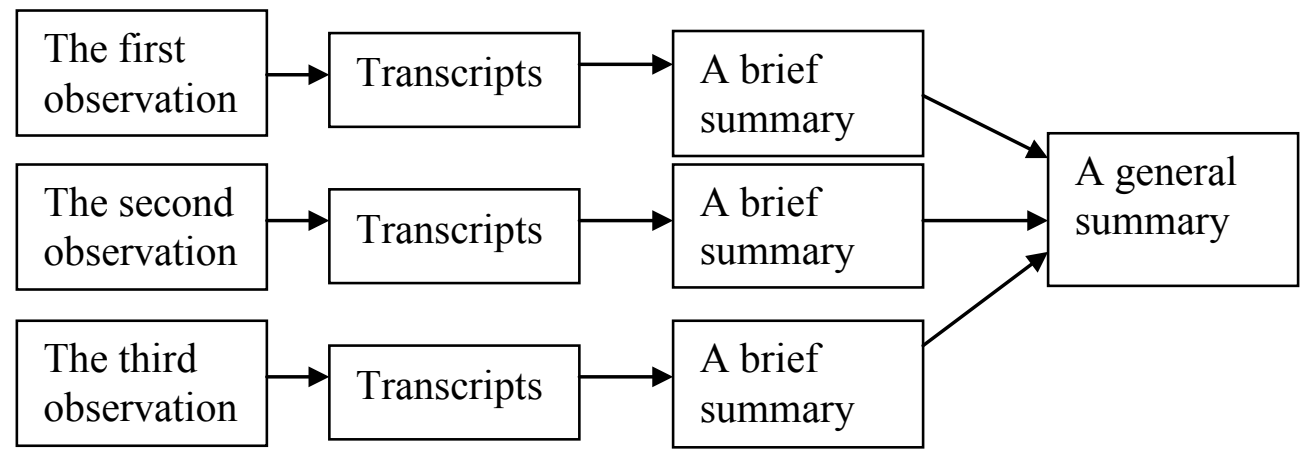

The transcription began with classroom observation. The researcher started transcribing the data immediately after observing each class, for three reasons: 1) To capture some gestures and events that the audio-recordings failed to record, or there was not enough time to write down an event in fieldnotes during the observation; 2) To confirm the significance of the instructor's teaching style that was assumed earlier during the observation, or to capture the significance of instruction activities that had not been identified on the spot; and 3) To get ready for subsequent observation: what should be observed more carefully, for example, students' reactions to the instructor's methods, or the instructor's response to the students' reaction. 
To follow Patton's (1990) suggestion that a skilled observer should use "rigorous methods to validate observations" (p. 201), the researcher of this study checked the transcripts while listening to the recording after a transcription was done. Listening to the recording brought the scenes back to the researcher's mind. But now the researcher had more time to catch meaningful actions, or to clarify what had happened in the class. Several times the researcher found that during an observation, it was easy to mix descriptive notes with reflective notes while taking fieldnotes. For example, original in the column for descriptive notes:

Now the students realized that the teacher was going to divide them into two groups. The students stand up, form two groups, move the chairs and sit in two circles.

The first sentence (Now the students realize that the teacher was going to divide them into two groups) was the researcher's assumptions, it should be moved to the column for reflective notes. Also, according to the scene that the researcher recalled in her mind, the description should be rewritten as:

A few students stood up and went to either side of the classroom, the others followed. They moved the chairs and sat in two circles. 
Another example showed that bias might occur when writing reflective notes:

$\mathrm{T}$ : teacher

S: student

\begin{tabular}{|c|c|c|}
\hline Time & Descriptive notes & Reflective notes \\
\hline $6: 30$ & $\begin{array}{l}\text { T: 这个 “是”有时候可以强调几种情况, 可 } \\
\text { 以强调人, 时间, 地点. 可以强调原因, 方 } \\
\text { 法, 主语,做这个事的人. 比如说, 你举个 } \\
\text { 例子看看. (“The word 'shi 是' can be used } \\
\text { for emphasizing in several situations. It can } \\
\text { be used to emphasize person, time, and } \\
\text { location. It can emphasize a cause, a } \\
\text { method, the subject of a sentence, or the } \\
\text { person who did the action. Can you give an } \\
\text { example?”) } \\
\text { S: 我 (thinking for a second) 是在波特兰 } \\
\text { 长大的. (“It was in Portland that I grew } \\
\text { up.”) } \\
\text { T: 喔, 非常好. 强调了地方. 我是在波特兰 } \\
\text { 长大的. 非常好. 我们知道用 “是....... 的” } \\
\text { 可以指发生了,还是没有发生? (“Oh, very } \\
\text { good! You have emphasized the location. } \\
\text { Very good. “It was in Portland that I grew } \\
\text { up.” We have learned that the sentence } \\
\text { pattern “ It is ... that...” can be used to } \\
\text { refer something that has happened, or not } \\
\text { happened yet?”) } \\
\text {.. }\end{array}$ & $\begin{array}{l}\text { The teacher is very happy } \\
\text { that the student made a } \\
\text { good sentence. }\end{array}$ \\
\hline
\end{tabular}

When listening to the recording of the observation again, the researcher realized that the original reflective note (See the above table) was bias from the researcher. To be more objective and appropriate for writing fieldnotes, it should be changed to "The teacher gives a positive comment on the student's performance."

After checking the transcripts of the classroom observations, a summary of each observation was written according to the Guidelines for Classroom Observation (See 
Appendix A). After the summary of the third observation for a participant was done, a general summary was written for the participant, including a comment on each of the seven observation areas and the significance of the participant's teaching, because: “... in such a way that we can understand the phenomenon studies and draw our own interpretations about meanings and significance" (Patton, 2002, p.438).

\section{Transcription for Interviews}

According to Creswell (2008), transcription should provide data that capture the details of an interview. As with transcribing classroom observations, right after each interview, the researcher of this study listened to the recording in order to 1) Recall body language and other gastrula cues that lent meaning to the words of the participant being interviewed (Angrosino \& Mays de Perez, 2000), or to remember sections of the interview when the researcher had to stop taking notes because she noticed that participants looked uncomfortable to see her writing while they were speaking; 2) Review or recollect "in-the-field insights" (Patton, 2002, p. 436). After listening to the audio-recording, adding information that the digital recorder missed, and making up the fieldnotes, the researcher started to transcribe the data.

\section{The Accuracy of Transcripts}

While transcribing, the researcher focused on the accuracy of converting the audio-recording into text data. The transcription was done sentence by sentence. After the words of a long sentence were typed, the researcher checked the sentence immediately by listening to the recording again. All words and body language, including pauses for thinking or because of hesitation, were transcribed, as Creswell 
(2008) suggests. After transcribing each interview or classroom observation, the researcher checked for accuracy: reading the whole transcript while listening to the audio-recording.

After a transcription was checked, a hard copy of the transcripts for the first or second interview was sent to each participant for his/her approval. So far, no complaints have been received from any participants.

\section{Capturing more details in the process of transcription}

Berg (2004) and Marshall and Rossman (1999) suggest that researchers should focus on naturally emerging languages, emotions, motivations, symbols and their meanings associated with interviewees. This suggestion helped with capturing more details in the process of transcription.

The researcher found that it was rewarding to listen to the recording right after an interview. When the voices and tones were heard and the scenes in the interview came back to the researcher's mind, extra information emerged. For example, two participants both made comments about the advantages and disadvantages of the grammartranslation method. Reading the transcripts did not reveal much difference in their attitudes toward the method, but their feelings about the method could be identified when comparing the different voices and tones with each of the participant's words. And this difference was consistent with the instruction observed in their classrooms: one tended not to explain grammar rules to students, the other created a new way to use the grammar-translation method. One more example: excited feelings were obviously heard when a participant talked about her English learning experiences: to give lectures 
on American history to her colleagues in the graduate cohort, and to organize an English Corner that several hundred English learners attended in a park. Similarly, a feeling of disappointment about her learning of "deaf and dumb English" could be identified when another participant talked about learning English in her hometown. All these feelings were transforming into a desire, as they later stated in the second interview: to change or renew their beliefs about foreign language teaching. Further actual changes were demonstrated in their current Chinese teaching classroom. Attention paid to such details that happened during an interview assisted the researcher to notice more, to prepare questions for second interviews, and to explore the data deeper.

The researcher's bias during interviews

Listening to the recording right after an interview was like looking at a mirror that reflected the researcher's behavior during an interview. This reflection helped to improve interview skills, and to solve some problems. For example, once the researcher's bias during an interview was caught: Data collected from the classroom observations and a participant's earlier statement showed that the participant's perspectives about Chinese teaching agreed with some arguments on the connection between language and culture (Kramsch, 2003). To learn more about the participant's beliefs, the researcher asked a participant to talk more about the relationship between language and culture. However, the researcher found that the participant looked a little impatient, but was not sure why. It was not until the researcher listened to the recording again that she realized the problem. She was trying to elicit something from the participant similar to the arguments in the literature she had read. It was unreasonable 
for the researcher to expect an interviewee to make a statement as well-organized and intellectual as the arguments made by those writers. The participant had a good reason to get impatient!

\section{Duration of Interviews}

During the process of transcription, the researcher found that the duration of an interview was not a factor in determining how much information might be gathered from an interviewee. One interviewee could say more in a shorter time than another did in a longer time. For example, the first interview for one participant lasted 36 minutes because she had to attend an unexpected meeting. During this interview, she spoke 3,377 words. A second interview for another participant lasted 57 minutes; she spoke 3,361 words. Rich and valuable information was collected from both interviews.

\section{Coding the Data}

"Coding is the process of segmenting and labeling text to form descriptions and broad themes in the data. The object of the coding process is to make sense out of the text data" (Creswell, 2008, p. 251). "Coding is the heart and soul of whole-text analysis. Coding forces the researcher to make judgments about the meanings of contiguous blocks of text" (Ryan \& Bernard, 2000, p. 780). "Coding data is the formal representation of analytic thinking” (Marshall \& Rossman, 1999, p. 155). In a word, "Coding is analysis" (Miles \& Huberman, as cited in Ryan \& Bernard, 2000, p. 780). "Coding serves two distinct purposes in qualitative analysis. First, codes act as tags to mark off text in a corpus for later retrieval or indexing... Second, codes act as values 
assigned to fixed units" (Bernard, Seidel \& Kelle, as cited in Ryan \& Bernard, 2000. p. 781).

As discussed in the last section, the researcher of this study had "in-the-field insights" (Patton, 2002, p. 436), an interpretation of data during the process of collection (Marshall \& Rossman, 1999). However, coding was the first step for the researcher of this study to form an in-depth understanding of the Chinese teachers' beliefs and assumptions, and to dig out meaning from their words.

The researcher went through the eight steps of coding as suggested by Creswell (2008), Marshall and Rossman (1999), and Ryan and Bernard (2000): 1) Read through all the transcripts carefully; 2) Started with one transcript; 3) Identified meaningful text segments; 4) Grouped similar codes, assigned code words, marked with numbers; 5) Listed all code words; 6) Took the list and went back to the data to see whether new codes emerged, and searched specific quotes from participants that supported the codes;

7) Reduced overlap and redundancy of codes; 8) Collapsed codes into themes.

In the mean time, the researcher adopted Patton's (2002) strategy for analyzing interviews: beginning with case analysis, followed by cross-case analysis.

\section{Case Analysis}

As mentioned earlier in the Rationale for the Researcher Design in this chapter, the case-study method was employed for analysis (Patton, 2002). According to Patton, "The analyst's first and foremost responsibility consists of doing justice to each individual case. All else depends on that" (p. 449). For each participant, the researcher had done at least three classroom observations and two interviews. Coding for all the 
data collected from one participant was taken as one case analysis. Also, the researcher used inductive analysis to identify meaningful text segments in the transcripts. Patton (2002) describes the processes of inductive analysis as "discovering pattern, themes, and categories in one's data" (p. 453). The researcher paid close attention to “indigenous concepts and practices" (Patton, 2002, P. 453). Key phrases, terms, and practices that are special to the participants were defined in order to explore "What are the indigenous categories that the people interviewed have created to make sense of their world? What are practices they engage in that can be understood only within their worldview?" (Patton, 2002, p. 453). For example, “deaf and dumb English”, "putting students into the water to swim", and "develop a new habit" were three cases of "selecting conceptually intriguing phrases that either connected with previous literature or suggesting patterns emerging from the analysis of previous data" (Marshall \& Rossman, 2006, p. 153).

After performing the first seven steps for coding (Creswell, 2008; Marshall \& Rossman, 1999; Ryan \&Bernard, 2000) on data collected from a first interview with a participant, the researcher began to prepare questions for the second interview. Preparing questions for second interviews

Since second interviews were intended to probe more accurately and deeply into participants' beliefs and assumptions about language teaching, questions for the second interviews were prepared based on information collected from the first interviews and from the three classroom observations. The researcher first explored the whats and the hows of the data collected from the first interview. Attention was paid to unclear views, 
clues for interesting thoughts, events or behaviors that needed more details and explanation. Then, she reviewed the text data collected from classroom observations, and went back to the study's theoretical framework to see what needed to go deeper, or how to elicit information that had not been collected during the first interview. Any clues for interesting thoughts, events or behaviors that needed more details and explanation were pulled out and turned into questions for a second interview (See Figure 9). Interview questions focused on key concepts, core values, significant statements or comments that implied beliefs and assumptions about language teaching.

Figure 9 Data Collection and Analysis Go Hand in Hand (Patton, 2002)

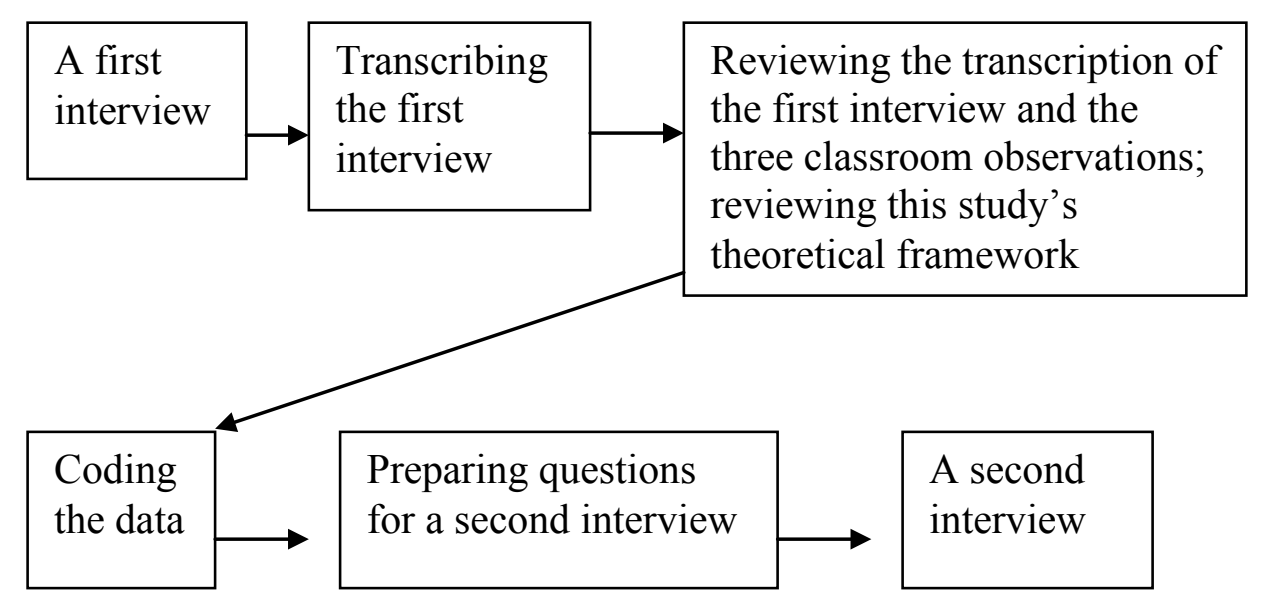

Capturing the "hows" in the process of coding As discussed earlier in the Data collection section, Fontana and Frey (2000), and Holstein and Gubrium (1995) advocate that researchers should pay attention to the hows, not just the whats of an interview. This argument agreed with the major assertions that the researcher of this study wanted to make. During the process of coding, close attention was paid to the hows (the constructive work involved in the Chinese teachers' beliefs and classroom teaching). Much work was done to capture, or to elicit during second interviews, the triggers and 
preconditions that changed participants' beliefs and assumptions about language and language teaching. When information about the hows showed up, the whats (participants' beliefs and assumptions about language and language teaching) also emerged.

An emerging topic During the first interview, three participants each mentioned the differences between teaching in China and in the United States. Their statements brought up an issue about instruction based on cultural social theories. In the proposal for this study, "Political power and social values" was one of the elements that were assumed to influence teacher's decision-making, but it was not regarded as an essential issue to be discussed. Therefore, it was not included in the questions for the first interview. But now, since 60 per cent of the participants had talked about this issue, the researcher decided to go deeper. Questions around this topic were prepared for the second interview for each of the three participants. As expected, information collected around this topic later enhanced the discussion about meeting students' needs (See Student diversity context in Chapter Four of this paper).

Un-responded "how" questions While conducting and transcribing first interviews, the researcher found that some participants tended to answer a how question with information about what. For example, to the question "Could you please talk about how you learn to teach Chinese", three participants offered names of the courses they had taken at school. Similarly, another participant was a little confused by the question "How did you attain this knowledge?" When the researcher explained that the 
information she had offered earlier was about what knowledge she had attained, but not how she had attained, she laughed and said, "That is kind of hard to explain [the how]." Indeed, traditionally more attention is paid to the whats than the hows in teaching and learning at school. How learning happens (Dewey, 1916; Kolb, 1981; Mezirow, 2000; Tailor, Marienau, \& Fiddler, 2000; Walker, 2002) seemed not as well-known as what should be taught or learned in classrooms. In this study, it was very interesting to see that even though some participants were not that well-prepared to answer some of the how questions during interviews, still their decision-making about classroom teaching revealed that they did know how to help students learn (Further discussion about this issue will come in the next chapter). Data collected from classroom observations offered valuable information for the researcher to dig out those hows during second interviews.

Checking bias in questions for second interviews Bias could occur when preparing questions for second interviews if the researcher was not careful enough. The following are two examples caught by the researcher when checking the drafts for second interviews.

1. Do you think students learn better through Communicative Language Teaching?

2. In our last interview, to the question "what should be introduced (taught) in a Chinese language class?" you gave "the phonetics, the character, and the basic grammatical rules". Is there anything else we should introduce?

The first example contained the researcher's affirmative attitude towards the Communicative Language Teaching approach. The question itself implied that students would learn better if that approach was adopted. The question "Is there anything else we should introduce?" in the second example implied that "There is something else we 
should introduce." Actually, data collected from classroom observations showed that the interviewee did introduce culture in her classroom but did not include it in her response to the question. The researcher was trying to elicit this missing information, but created bias by asking that way. The two questions were replaced by:

1. Could you please let me know what approaches you use more often in class?

2. Could you please talk about the content you teach in your class?

In conclusion, questions for second interviews intended to understand participants' points of view about foreign language teaching more accurately, and to go deeper into their beliefs and assumptions so as to explore how they constructed their pedagogical beliefs. For the format and questions for second interviews, please see Appendix C-2 in this paper.

Cross-case Analysis

As with data collected from the first interviews, after transcribing the data collected from a second interview, the first seven steps for coding began, except Step 8, "collapse codes into themes". When finishing coding the text data collected from each participant, the researcher summarized all the data collected from a participant through three classroom observations and two interviews (See Figure 10). 
Figure 10 Case Analysis

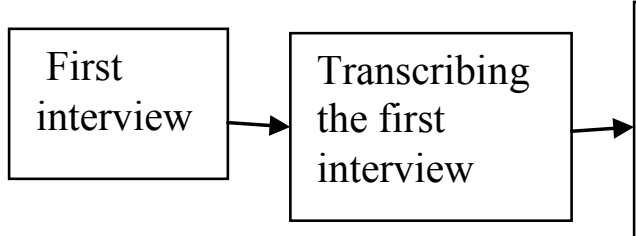

Reviewing this study's theoretical framework and the transcriptions of the first interview and the three classroom

Preparing questions

for the second interview

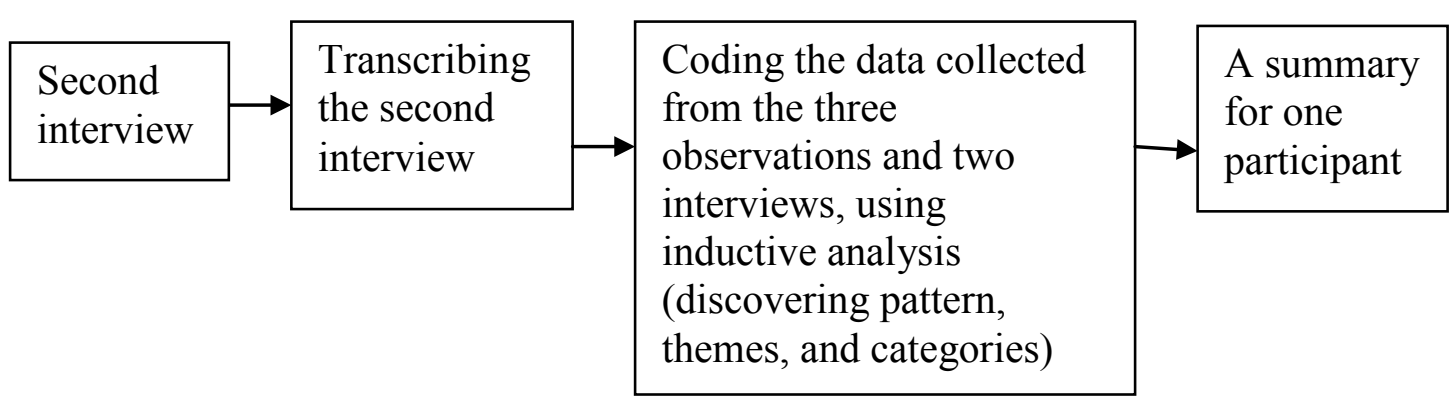

Then, after a summary was done for each participant, the cross-case analysis

(Patton, 2002) for this study started. According to Patton (2002):

Beginning with cross-case analysis means grouping together answers from different people to common questions, or analyzing different perspectives on central issues. If a standardized open-ended interview has been used, it is fairly easy to do cross-case or cross-interview analysis for each question in the interview. With an interview guide approach, answers from different people can be grouped by topic for the guide, but the relevant data wouldn't be found in the same place in each interview. (p. 440)

Indeed, relevant data were not always found in the same place in each interview for this study. Participants' responses to the same question were rather diverse.

Sometime, a response to a question would have been more appropriate as a response to another question (further discussion will come later in this section). Anyway, it was interesting to start with cross-case analysis, though it required considerable work. Here are the steps for the cross-case analysis for this study. 
First, the researcher read through the summary of each case analysis, labeling key words, meaningful expressions, and unexpected phenomena in order to identify the significance of each participant, or to compare the similarities among the participants. For example, two participants tended not to teach grammar rules, while another introduced grammar points in every one of the three classes observed.

Secondly, the researcher focused on data collected from the first interviews. After listening to the audio-recording, exploring the hows of an interview, adding information that the digital recorder missed, transcribing the recording into text data, and checking the transcripts while listening to the recording again, the researcher drew key points from participants' responses to each interview question in order to: 1) Get ready to compare the responses with other participants' response to the same question; 2) Identify the significance of a participant's statements (highlighted in red). Each interview question was highlighted in green. This helped with analyzing all the answers to each question (Creswell, 2008).

Then, all the answers to each of the twelve questions for the first interview were grouped together. Similar views or different perspectives to a question were drawn out and divided into groups again. For example, there was a group of similar views about communication as the goal for language learning; and another group of disparate views on grammar teaching. The researcher paid special attention to those responses that seemed to wander away from an interview question, because often, the information offered was relevant to other interview questions, and could be grouped with those questions' data. 
Thirdly, The researcher made a list of all the codes drawn from the first two steps, read through them, grouped similar codes, then combined them into a topic, for example, former schooling, triggers and preconditions for change. A few significant views were drawn out from the codes to form a topic, for example, significant remarks on practices, or on students' motivations.

In the meantime, the researcher kept "analyzing different perspectives on central issues" (Patton, 2002, p. 440), using “content analysis" strategy to "identify core consistencies and meanings" (Patton, 2002, p. 452). For example, one of the central issues for this study was that teachers' beliefs and past experiences as learners tend to create ways of thinking about teaching (Freeman \& Freeman, 1994; Freeman \& Johnson, 1998; Lortie, 1975; Velez-Rendon, 2002). The researcher combed the texts and codes for recurring words or topics related to this issue. Next, the researcher carried out deductive analysis, as Patton states:

Generating theoretical propositions of formal hypotheses after inductively identifying categories is considered deductive analysis by grounded theorists Strauss and Corbin (1998): "Anytime that a researcher derives hypotheses from data, because it involves interpretation, we consider that to be a deductive process" (p. 22). (p.453)

It was with this interpretation about the recurring words among the text data that the researcher of this study could engage in "explaining the findings, answering why questions, attaching significance to particular results, and putting patterns into an analytic framework" (Patton, 2002, p. 440) (See Figure 11). The discussion about results of the cross-case analysis will be in Chapter Four and Five. The following describes how data was organized. 
Figure 11 Cross-case Analysis

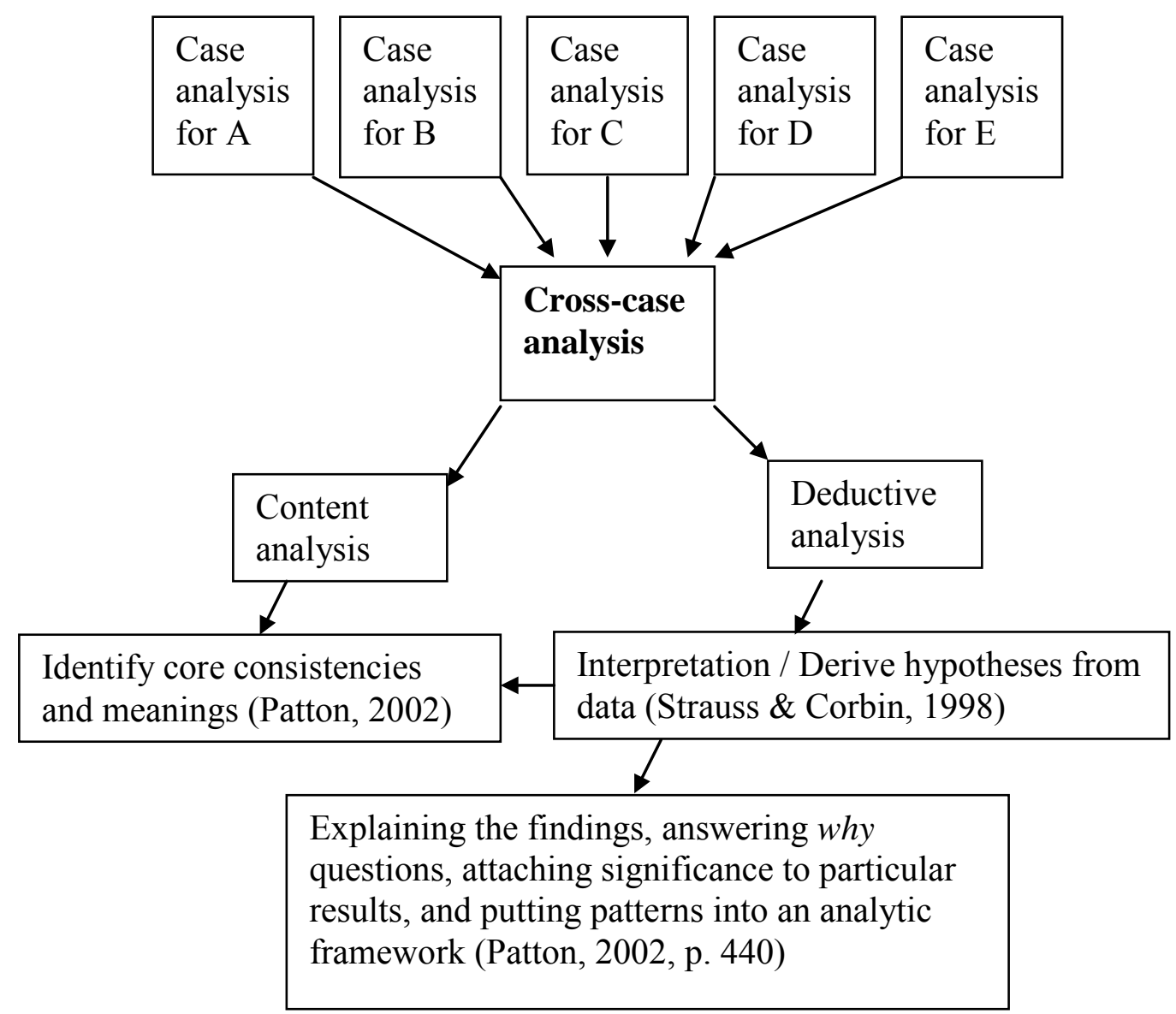

\section{Organizing Data}

Data was organized into both paper file folders and computer files. A folder was built up for each participant (Participants' name were not kept in any documents or files), including such documents as the participant's background, course syllabus (only two participants offered their course syllabus), and data collected from classroom observations and interviews. Another folder contained about 20 different topics, i.e., all the codes reduced to 20: former schooling, personal experiences of learning English (out of the classroom), language acquisition vs. language learning, knowledge needed to be a language teacher, learning from co-teachers or students, knowledge of education, 
triggers and preconditions for change, content taught in the classroom, cultural learning, reflections and comments on approaches and methods in foreign language teaching (CLT, grammar, translation, etc.), understanding of National Standards (2006), goal of language teaching and learning, language proficiency, how students learn, students' motivation to learn, meeting students' needs, personal philosophy of teaching, differences between teaching in China and in the United States, significant remarks or practices, advice for new teachers. The 20 topics were later reduced to seven themes. Writing Analytic Memos

Marshall and Rossman (2006) suggest:

Throughout the analytic process - the transformational process, according to Wolcott (1994) - we strongly encourage the researcher to write. Writing notes, reflective memos, thoughts and insights is invaluable for generating the unusual insights that move the analysis from the mundane and obvious to the creative. Several recent scholars underscore the value of writing early and often throughout the research process but especially during more focused analysis. (p.161)

During the process of transcribing, coding, and preparing questions for second interviews, the researcher of this study did realize that it was essential to write down her reflections and to generate the questions right on the spot. She was afraid that she might not have the same reflections, or would forget about the ideas in the subsequent analysis process. Indeed, these analytic memos helped her improve her skills for interviews, analysis, and for writing this paper.

The following explains how codes were collapsed into themes (Creswell, 2008).

\section{Themes}

"Themes are similar codes aggregated together to form major ideas in the database" (Creswell, 2008). Creswell suggests that codes should be reduced to 5-7 
themes. The other writers' discussions focus more on the nature of developing themes than on the number (Marshall \& Rossman, 1999; Ryan \& Bernard, 2000):

Themes are abstract (and often fuzzy) constructs that investigators identify before, during, and after data collection... No matter how the researcher actually does inductive coding, by the time he or she identified the themes and refined them to the point where they can be applied to an entire corpus of text, a lot of interpretive analysis has already been done. (Ryan \& Bernard, 2000, p. 780 - 781)

Indeed, during the process of data collection and analysis for this study, interpretive analysis occurred all the time. Of the seven themes reduced from the 20 topics (reduced codes), two were abstract constructs (influence of former schooling, foreign language and culture of the target language should be taught hand in hand ) identified before data collection, the other five were abstract constructs that appeared during the process of data collection and analysis.

For the work of identifying themes, Marshall and Rossman (2006) state:

For researchers relying on editing or immersion strategies, this phase of data analysis is the most difficult, complex, ambiguous, creative, and fun.... Identifying salient themes, recurring ideas or language, and patterns of belief that link people and settings together is the most intellectually challenging phase of data analysis, and one that can integrate the entire endeavor. Through questioning the data and reflecting on the conceptual framework, the researcher engages the ideas and the data in significant intellectual work. (p. 158)

For this study, it was true that identifying themes was the most challenging, complex, ambiguous, and creative process. However, it was not "fun" until themes were identified and the connections among each theme were recognized. A key linkage (Erickson, 1986)

According to the literature review (Freeman \& Freeman, 1994; Freeman \& Johnson, 1998; Lortie, 1975; Velez-Rendon, 2002) and data collected for this study, 
former schooling was a factor that influenced teachers' beliefs and assumptions on language teaching, but how to show this influence in a reified state for this study? How to organize data to prove that a teacher's decisions about classroom teaching would potentially influence students' language proficiency after they graduate from school? This challenge was the key to see whether the adoption of an approach or a method was effective for learning. Characteristics of effective classroom teaching (the judgment was based on the literature review for this study) could be drawn from data collected through observations. However, it would create prejudice to say that participants' adoption of certain approaches or methods would influence students' language proficiency in the future, because for the time being, there was no way for the researcher to explore the students' future. It took the researcher about two months to recur ideas, review codes, and re-sort patterns of belief. Finally, she worked out a way to solve the problem. It appeared that participants first formed their pedagogical and epistemological beliefs about language teaching based on how they had learned English: specifically, on how their English teachers' decisions about classroom methods had influenced the participants' English proficiency. The resulting beliefs about their English learning now played an essential role in the participants' decision-making for their Chinese teaching. Now it was possible, in return, to predict how the participants' decision making about classroom teaching might impact their students' Chinese language proficiency after graduating. Data collected from the interviews and observations offered rich information to support the researcher's endeavor. This solution worked "as a coherent interpretation with related concepts and themes [that] 
emerges from analysis" (Marshall \& Rossman, 2006, p. 156) and worked like "a key linkage ... that it is of central significance for the major assertions the researcher wants to make" (Erickson, 1986, p. 147).

Forming themes to answer the research questions

When the key linkage was identified, the next step was to draw themes and to identify how these themes were related to each other, and how they could form answers to the research questions (Creswell 2008; Marshall \& Rossman, 1999; Patton, 2002; Ryan \& Bernard, 2000). According to the process by which participants developed their beliefs on teaching, from the early formation of pedagogical and epistemological beliefs, through the development of pedagogical strategies, down to the refining of teaching approaches, the researcher drew seven themes from all the codes one by one. The first six themes responded to Research Question 1 (What serves as the foundation for Chinese teachers' pedagogical beliefs about teaching?); and the seventh answered Question 2 (How do Chinese teachers' pedagogical beliefs relate to their classroom teaching, and what characterizes this relationship?) Discussions about these themes will come in Chapter Four and Five.

Bellow is a discussion about validity and reliability.

Validity and Reliability

Since qualitative studies describe people acting in events, a qualitative researcher must convince the reader that the validity and reliability of the instrumentation, the appropriateness of the data analysis techniques, the degree of relationship between the conclusions drawn and the data collected (Guba \&Lincoln, 1981; Merriam, 1998). 
Merriam (1998) suggests a few strategies to enhance the validity and reliability of qualitative studies: internal validity, reliability, and external validity.

\section{Internal Validity}

First, what is validity? Schwandt (2007) states:

In social science, validity is one of the criteria that traditionally serve as a benchmark for inquiry. Validity is an epistemic criterion: To say that the findings of social scientific investigations are (or must be) valid is to argue that the findings are in fact (or must be) true and certain. Here, 'true' means that the findings accurately represent the phenomena to which they refer, and 'certain' means that the findings are backed by evidence - or warranted - and there are no good grounds for doubting the findings, or the evidence for the findings in question is stronger than the evidence for alternative findings." (p. 309)

Traditional criteria of validity are questioned by many social inquirers committed to constructivist, postmodernist, feminist, and pragmatic perspectives (Schwandt, 2007). Schwandt states that there are at least four different perspectives from which to understand the notion of validity: 1) Fallibilism; 2) Contextualism; 3) Radical Relativism; and 4) Replacement or Displacement of Validity. According to Schwandt, the fallibilist might argue that assessing the validity of a claim is a test of whether the claim accurately represents the social phenomena to which it refers. No claim actually reproduces an independently existing meaning, and no claims are ever absolutely certain. Contextualism is the argument that what is considered "valid" is relative to the standards of a particular community at a particular place and time. The most radical of postmodernists would argue that it is meaningless to talk of a valid account of the world; there are only different linguistically mediated social constructions. The central argument of Replacement or Displacement of Validity is that the traditional epistemological concern with validity cannot be separated from aesthetic/rhetorical 
criteria and political agendas. Therefore, the focus should shift from determining whether an account is "true" to how the account was developed in conversation between inquirer and participants, how it was crafted in writing by the writer of the account, and whether the account advances a social agenda or offers cultural criticism (Schwarndt, 2007).

Similar to the arguments made by Replacement or Displacement of Validity, Merriam (1998) states that "validity and reliability are concerns that can be approached through careful attention to a study's conceptualization and the way in which the findings are presented" (pp. 199-200). Techniques to ensure the validity of this study will be discussed later in this section.

"Internal validity deals with the question of how research findings match reality.... Internal validity, in all research, thus hinges on the meaning of reality" (Merriam, 1998, p. 201). According to Lincoln and Guba (1985), reality is "a multiple set of mental constructions... made by humans; their constructions are on their minds, and they are, in the main, accessible to the humans who make them" (p. 295). On accessing validity in every kind of research, Ratcliffe (1983) reminds us that:

1) Data do not speak for themselves; there is always an interpreter, or a translator; 2) One cannot observe or measure a phenomenon/event without changing it, even in physics where reality is no longer considered to be single-faceted; and 3) Numbers, equations, and words are all abstract, symbolic representations of reality, but not reality itself. (p. 149-150)

Merriam (1998) argues that human beings are the main instrument of data collection and analysis in qualitative research. Interpretations of reality should be accessed directly through researchers' observations and interviews, which are 
conducted in natural settings reflecting the life experiences of participants more accurately than do more contrived or laboratory settings. Thus, the researchers are "closer" to reality than if a data collection instrument had been interjected between the researchers and the participants. It is important to understand the perspectives of those involved in the phenomenon of interest, to uncover the complexity of human behavior in a contextual framework, and to present a holistic interpretation of what is happening (Merriam, 1998).

To maintain valid and reliable qualitative research, and based on the above arguments, this researcher believed that what was investigated in this study should be the Chinese teachers' constructions of reality - how they viewed foreign language and classroom teaching, how they understood what counted as learning, and how they made decisions about classroom teaching based on their beliefs. During the process of data collection and analysis, the researcher kept asking herself if she was observing or measuring what she thought she was measuring (Merriam, 1998). When writing the report on this study, the researcher was thinking about whether the findings captured the Chinese teachers' real beliefs and their authentic classroom teaching.

\section{Reliability}

Traditionally, "reliability" refers to research findings that can be replicated by another inquirer (Merriam, 1998; Schwandt, 2007). Merriam states that the connection between "reliability" and "validity," from a traditional perspective, rests on the assumption that a study is more valid if repeated observations in the same study or replications of the entire study have produced the same results. However, "reliability" is 
problematic in the social sciences simply because human behavior is never static (Merriam, 1998) and no investigator can literally replicate another's fieldwork (Schwandt, 2007).

Lincoln and Guba (1985) suggest that researchers think about "dependability" or "consistency" of the results obtained from the data, if the traditional term "reliability" is not appropriate when applied to qualitative research. In this way, the question is not whether findings will be found again but if the results are consistent with the data collected (Merriam, 1998).

According to Lincoln and Guba (1985), reliability is a precondition for validity, and an "unreliable measure cannot be valid" (p. 292). The notion of reliability with regard to instrumentation can be applied to qualitative case studies in a sense similar to its meaning in traditional research. A human instrument can become more reliable through training and practice (Lincoln \& Guba, 1985). The researcher of this study was training herself in notions of reliable instrumentation, for example, reviewing the literature on validity and reliability, and clarifying her biases (See The researcher's role later in this section).

\section{External Validity}

"External validity" means that the findings of one study can be applied to other situations: "the approximate validity with which we infer that the presumed causal relationship can be generalized to and across alternate measures of the cause and effect and across different types of persons, settings, and times" (Cook \& Campbell, as cited in Lincoln \& Guba, 1985, p. 291). To make this criterion achievable, randomized 
sampling from a given, defined population is necessary (Lincoln \& Guba, 1985). Could external validity be applied to this study?

The researcher of this study intended to understand the relationship between Chinese teachers' pedagogical beliefs and their classroom teaching, by selecting five Chinese teachers as participants (nonrandom sample). Was generalization from a small, nonrandom sample possible? Merriam (1998) states that it is possible only if the term "generalization" is reframed to reflect the assumptions underlying the qualitative inquiry. Merriam introduces four Reconceptualizations of generalizability: working hypotheses (Crondbach, 1975; Donmoyer, 1990), concrete universals (Erickson, 1986), naturalistic generalization (Stake, 1978), and user or reader generalizability (Walker, 1980; Wilson, 1979). The discussion here focuses on concrete universals.

Erickson (1986) criticizes that the construction of generalizable knowledge is an inappropriate goal for interpretive (p. 119) research. Erickson argues that the general actually lies in the particular. Concrete universals are Erickson's argument for reconceptualization of generalizability (Merriam, 1989). Erickson (1986) argues that concrete universals are achieved by studying a specific case in great detail, then comparing it with other cases studied in similar great detail.

...when we see a particular instance of a teacher teaching, some aspects of what occurs are absolutely generic, that is, they apply cross-culturally and across human history to all teaching situations.... Each instance of a classroom is seen as its own unique system, which nonetheless displays universal properties of teaching. These properties are manifested in the concrete, however, not in the abstract. (Erickson, 1986, p. 130)

Generalizability can be reconceptualized as concrete universals (Erickson, 1986; Merriam, 1998). This alternative to the statistical notion of external validity could be 
applied to this study; this made it possible to generalize from a small, nonrandom sample. Although the context of this study is Chinese teaching in American classrooms, still the results of the study can offer teachers and learners of other foreign languages some potential factors, previously less noticed, that impact the outcome of foreign language teaching. What is learned in a particular situation can be transferred or generalized to situations subsequently encountered (Merriam, 1998). However, the researcher of this study should make sure of two things to make generalization possible: 1) The study must have internal validity. Meaningless information has no general applicability (Guba \& Lincoln, 1981); and 2) According to reader or user generalizability (Walker, 1980; Wilson, 1979), this researcher must provide enough detailed description of the study's context for readers to see if the findings can apply to their own situation.

Based on the above arguments, the researcher of this study employed the following techniques (Lincoln \& Guba, 1985; Merriam, 1998) to enhance the validity and reliability of the study:

(1) Social context: The researcher explained the reasons for selecting participants and the social context from which the data were collected.

(2) Member checks: After a transcription was finished, the researcher took the transcripts (including fieldnotes) back to the participants and asked if the results were reasonable.

(3) Gathering data over a period of time in order to increase the validity of the findings: The second classroom observation was done at least one week after the 
previous one, and the second interview was conducted at least three months after the first one.

(4) Peer examination: The researcher asked a professor of education and a professor of Chinese to comment on the findings as they came out.

(5) Researcher's biases: The researcher clarified her assumptions, worldview, and theoretical orientation before data collection and analysis (This will be discussed in the researcher's role in this section); the clarification continued during data collection and analysis, as stated in the Data Collection and Analysis section.

(6) Audit trail: The researcher did a detailed description to explain how she reached the results of this study, including data collection and analysis, and decisionmaking through the inquiry process.

\section{Ethics}

Besides validity and reliability, ethics is another concern in all forms of research. During the process of data collection, participants may feel their privacy is invaded, they may be embarrassed by some questions, and they may tell stories they had never intended to reveal. Painful memories may appear in an interview even if the topic is routine or benign (Merriam, 1998). Researchers should be careful with problems that may cause suffering and pain to participants (Lincoln \& Guga, 1985; Merriam, 1989; Patton, 1990). However,

No regulation can tell a researcher when the questioning of a respondent becomes coercive, when to intervene in abusive or illegal situations, or how to ensure that the study's findings will not be used to the detriment of those involved. The best a researcher can do is to be conscious of the ethical issues that pervade the research process and to examine his or her own philosophical orientation vis-à-vis these issues. (Merriam, 1998, p. 219) 
For this study, issues of ethics were even more significant because the study was local. Punch (as cited in Merriam, 1998) states that, at the local level, it is simply impossible to protect the identity of the case or the people involved. Therefore, it is critical to discuss issues of anonymity with participants of this study. The researcher made sure participants understood possible factors that could complicate their participation. On the other hand, the researcher informed participants about the purpose of the study, the process of data collection and analysis, and the potential benefits to foreign language teaching before fieldwork began. Information about interview questions was delivered before interviews when a participant asked for it. Questions for interviews were carefully prepared. The researcher skipped a question when an interviewee felt uncomfortable with it. For classroom observation, the role of researcher was as a non-participant, unless she was invited to speak a little. Classroom observation focused on teaching activities only. The researcher and participants had reached an agreement on the extent of the researcher's intervention. Participants were asked to sign an informed consent form (see Appendix E). The researcher kept the following in mind about the relationship between her and the participants as Schwandt (2007) suggests:

1. Researcher as detached, objective, outside expert, researched as subjects, data sources, respondents.

2. Researcher as marginal participant (participant-observer); researched as informants.

3. Researcher as facilitator (helping the researched activate their own capacities for self-observation, critique, advocacy), critic, advocate, change agent, adversary to the established and powerful; researched as coresearchers, coparticipants, collaborators. (p. 90) 
The following section concerns the researcher's role.

The Researcher's Role

A researcher is the instrument in qualitative research (Lincoln \& Guba, 1985;

Marshall \& Rossman 2006; Merriam, 1998; Shulamit Reinharz, 1997). This implies that the researcher should acknowledge the potential threat that his/her own bias poses to the reliability of data collection and analysis, because data are filtered through his or her particular theoretical position and biases (Lincoln \& Guba, 1985; Merriam, 1998; Patton, 1990). To be as nonbiased and accurate as possible, this researcher clarified her assumptions and theoretical orientation before data collection and analysis.

According to Shulamit Reinharz (1997), "When a researcher gets into the research setting, he/she not only brings the self to the field but also creates the self in the field" (p. 3), and she suggests that, "the selves that a researcher brings will fall into three categories: research-based selves, brought selves (the selves that historically, socially, and personally create his/her viewpoints), and situational created selves" (p. 5). Each of those selves plays a role in the research setting and consequently has a distinctive voice. The researcher should interrogate each of the selves and examine how they impact the process of the research (Lincoln \& Guba, 2000).

The researcher of this study agreed with Shulamit Reinharz (1997) that the selves, especially the brought selves, created by her experiences and cultural background could be brought into the process of this study. Being a teacher from China herself, she recognized the following challenges when she taught Chinese at the college level in the United States: 
(1) A new philosophy and orientation for foreign language learning (the National Standards, 2006)

(2) New requirements for foreign language teachers (Program Standards for the Preparation of Foreign Language Teachers, 2002)

(3) Different philosophies of education (Dewey, 1916; Freire, c2000; Palmer, 1998)

(4) Different paradigms for viewing teaching and learning (Kagan, 1992; Jarvis, 1992; Lambert et. al., 2002; Lange, 2003)

(5) Personal epistemology development (Baxter, 1992; Belenky et al, 1986; Perry, 1981; Pratt, 1998; Schommer, 1998; Schommer-Aikins, 2004)

(6) Culturally diverse learners (Lasley \& Matezynsk, 1997; Weisser, 2005)

(7) Different standards for an effective teacher (Brookfield, 1999; Galbraith, 1998; Kagan, 1992; Palmer, 1997)

(8) Different learning styles (Jarvis, 1995; Kolb, 1986; Mezirow, 2000; Taylor, Marienau, \& Fiddler, 2000)

(9) Deeper awareness of cultural differences (Bennett, 1993; Lange \& Paige, 2003; Kramsch, 2003; Nieto, 2002; Seelye, 1993)

On alert for these assumptions, the researcher of this study carefully did her best to keep these biases away from the process of data collection and analysis. She organized her own responses to her interview questions before doing the first interviews. This helped her to keep her own perspectives and assumptions away, so as to identify the significance of each participant's points of view. 
Marshall and Rossman $(1999,2006)$ state that the researcher, in qualitative studies, will more or less enter the lives of participants. The researcher of this study was careful not to make the Chinese teachers feel uncomfortable during classroom observations and interviews, and acted more like an observer and facilitator (Schwandt, 2007) than like a participant in the study. Only when the researcher was invited by participants did she participate in classroom activities. 


\section{CHAPTER IV}

\section{FINDINGS}

Findings and discussion center around the theme of "shifting the conception of teaching from a behavioral view of what people do when they teach language to a constructivist view of how people learn to teach" (Freeman \& Johnson, 1998, p. 402). To discuss the constructive work involved in the participants' beliefs and classroom teaching, it is important to explore one's past and current experiences through critical reflection while transforming one's way of knowing (Taylor, Marienau, \& Fiddler, 2000).

There are three sections in this chapter: 1) Research participants; 2) Findings; and 3) Summary.

\section{Research Participants}

Four teachers of Chinese were originally planned for inclusion in this study. However, in the process of selecting participants, the researcher found that among the teachers who were interested in the study, there were five teachers from different areas in China, all of whom had a significant learning and teaching background. This would bring more diverse and valuable information to the study. Therefore, these five teachers were selected as research participants. To protect the participants' identity and other people who were mentioned in this study, the researcher used pseudonyms for their names and their institution. Information about each of the five participants is as the following:

The first participant is Ming, a female around the age of 50. In China, Ming received her Bachelor's and Master's degree in the field of foreign language teaching 
and worked as an English instructor at the college level for over five years. Twenty-two years ago, Ming came to the United States for further study. She received a doctorate degree in the field of public administration and policy. She has served as a professor of Chinese at a graduate program in a university for over ten years. With a rich experience of Chinese teaching, Ming has published three textbooks: 1) Business Chinese; 2)

Generic Chinese; and 3) Textbook for learning Chinese characters assisted by computer.

The second participant is Zhong, a male around the age of 55. Zhong received his Bachelor's degree in the field of English language and literature. Twenty-five years ago, Zhong came to the United States for further study. After receiving his Master's degree in the field of education, Zhong returned to China and taught at the college level for 18 years. He has experience of teaching English to Chinese students and teaching Chinese to international students in China. Zhong was sent to teach Chinese in the United States by the Chinese government in March 2009.

The third participant is Guo, a female about the age of 35. In China, Guo learned English at school for ten years, though her major was Chinese language and literature. After receiving a doctorate degree in Chinese Art and Design, Guo served as an assistant professor in the Department of Theory (理论系) at a university in China. In March 2009, Guo was sent to teach Chinese in the United States by the Chinese Government.

The fourth participant is Hua, a female around the age of 30. In China, Hua received her bachelor's degree in Chinese, but taught English in elementary schools for six years. Hua has lived in the United States for eight years and has received a Master's degree of 
Teaching English to Speakers of Other Languages. She has been working as an instructor of Chinese at the college level for five years.

The fifth participant is Wen, a female around the age of 50. In China, Wen received her bachelor's degree in Chemistry. She had no experience teaching in her home country. However, Wen became a Chinese instructor soon after she came to the United States. She has been teaching Chinese at a community college for 18 years. Except Wen, all the participants had learned English at school for at least ten years and had received training in teaching foreign languages.

\section{Findings}

Data collected from classroom observations and interviews were all transcribed by the researcher herself, and were sorted according to the conceptual framework as established by the relevant literature in Chapter Two of this paper, focusing on the naturally emerging languages and the meanings the participants assigned to their experiences: Meaningful text segments were grouped into about 20 codes. Seven themes were drawn from these codes, according to the process by which participants developed their beliefs on teaching: 1) Early formation of epistemological belief; 2) Initial application of knowledge and skills; 3) Refinement of pedagogical approaches in real world applications; 4) Reframing of pedagogical and epistemological beliefs; 5) Cultural considerations; 6) Student diversity context; and 7) Reflective learning cycle. The first six themes respond to Research Question One for this study, and the seventh theme answers Research Question Two (See Figure 12). 
Figure 12 Seven Themes Respond to the Two Research Questions

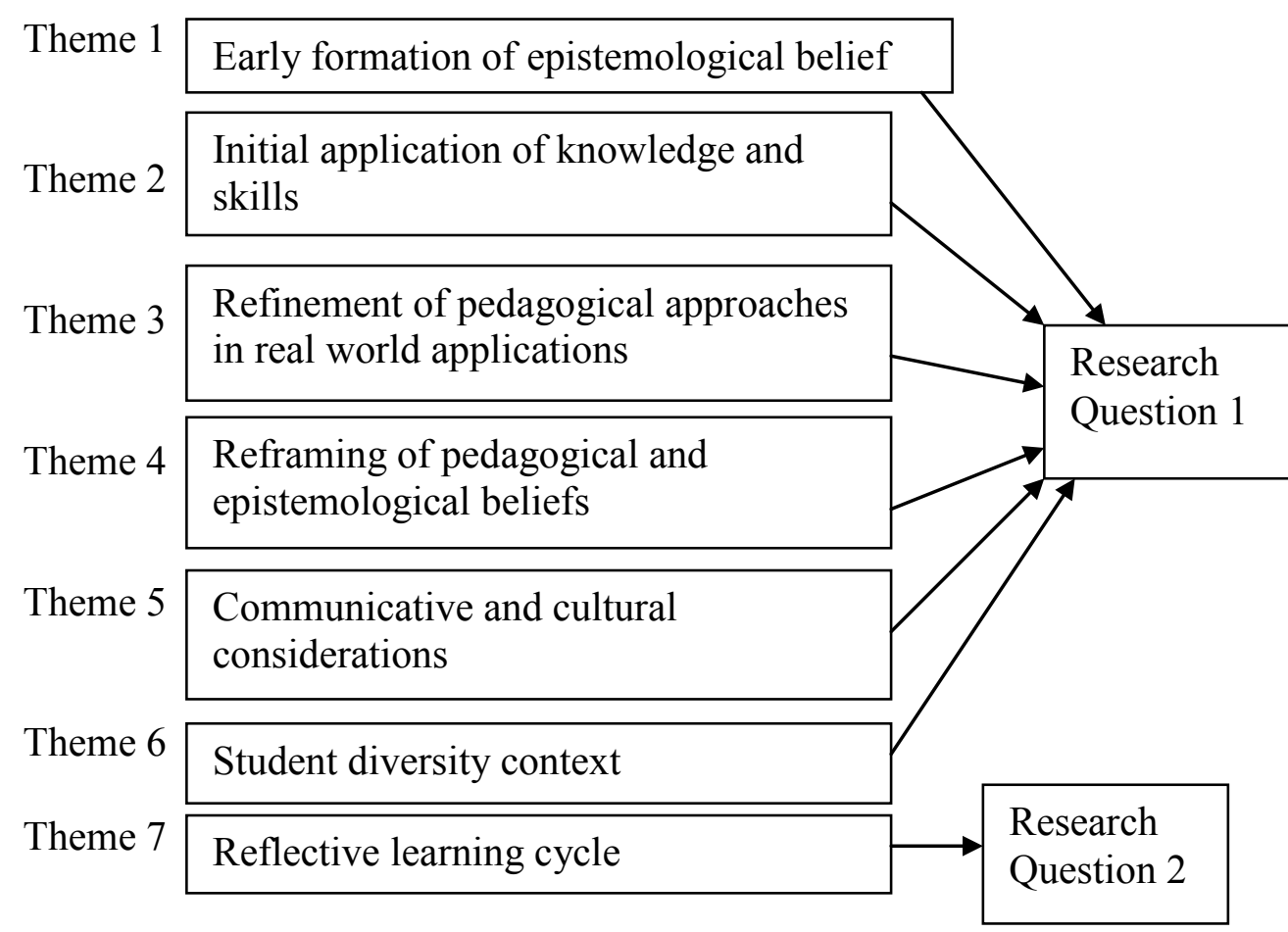

Findings from Interviews

First, a brief introduction is necessary to learn about how former schooling influenced the participants' ways of learning to teach. As discussed in the literature review for this paper, several writers argue that much of what language teachers know about teaching comes from their memories as students, as language learners, and as students of language teaching. Teachers' beliefs and past experiences as learners tend to create ways of thinking about teaching. (Freeman \& Freeman, 1994; Freeman \& Johnson, 1998; Lortie, 1975; Velez-Rendon, 2002). This argument holds true for the participants of this study. During the interviews, all the participants talked about their experience of learning English as a foreign language in their hometowns and how these experiences influenced their decision-making in their current teaching. 
Zhong stated that former schooling was a vital factor in helping him build up his current teaching. According to Zhong, a person may not recall his former teachers if he did not work as a teacher. But once he became a teacher, he would recall from time to time what his former teachers did in class. He would duplicate the good things, and avoid the unpleasant. He said that he was learning subconsciously what his teachers did in class through the over ten-year process of studying at school. He gave an example:

I learn the grammar from my former grammatical teachers, they were very good teachers, they left very good impression with [me], I think some of my methodology of teaching grammar [is what] I learn from them.... I will remember that when they taught grammar, they put practice in the first place.

Zhong's words tended to represent the other four participants' comments about their former schooling and agreed with the statement made by Lortie (1975) a " 13,000 hour apprenticeship of observation" (p. 160) played an essential role in their understanding of teaching even before they began their teaching career (Brookhart \& Freeman, 1992). Unfortunately, not all the learning during this long process was effective for these five participants. The following are their critical reflections.

\section{Theme 1: Early Formation of Epistemological Beliefs}

Like all students in China in the 1970s and 1980s, Ming started to learn English in middle school. She did not much like the English textbooks used in class, but she followed an English learning program at an intermediate level on the radio. Ming majored in English education at a teachers university in north China. At the college, her teachers were very strict with students' pronunciation, intonation, and fluency in reading textbooks. The students were required to memorize all the texts they learned. Ming commented that the professors paid much more attention to their memorization 
than their communicative skills. Grammar-translation was the main approach adopted in classroom teaching. Ming called learning through the grammar-translation approach "dry swimming".

... learning English like, er, swimming on the bank, dry swimming. And then, we learned English, you know, from 老师 (teacher), from the book, from the dictionary, but we never, you know, get a chance to practice. We never jump into the water and practice swimming even though we know all the, you know, the strokes, and how to do them theoretically.

Wen recalled that in her middle school and high school, her English teachers taught new words and phrases, "not conversation at all, We just studied from a textbook" (Wen). In college, Wen majored in chemistry and there were no English classes for her. Wen wished she could have learned more useful English in her former schooling, "then I won't be so hard to learn the English when I just got here [the United States]. I was totally lost when I first came here.”

Hua was the youngest among the five participants. She stated:

I have been learning English since I was third grade in elementary school, and I wasn't able to speak English when I was got here because all I have, I did with English is to read and to write, and when I first got here, I got to speak English that was very difficult to me, and I can't understand people around me, I just can not use listening, my ears, my mouth to use the language, so when I teach Chinese, I realize it is very important to help students to participate speaking Chinese in class.

Similar to Hua, Guo stated that her experience of learning English in her hometown was not a very nice experience for her. English was a required course from her middle school to her doctoral program. However, the learning outcome was not good.

... we learned a lot of words, and er grammar, I think I know every grammar of English. But we haven't the chance to use it. So when I come to America, it is 
hard for me for listening, and also, I must have a lot of time to think it over, ... I can't understand what they [Americans] say, and ( I have to) ask them to write it down, ... so I think it is a problem for our English learning. It is 哑吧英语 [“deaf and dumb English" means an English learner was not able to understand or speak English, but could read and write a little]. The classes were boring.... I cannot find anything from my teacher's English teaching that I can use for my teaching here [in the United States].

If we sum up the participants' descriptions about how they learned English at their former schools, we shall see that pronunciation, intonation, vocabulary, and grammar were the main content taught in class. English was taught mainly through the Chinese language. Opportunities for them to hear and understand English in class tended to be few. Speaking English was not encouraged in or out of class. There were few chances for them to learn how to use the content that was taught in class. (Further discussion will be in Knowledge of Principles of Practice and Knowledge of Self in the next section.) What follows below is a description of the later experiences of Ming, Hua, and Wen in learning English that directly influenced their knowledge of methods.

\section{Theme 2: Initial Application of Knowledge and Skills}

Ming's experiences with learning English in middle school and college were similar to the other participants. However, one of her college professors encouraged the students to listen to the Voice of America (VOA) and get familiar with the vocabulary related to news and newspapers. Ming started by listening to the Special Program of VOA, then the standard program. Ming said, "It was a very good experience, listening to the Voice of America. I think I owe a lot to this professor who introduced this to us ...." 
Furthermore, Ming stated that a professor in her graduate program changed her beliefs about English teaching. Ming attended one of the most famous universities for foreign language learning in China. She majored in applied linguistics but focused more on English teaching. She had the opportunity to learn from a very influential professor and writer on the English language, Prof. Zhang. Prof. Zhang had published quite a few books on English grammar. Ming remarked that a lot of people thought that because he was a grammarian, he would be formal (traditional). However, this was not the case. Prof. Zhang's teaching changed Ming's belief about English learning. Besides asking students to do a lot of research and paper writing, Prof. Zhang encouraged the students to speak in class, and to talk to the English native professors who were working at the university. The students were required to give a presentation every week. From then on, Ming pursued every opportunity to listen and speak English and to learn from audio and video materials that she had borrowed from professors who came from English speaking countries. For example, Ming organized an English Corner at a major city park in Beijing on Sunday mornings. Ming recalled that professors from the United States, Great Britain, New Zealand, and Australia went to join them, and the place was packed with students and learners of English from all over the city who were eager to practice speaking English. Ming commented it was a very educational experience.

The application of English in her learning process became a trigger and precondition by which Ming changed her beliefs about language teaching. Ming stated:

... I was eager to talk, always wanted to express myself, communicate with whoever I meet who speak English.... that's why when I train my students, I encourage them to speak as much as possible. 
... I benefit a lot from them (the active learning activities), so I didn't feel a lot of barrier when I first came to the United States, I didn't feel like other people say that it takes several weeks to understand, to get used to the people speak, ... So that really helped me a lot, so even today, I ask my students to give presentations because I realize it is very helpful.

Through her own learning experience, Ming realized that applying the target language in the learning process is essential for classroom teaching. (Discussion about Prof. Zhang's influence on Ming will be in Knowledge of principles of practice and knowledge of self in the next section.)

Theme 3: Refinement of Pedagogical Approaches in real world Applications

Learning in class at school is one of the main factors that shaped this group of teacher's beliefs and assumptions about foreign language learning. Another main factor was their experience of learning out of class. Hua reflected that learning English in public school in her hometown did not work for her. She said that after she came to the United States, she

... started to interact with American people, and that's learning really happens, I started learning how to speak, I started learning how to use words appropriately... learning happens most when you're doing it.

... so when I teach Chinese, I realize it is very important to help students to participate speaking Chinese in class. And so that has been my goal to help students to develop their listening and speaking skills, and of course we are academic school, so we have to ask them to read and write as well (Hua).

Similar to Hua, Wen stated that she had not learned much English at school before she came to the United States. Her interaction with American people really helped her to learn the English language. She said:

I learn English here [in the United States], I don't really start with grammar. ... Actually, [I learned] by to talk to people. That's, that's the key I taught to my students too. So like I said, I just use my own experiences to 
teach students ... Because I know how I learn English helps my students learn Chinese.

Similarly, as discussed in the last section, the application of English in Ming's learning process and the effective learning outcome became triggers by which Ming changed her belief about foreign language teaching. Senge (as cited in Bolman \& Deal, 2003) stated, "We learned best from our experience, but we never directly experience the consequences of many of our decisions" (p. 28). Ming, Hua, and Wen all learned from their own experiences because they experienced the consequences of their English teachers' decisions for classroom teaching. Therefore, "It is relatively easy for people to learn when cause and effect are close enough that the connection is easy to see" (Bolman \& Deal, 2003, p. 28). (Further discussion about their critical reflections and how the change influenced their teaching will come in Knowledge of Self and Knowledge of Method in the next section.) Another recourse that influenced the participants' views on teaching was from co-teachers and students.

Theme 4: Reframing of Pedagogical and Epistemological Beliefs

\section{Learning from co-teachers}

We know that changes in teacher belief are generally not affected by reading and applying the findings of educational research (Hall \& Loucks, 1982). Instead, teachers appear to obtain most of their ideas from actual practice, primarily from their own and then from the practice of fellow teachers (Zahorik, 1987). (Kagan, 1992, p. 75)

Previous research indicates that fellow teachers are the first source of professional help in schools (Blumberg, Lortie, Sergiobanni \& Staratt as cited in Zahorik, 1987). It is crucial to learn "more about teacher-teacher collegiality concerning classroom teaching as it occurs naturally on a daily basis in schools" (Zahorik, 1987, p. 387). McNergney 
and Carrier (as cited in Zahorik) provide a model that emphasizes teacher-teacher collegiality. The key feature of this model is "reciprocity or the process of teachers assisting each other to identify their strengths and weaknesses" (Zahorik, 1987, p. 386). Change in one's views of teaching is embedded in collaborations involving planning and critiques of instruction. Thus, this exchange about classroom teaching can "result in improved teaching and, subsequently, in better learning activities and student achievement and attitudes." It can also "contribute to teachers' sense of efficacy...." (Zahorik, 1987, p. 386).

All participants of this study acknowledged the advantages of exchanging information about instruction among colleagues. Guo, Hua, Ming, and Zhong all talked about their experiences of learning from co-teachers. Ming mentioned she had learned from fellow teachers when attending conferences, workshops, seminars, and also through American Council for the Teachers of Foreign Languages (ACTFL).

Zhong stated that it was very helpful to learn from experienced colleagues. Before he came to the United States, the teachers of the department would have regular meetings to share their ideas, methods, skills, and experiences with teaching students who came from all over the world to learn Chinese there. After Zhong came to the United States, he learned valuable information through training programs for teachers of Chinese.

For example, "Sometimes you spend hours try to explain (something) to students, but some teachers can make [help] the students understand just in a few minutes" (Zhong). 
Indeed, When

... classroom problems become jointly owned and jointly resolved. Teachers collaborate on defining the legitimate goals and processes of classroom instruction. As collaboration rather than isolation becomes the norm, teachers grow more certain about their practices, they begin to merge their subjective belief systems, and a common technical culture emerges. The school becomes a place where "virtuoso soloists arrange themselves into an ensemble" (Rosenholtz as cited in Kagan, 1992, p. 84)

Guo attended two training programs for language teachers after coming to the United States. The first program was for local K-12 teachers of Chinese. Those teachers might not have learned systematic theories about teaching, but they had a lot of skills and tips about classroom teaching. The second program was for English teachers from a university in China. Those teachers had received higher education in teaching, "but what they lack is skill, technique, and the tips, and some vivid way. Yeah, so it is very interesting... and both of them (the two programs) give me a lot of things to learn"(Guo). Guo stated that she had similar problems with teaching as the other participants in these two programs did, such as how to teach the four tones of Chinese pronunciation. The solutions offered by the experienced teachers helped with her current teaching in the United States.

Similarly, Hua talked about her experiences in observing classes taught by her colleagues who were native speakers of English in her hometown. As a student in the MA TESOL program, she was required to observe many language classes. As a student of language teaching, Hua had the chance to observe her own instructors. When she worked as a graduate teaching assistant (TA) for Chinese, Hua observed classes taught by the professor of Chinese and other TAs. "That really helps me to improve my 
teaching techniques, and understand what works and what doesn't work in class" (Hua). The attitude of learning from colleagues agreed with the Confucius teaching “三人行, 必有我师焉 (Among three people walking, I can find a teacher).”

\section{Learning from students}

Both Guo and Zhong mentioned that they had learned from students after coming to the United states. Zhong stated that sometimes students summarized grammar rules better than a teacher could. Guo said that students' questions often alerted her to language points that she had never thought of before. She gave an example.

... when I teach them [students] hui 会 and keyi 可以 [ “can" and “may"], I just take granted for it, for me, I just use it. But they ask what is the difference, what is the difference between hui 会 and keyi 可以? So I must think it a lot. And then give them the rule to use.

... I learn from students.... Teachers from China need to change [to meet American students' needs]... [teaching in the United Stated] also benefit for my teaching in the future.

The attitude that Guo and Zhong hold to learn from students agreed with an old Chinese saying “jiaoxue xiangzhang 教学相长” (Teacher and student learn from each other and both improve their learning). Similarly, Daloz (as cited in Gaibraith, 1998) metaphorically uses a journey to describe the process by which a teacher helps adults learn as "both teachers and students to see their lives in motion: it provides as accessible and effective way to viewing educational change" (Daloz, as cited in Gaibraith, 1998, p. 3). The change of the participants' beliefs and assumptions about foreign language teaching led them to realize that adjustments should be done for the traditional curriculum for classroom teaching. What follows is about the participants' new views about content to be taught in class. 
Theme 5: Communicative and Cultural Considerations

The National Standards (2006) states that “... the eventual goal of today's foreign language classroom is the acquisition of the ability to communicate in meaningful and appropriate ways with users of other languages at home and abroad" (p. ). One of the implications of the National Standards is "forcing attention to the broader view of second language study and competence: what should students know and be able to do -and how well?" (p. 15).

When asked about the National Standards (2006), Hua, Guo, and Wen said they had heard about them. Zhong had not heard about the National Standards, but he followed the guideline of the Chinese Language Proficiency Scales for Speakers of Other Languages (国际汉语能力标准) published by The Office of Chinese Language Council International. Ming knew more about the National Standards than the other participants. She stated:

I cannot memorize all the five standards [levels], but I know they have the intermediate, the beginning level, for low intermediate... and high intermediate, and advanced, yeah, so those five levels for speaking and for writing, for different assessments. ... especially the five Cs [communication, cultures, communities, comparison, and connections] and also for assessments, but attending seminars, and also workshops to learn how to assess student progress.

Although not all the participants of this study were familiar with the National Standards (2006), what was observed in their classroom teaching showed that their instruction was in fact on the same track as what the National Standards specified. The five participants were more or less doing the job that the MLA has called for: the traditional foreign language teaching model (two or three years of vocabulary, grammar, and conversation, followed by literature courses) should be replaced by new approaches 
that incorporate more culture from the start (Bollag, 2007; MLA, 2007). Before discussing what they did in their classroom teaching, it is necessary to explore the participants' views on what should be taught in class. Since "The United States must educate students who are equipped linguistically and culturally to communicate successfully in a pluralistic American society and abroad" (National Standards, 2006), the discussion here will focus on the participants' views of linguistic knowledge and cultural teaching.

For content to be taught in class, Wen named the four tones, the Chinese words, Chinese modal particles, pronunciation, and the measure words. Wen said that her interest in teaching Chinese was to introduce Chinese culture and China to her students. She stated that students were interested in real-life cultural differences, including those differences between the two cultures that might cause misunderstandings. Wen gave an example,

In America ... when people praise about something, er, for example, like, say, "Oh, you are so pretty." ... the Americans ... will say 'Oh, thank you.' They accept that. OK. But for Chinese, because that's Chinese culture, they always try to be humble in any way, so they always respond that 'Oh, no no no' [ to the remark 'Oh, you are so pretty']. Actually, for Chinese, they are the same as American, they accept [emphasized in origin] those praises, OK, but they just respond differently.

As for linguistic knowledge, Wen stated that most students did not like grammar, they wanted to learn how to talk. Interestedly, Hua said that students were unwilling to talk but interested in grammar:

I know students want something more skill based, so they want to know pronunciation, they want to know grammar, so we also need to give students that. It is kind of hard to encourage them to talk because they want to practice grammar so they can be perfect in that sentence pattern, ... I think it is just 
human nature, ... they don't want to embarrass themselves when they talk in that language. And so, they try to rely on the grammar to help them to reach that goal. and they feel, or most people feel if they can write or read something in the target language perfectly they can speak perfectly, but it doesn't work that way. so however, at least you can grab something, that is the words, that is grammar that you can grab, talking, pronunciation, listening is so hard, they don't have the environment, they don't have the time, so they just kind of give that up. So I think that is just kind of human nature that it is an easy thing, reading and writing is an easy thing, so I grab that [grammar] first, listening and speaking depends on motivation, depends on, you know, environment if I can do it I will do it.

However, Hua stated that she tended not to teach grammar in class. She said that language was an innate ability. She had seen students learn Chinese without grammar instruction. Still, she believed that there were advantages and disadvantages with grammar. She said that the good part about grammar was that it helped students with reading and writing. On the other hand, "Sometimes teaching grammar will prevent students thinking spontaneously, and that will kind of stuck with the grammar points ..." (Hua). According to Hua, culture and communication were the most important things that should be introduced in a Chinese class. Vocabulary was the most important thing besides culture. Hua also talked about how culture could be introduced to students by explaining the meaning of a word, or watching videos, listening to music, and practicing how to behave accordingly, for example, how to make a phone call.

Another participant who introduced Chinese culture by explaining the meaning of a word was Guo. Guo stated that a single Chinese word meant nothing to American students, it should be put into a context to be meaningful. For example, Guo introduced Chinese wedding when her students learned the word jiehun 结婚 (marriage). To help students learn better about the Chinese words. She explained how the word was 
composed. The first character in jiehun 结婚 (marriage) is jie 结 which means "tie together". The Chinese word for "female" is nu 女. In ancient China, weddings were held in the evening. The Chinese word for "evening" is hun 昏. These two characters combined together to form the word hun 婚. In this way, the students learned four words, jie 结, nu 女, 昏, and jiehun 结婚 (marriage) and some information about Chinese weddings. Here Guo's explanation for the word jiehun 结婚 (marriage) was not valid in etymology, but was culturally authentic, and it helped students learn the word.

Guo stated that a foreigner "can't step into the deep, deep level of Chinese culture" if he or she did not learn "the good, the perfect grammar, and to write the characters." As how to introduce the Chinese culture to students, Guo said, "Culture is not just in book, it is in the life. Myself is also a culture in the classroom because here, in the classroom, I am the first choice for them to learn Chinese culture." She explained that a person would bring his/her home culture when he/she went to another country. For example, her students were interested in almost everything she brought with her to the classroom: her paper fan with Confucius' five main principles: benevolence, righteousness, ritual, wisdom, and fidelity (仁, 义, 礼, 智, 信) written in Chinese calligraphy, or a glass of hot tea on a hot day.

Guo talked about the issue of character learning, a challenging task for foreign language learners. She said that some American students were scared by the Chinese characters, and learned Pinyin (Romanization) instead. She pointed out:

... in China, the website never have the Pinyin website, right? And also the traffic sign is in Chinese characters. For example, the "stop" or "yield" is in Chinese 
character. If you don't know what it is, and you just can't move in China. It is very important things [to learn Chinese characters].

Another participant who suggested Chinese characters should be taught was Zhong. For content to be taught in classroom, Zhong stated it is important for learners to learn the four basic skills of language learning (listening, speaking, reading, and writing) and translating; phonetics, the basic grammar rules, and the Chinese characters were essential:

... some people see it, it is not necessary to, to learn the Chinese characters, because without learning the Chinese characters ... you also can learn to speak the Chinese... but as a second language learner, I think the written form of character will help [students] improve the literacy of the, in the language.

Zhong stated that for authentic Chinese language learning, grammar is necessary:

Grammar has to do [with] to learn the language more, more efficiently. ... you can learn to speak the language in the target language environment without learning the grammar. ... Many students (in the US) are not quite interested (in grammar), but to be able to speak Chinese, the grammar is the first thing for them to learn.

Still, Zhong believed that "Communication is the purpose of learning a language." Ming stated that content to be taught in class should be determined by who the students were. Listening, speaking, reading, writing, translating, and all types of Chinese should be taught to students who majored in Chinese. For students who "focus on learning a language just for functional and want to use it right after adopted" (Ming), instruction should focus on a more practical or communicative way -- learning focused on "Pinyin and organization" (Ming). Still, Ming also stated that a person would understand a foreign language better if he/she had a better understanding about the culture connected with the language. She would introduce cultural information to students along with the content taught in class. 
According to the data collected from the interviews, there were similarities and differences in the participants' views about content to be taught in classroom. They all agreed that the four skills (listening, speaking, reading, and writing) were essential to students. But the importance of grammar was identified differently, and whether the Chinese characters should be learned by all learners remained controversial. However, the understanding about communication as the goal (National Standards, 2006), and culture as the core (Lange \& Paige, 2003) for foreign language learning could be recognized both in interviews and classroom observations. Although they all stated culture was important for foreign language learning, their understandings about culture seemed diverse. (Further discussion about the participants' views about content to be taught in classroom will be in Knowledge of content and Knowledge of method in the next section.) What follows is the participants' comments and reflections on working with American students.

\section{Theme 6: Student Diversity Context}

Guo, Ming, and Zhong had all worked as teachers at the college level in China before they came to the United States. They all recognized some characteristics of the culturally diverse students while teaching in the United Sates. To meet the students' needs, they all realized that it is necessary to learn and adjust their personal philosophy, values, methods, and attitudes (e.g. tolerance to other cultures) (Kramsch, 2003). Ming stated:

... You have to pay attention to the culture, you have to respect the culture here ... the students are very different ... we need to learn, to adjust. And if we discipline those students like the way we do to our Chinese students, that may cause problem ....You are not (to say) "you are not allowed to drink water, you are not 
allowed to sit like that ..." those kind of things, ... I don't think the students can accept that ... Can you make comments on about your students' looks, appearances, and the way they dress, the way they wear clothes? You cannot do that ... Those you really need to be very careful. How do you deal with the students, yeah, what you should say, what you should never say in your class... so these, probably in China you don't have to pay too much attention to this kind of things.... As a teacher [here], [You should] try to behave appropriately.... [You] must be professional with the relationship between the teacher and the students. And, also be kind and friendly to the students. Yeah, I will, and you need to encourage more than criticize them. Yeah, you do not say, like our, you know, in Chinese practice, Chinese teacher while you get 98 [points] out of 100 [points, full marks], they say, "How come? Why did you lose that two points?" ... [Here] you always tell the students, you don't say, "Oh, this bottle is half empty." You have to tell them, "Oh, it's half full, good job, work hard to fill the other half."

Influenced by traditional Chinese educational thought, most educational leaders

and teachers in China, especially those middle-aged or older teachers, are accustomed to a teacher-centered classroom, and tend to believe in an old Chinese saying that “严师出 高徒 (Excellent students come from strict teachers).” Students will receive more criticism than praise in and out of the classroom, as Ming described. Traditionally, education has been highly valued in China. Most students' parents would prefer a strict, knowledgeable teacher over a kind teacher who praises students most of the time. And most Chinese students take the strictness as normal instructions, as Guo stated:

Chinese students are very different from American students, Chinese students have a very great tolerance, they can obey the teacher what they say what they do ... American students have a lot of requirements about the teacher ... [however] they are very kind to me. ... I used to be a bottle to accept the water that the teacher poured in, now the bottle would move.

Guo explained that, like most students in China, she used to take everything that her teachers told her (like a bottle to hold the water that was poured in). However, students here were not ready to accept all the information that teachers told them (like a 
bottle that would move when water is being poured in) though they were very interested in learning the Chinese language and culture. They were not the "passive recipients of instructional treatments" (Doyle, as cited in Erickson, 1986, p. 137).

Another challenge to Guo was that the students had diverse backgrounds, and each had some specific characteristics. They could not be taught in the same manner as she did in China. For example, grammar was easier for students who came from Cantonese families; students who were English speakers were always using their English knowledge to understand Chinese and struggling with the Chinese tones. They were not able to tell the differences in “mama ma ma ma? 妈妈骂马吗?” (The five characters in this sentence are all pronounced the same but the tones and meanings are different); Korean students were confused with the "f" and "p" sound, because Korean has "p" but not "f". Students from Thailand, Japan, and other countries all had different problems when learning Chinese. Guo stated that it was impossible for a teacher to meet every student's needs within that 50- minute-class time. To accept this challenge, Guo tried to learn more about her students on the first day of class, and had students learn from each other. For example, students who spoke Cantonese helped the others with grammar and tones, and students who spoke English helped Korean students with pronunciation. Here, Guo's practice responded to the argument that “Teachers need to 'play to' students' strengths and to mitigate students' learning weaknesses" (Lasley \& Matezynsk, 1997, p. 29) and utilize a variety of instructional models so as to maximize the achievement of all students (Lasley \& Matezynsk, 1997). 
As for students' motivation to learn, Zhong stated that there were serious students and less hard-working students in both countries. He pointed out that students in China did not pay for college themselves; their parents and the government took care of all the bills for their education. Thus, some students did not cherish learning that much. Here, most students paid for learning themselves, so they valued the opportunity to learn. They participated in classroom activities more actively and often raised questions in class. "But in terms of memorization and comprehension, I think Chinese students can do better job than American students", Zhong said. He explained that students in China would sit there and listen to teachers without asking questions. But "they understand every sentence you said, sometimes they have questions, but they are shy, they don't want to get involve into it. But now they are changing. I think now the Chinese students are much more active, more initiate in discussion" (Zhong).

Ming's, Guo's, and Zhong's statements were all related to an issue about student learning preferences and cognitive style. It has been a serious challenge for the participants of this study to meet culturally diverse students' needs in classroom teaching (Further discussion about this issue will come in knowledge of learners in the next section.). In other words, students were pushing these teachers to make changes in their classroom teaching. The following will discuss the participants' knowledge of method and how they incorporate their beliefs and assumptions into their classroom teaching. 


\section{Findings from Observations}

Findings from the three observations were closely connected to findings from the two interviews, because “...a teacher's beliefs usually reflect the actual nature of the instruction the teacher provides to students" (Kagan, 1992, p. 73).

\section{Theme 7: Reflective Learning Cycle}

The knowledge of method "is not the what but the why", which allows the teacher "to bring personal beliefs, values, and philosophy of teaching and learning to the application of the method" (Heimlich \& Norland, 1994, p. 163). Indeed, each participant's statements on approaches and methods were connected with their own English learning experiences and their current teaching. Their remarks on the approaches and methods more or less reveal their beliefs, assumptions, values, and philosophy of teaching.

As knowledge of method is important in the development of teaching style because it combines a teacher's principles of practice, self, content, and learners (Galbraith, 1998), the discussion about the participants' views in approaches and methods in foreign language teaching will be combined with the data collected from classroom observations. (This will respond to the Research Question Two for this study: How do Chinese teachers' pedagogical beliefs relate to their classroom teaching, and what characterizes this relation?)

According to the data collected, each participant had their own beliefs and assumptions about teaching, and each had his/her own priority in their teaching style. 
Hence, the following section will be divided into five parts, each part being an analysis of the data collected from one participant.

Wen's Remarks on Methods and Approaches

Talking about methods and approaches to language teaching, Wen said, “... [ I would] use different ways to teach, make class more interesting, give students more chances to talk, go by the learning pace..." She explained:

I teach Chinese through my own experiences. I never took a class to learn how to teach Chinese. I teach *** [the name of the college was kept as confidential] for twenty something years. I got everything from my own experiences ... From my experience to learn English... Actually, [I learned English] by to talk to people. I teach them [students], I say, just talk, be free to talk. ... it doesn't matter even you say incorrectly, people will help you too, don't be shy, it's the language, you got to talk.

For the grammar-translation approach, Wen said:

... first I do [did] translate in my mind, I translated from Chinese to English, then I know I learn [in] a hard way, then I say forget it [translation], I just say whatever I heard from other [American] people. You just have to tell yourself, OK, that's how I [am] supposed to say... I told them [students] ... Don't translate, you might put the English in there ... Most students don't like grammar, they want to learn how to talk. Students can get it without grammar. Those basic grammar I will explain to them [students]. I will cover some of those. If you don't learn grammar, I know that, but sometimes that works. I think that's the express way, to, to make my students to learn faster.

According to Wen, language proficiency is "know how to say in the different circumstances." Since her English learning did not really start with grammar rules, but with her interactions with Americans, Wen stated that her students could learn the same way. 
Summary of the classroom observations for Wen

The class observed was a conversation class at a beginning level. The content delivered in the classroom included knowledge of the Chinese language and some cultural context of the language. For example, when introducing the word duoshao 多少 (how much/ how many), the teacher explained in English how to use duoshao qian 多少 钱? (How much does it cost?) when shopping in China. The teacher's role was between that of a manager and a helper, in other words, the teacher conducted classroom activities directly but was ready to offer help when needed. Both English and Chinese language were used in the classroom. Instead of Chinese characters, Pinyin was used in classroom teaching and in all the handouts.

All the instruction was given in English. Classroom activities were mainly questions and responses between teacher and student. Adjustments in specific content for individual students were observed. For example, when the teacher raised questions to students one by one, a female student said, "I am not ready.” The teacher said,“ I'll give you an easy one [a simple question].” Then, the teacher asked, “你好吗? (How are you?)" The student was pleased that she was able to respond to the question. An interesting way to teach speaking Chinese

An interesting way to help students with speaking was observed all the time. Wen would say an English word and let the students translate the word into Chinese. For example,

1. Wen: "please"

2. Wen: "again"

3. Wen: "to say"
Students: “qing 请”

Students: "zai 再”

Students: "shuo 说" 
4. Wen: "one time" Students: "yibian 一遍"

Wen gave the English word one by one according to the word order of the Chinese sentence 请再说一遍 (Please say it again). Another example was: From Beijing to Shanghai take train how many hours 从北京去上海坐火车几小时? In this way, Wen introduced the word order of Chinese sentences. No instruction or explanations on sentence structure were observed during the three classroom observations.

Meeting students' needs - no textbooks

No textbooks but handouts were used in Wen's class. Wen explained:

I try to fit everybody's needs. [In] the first class, I ask students' purpose for taking Chinese ... Let student bring any topics [that]they want to learn, this help students to share information. ... for example, ... for the business people, I want to, talk about the contract, a little bit contract things, not a professional, special contract, general words for the business... If people want to go to China to be students there, then I will teach, how to ask a question, ... those kind of things. And if for the traveler, of course, shopping, bargain, you know, or restaurant and hotel that kind of things. So it depends, I really go by the students, what they need.

Wen stated that she had prepared handout sheets for years. Even when they did have a textbook, they used the textbook only $30 \%$ to $40 \%$ of the time and handouts $60 \%$ to $70 \%$ of the time. Wen believed that students learned more with handouts. Also she would help students save money without a textbook. "I try not to use textbooks for two terms already, ... they [students] just love that, no books" (Wen). Observed in her classroom teaching, the topics for classroom discussion included greetings, weather, time, telephone numbers, dinner, speaking Chinese, study or travel in China, all at a beginning level. 
A brief discussion about Wen's view on method and about her classroom teaching

Data collected showed that Wen's beliefs and assumptions on teaching came from her own learning experience: Her English learning did not start with grammar rules but with her interaction with American people. She believed her students could do the same way. This concept influenced her decision-making for the content to be taught and the method to be adopted in classroom teaching: No textbooks but the topics collected from students; no grammar teaching but simply practice speaking between teacher and student, or among students in class meetings.

Another participant who focused her instruction on speaking Chinese was Ming.

\section{Ming's Comments on Methods and Approaches}

Ming's discussion about methods and approaches to foreign language teaching involved the what and the why for her choice:

My philosophy, I always focus on, you know, first all, communicate, communicative, develop students' communicative skills. So my method of teaching is communication based, task based. And er, yea, even for true beginners, in day one, I give them task, in the textbook. ... so my method is not only communicative, but also task-based. So er, to learn how to communicate, and to learn how to fulfill the task. So in class, we do communication, interaction. And after the class, they need to fulfill the task, and then, the next class, they need to report how they fulfill the task. ... I give them settings... For instance, I have one student, er, meeting a friend at the airport, and after they met, they started, you know, converse, using the linguistic content. Or they come across someone accidentally, and then they start a conversation, ask each other those questions ... The task linguistically is the same, but that, at real world situations ... the students find it easier and find it more practical, more functional. That's my approach.

Ming stated that nowadays many people regard translation as an old method. They try to avoid using the word "translation" when talking about foreign language teaching 
even though they used the translation method in their classroom. However, Ming had a different idea:

... for adults, they have to adopt different methods ... I use translation to lay a very good linguistic foundation for them [students]... to train them to speak the language fluently, and to remember what they have learned better. Er, my favorite exercise is a pyramid exercise, 金字塔式的练习[pyramid exercise]. Like a long sentence, I develop starting from word to phrase, and at the end the long sentence come at the bottom. So we do, we use this, I have the students read them through to practice the pronunciation and tones, and also fluency. I say 'tongue' exercises, 舌操 [tongue exercises]. So that, I usually give them a time limit. For this paragraph, you should read without, within 30 seconds ... We do translation for word, phrase, and sentences backward and forward, from English to Chinese and from Chinese into English. So after about twenty minutes practice, the students learn this paragraph very well, and they can do, er, speak fast and fluently...Yeah, my philosophy... The less I speak the better, the more the students speak the better.

For example, for Business Chinese students, Ming asked them to create or she helped them to set up a real situation to use Chinese: a job interview, a business previewing, an employee reporting back to the boss, etc. By doing this, Ming wanted to help her students "to swim faster. So they won't drown" (Ming) in real world practice. Students should be "put into the water to swim"

Ming believed that students should be "put into the water to swim" in classroom teaching. Ming would use five minutes to explain grammar rules to the students, like teaching them how to swim. Immediately she asked the students to use the grammar rules in speaking though some students might not fully understand the rules. Ming gave the reason why she did this:

I just, er, put them into the water to swim, instead of coaching them on the land dry swim, in swimming, I put them into the water, and have them start learning right in the water... and if they, you know, drank some water and didn't know what to do, and then I can teach them, I jump into the water myself and teach them how to do it. So in this way, I think the students, er they learn before they know 
and then improve more, and after that they know all the process of practicing, they are learning better understand what I teach them, so that's why I try to limit myself don't explain, er, give a lecture myself too much ...

In this way, Ming explained, it would avoid the mechanical training, which she called "dry swimming", she had experienced at her former schooling. Ming stated that the Chinese character learning was put in the second year of the program.

Besides, Ming stated:

I try to make myself as active as possible, so that the students won't feel boring, won't feel bored when they learn the language, and also by adopting different ways of learning it, I have to make them learn the language easier, make the class lively.

\section{Summary of the classroom observations for Ming's teaching}

During the three observations, the content delivered were mainly words and expressions, which were taught as networks with links in real situations. For example, the word zhoumo 周末 (weekend) was not taught directly, but started with the names of weekdays which the students had learned. The teacher led the students to figure out the meaning of this new word. Immediately, the teacher asked one student about how his weekend was. After the student gave a response, the teacher asked the whole class how the student's weekend was. Then, the students took turns to do as the teacher did. This strategy involved the whole class practicing both individually and collectively. The same question was repeated one by one, but each response brought real new information. This practice was like Ming's "putting the students into the water to swim." The practice was effective linguistically, used a real situation meaningfully, and attracted every student's attention. Examples like this one indicated that the content delivered in Ming's teaching was organized as highly interrelated concepts. 
For approaches and methods adopted in classroom teaching, characteristics of communicative, grammar-translation, and audiolingualism were observed. The learning of zhoumo 周末 (weekend) was one example of applying the communicative approach. Translation and audiolingualism were combined to train the students' in spoken fluency. For example, communicative speech drills, which Ming called a "pyramid exercise 金 字塔式的练习” and “tongue exercises 舌操”, were practiced in all three classroom meetings observed.

Classroom assessment focused on students' learning the use of language. Yes-No questions and Why questions were applied all the time. In every one of the three classroom observations, every student gave a presentation. It was a routine for class meetings. During the first observation, the researcher of this study was impressed to see every student's ability to speak Chinese while giving his/her presentation. It was their fourth week in the class and it was a challenging job to stand before the whole class and give all the information required for the one-minute presentation: their name, professional, major, what they liked, what languages they spoke, and some information about one or two of his/her friends in the class. The students' improvement in speaking ability was observed during the following two observations. In a two-minutepresentation, every student introduced information about both himself/herself and one of their friends in the class: name, nationality, birthday, family, hometown, phone numbers, languages spoken, where they studied and worked. Some students even talked about their feelings about learning Chinese. After learning the map of China, a female student who had no Chinese background at all gave every name of the 23 provinces in 
China by pointing where they were on the map in less than one minute. Ming encouraged her students to apply Chinese as much as possible via meeting visitors from China and joining Chinese corners.

Ming's role was more like a facilitator, coordinator, and helper than expert in her classroom teaching. The language used in the classroom was mainly Chinese. No obvious adjustments in specific content, instructional strategies, or activities were observed, because the teaching and learning process went smoothly during the three observations.

A brief discussion about Ming's view on methods and about her classroom teaching

Ming's own experiences of English learning had a great influence on her beliefs about Chinese teaching. As the application of English in her own learning process (communicating with English native speakers, giving presentations, organizing an English Corner, etc.) became a trigger and precondition by which Ming changed her beliefs about language learning, and the learning outcome was satisfactory, Ming constructed her philosophy of teaching as “develop students" communicative skills." Ming conducted a student-centered classroom. What she did in there was consistent with her statements about methods and approaches: communicative, project-based. Her classroom practices showed some characteristics of the procedures for effective learning (Dewey, 1916; Kolb, 1981). (Further discussion will come in the discussion section.) 
Zhong's Comments on Methods and Approaches

As Ming had made a specific comment about the translation method, Zhong had a discussion on grammar when talking about methods and approaches to language learning.

Zhong stated that he learned methodology from his former teachers:

I learned the grammar from my former grammatical teachers, they were very good teachers, they left very good impression with [me] er, I think some of my methodology of teaching grammar I learn from them.... I will remember that when they taught grammar, they put practice in the first place.

Zhong stated that he still remembers that his two grammar teachers gave the students a lot of very interesting paper-and-pencil exercises to help them learn English grammar and the students liked them, such as practices in the infinitive, participles etc. in the format of blank filling, matching, error correction, or multiple choice. One way to teach grammar, Zhong stated, was to ask students to make sentences. The teacher offered a basic sentence through body language, then asked the students to summarize the grammar rules themselves. In this way, “... they [students] can acquire, get the grammatical point much more easily than simply telling them what the rule is. So I think ... practice is a very important part" (Zhong).

Zhong stated that Chinese grammar was not so difficult compared with other languages. A serious learner can learn all the basic grammar in one year in China. However, students needed much more time when learning Chinese out of China. Zhong emphasized that practice should be put in the first place, "Practice makes perfect" 熟能 
生巧. Grammar helped a lot with writing. For grammar teaching and learning, he suggested:

... the teacher should be very very knowledgeable (with) what to teach the students, because in teaching grammar rules, many exceptions, sometimes it is difficult to explain some rules, so the teacher, before the class, to consult many books, many er theories, different theories, you have given theories, on certain grammar different people explain it in different way... for grammar learning, students practice first, let the students to summary the rules better than tell them what the rule it is. Students had good ideas to teach structures.

Still, Zhong pointed out:

But grammar is only a theory, grammar is far from enough, when you remember the grammar rules, it is [does] not mean you can speak the language, it is far from being that. So more important, you have to practice speaking.

Zhong believed that "...communication is the purpose of learning a language," therefore, “... in terms of teaching methodology. They [teachers] have to find out what is the best method in through teaching."

\section{Summary of classroom observations for Zhong}

The class observed was an intermediate level. The content delivered was mainly knowledge about Chinese, especially grammar rules and sentence structures, such as the seven sentence patterns for emphatic structure 强调句型, sentence patterns for comparison 比 and the instrumental structure using “ba”把. Not much cultural context of language use was introduced. Classroom activities included teacher lectures and student practice and reinforcement. Classroom assessment was organized by oral practice to see how well the students mastered the sentence patterns and grammar rules. The language used in class was all Chinese. The role of teacher tended to be knowledge giver and helper. 
Zhong was experienced with grammar teaching. The content to be taught was well-prepared and the instructions were well-organized. For example, while the students were reporting their grammar assignments in class, student oral practice, teacher classroom assessment, and error correction were all carried out simultaneously. Zhong was good at explaining grammatical questions. For example, when the students did not understand the question “动宾结构的句子和把字句有没有区别” (Are there any difference between the verb + object structure and the "ba”把 sentence pattern), Zhong explained in a few words, “ 'ba’把字句表示处理的结果. 动宾结构是说明一个 事实 (the 'ba' 把 sentence pattern offers a result of an action while the verb + object structure gives a fact)." The explanation was short but right to the point for the students to learn the difference between the two structures. Zhong's instruction revealed he was knowledgeable in Chinese grammar.

All the classroom teaching focused on grammar but little English was spoken in class. The talk between the teacher and students was all in the target language - Chinese. A conversation was observed between Zhong and a student before class. The topics for this conversation included the economy, inflation, CPI, the prices of houses, salary, currencies in China, and the local Chinese restaurants. This free talk demonstrated the communicative ability of the student.

A brief discussion about Zhong's views on method and about his classroom teaching

Since grammar teaching impressed Zhong most during his English learning, he viewed grammar as necessary in his Chinese teaching. He believed that "from theory to practice, and from practice to theory again" is a must for students. So he used it in his 
classroom teaching. Although the academic practices in the classroom all focused on grammar rules, the explanations for the grammar rules were all in Chinese, as was the communication between Zhong and the students. These practices brought out Zhong's beliefs, values, and philosophy of teaching. Zhong's remarks on grammar teaching touched on a major issue in the foreign language field: fluency vs. accuracy. (Further discussion about this issue will come in Knowledge of Method in the next section.)

\section{Guo’s Views about Methods and Approaches}

Unlike Zhong, who was impressed by his former teachers' methods of grammar teaching, Guo remarked that there was little from her former English teachers' methods that she could adopt in her current teaching. Because of her unsatisfactory learning outcome with “deaf and dumb English 哑吧英语”, Guo actually got a counter-example from her former English teachers' methods and approaches to foreign language teaching.

Guo would not have her students do the same as she had experienced. She had her own idea about methods:

... don't always depend on the method. I can't ask aged students to practice the language the same [as] a boy, how to jump... for the kids class, I use more map [pictures], and for the adult and intermediate [level], I can use er computer and video, and retell what happen, ... But it is a combined way, not not the single method always it [not always use a single method] ... Of course, I will give a lecture... and then ask them [students] questions, response, 防止[keep away] mistakes, and er it is a normal way, and also I will give [ask] them [to] practice in pairs, and ... write the characters follow me[follow me to write characters]. Teachers must learn a lot of theories, but you must arrange the classroom according to different students. So we'll use different theories based on different surroundings and for different students. So, it is my theory. 
Summary of the classroom observations for Guo

The class observed was for beginners. Knowledge about the Chinese language was delivered. New words and brief introductions about the structure for new words were observed. Instruction tended to focus on vocabulary and grammar rules. However, cultural context of word usage was also introduced. For example, she linked the word $e$ 饿 (hungry) with fan 饭 (rice). In a form of etymology, the teacher introduced the written element shi 食(food) with the sentence “我请你吃饭 (I'll invite you to dinner).” Also, cultural background of words and expressions were often introduced. For example, the teacher explained the cultural background for taitai 太太 (wife; lady) and xiansheng 先生 (husband; mister) and guided the students on how to use the words. When numbers were taught, the teacher gave an example that when a customer asked, “你老 板的电话号码是多少?” (What's your boss's telephone number?), this sentence implied a threat that the speaker is going to send a complaint message to the boss.

Grammar-translation tended to be the main approach adopted in the class. More lectures and practices for reinforcement than activities involving creative use of the content delivered were observed. However, strategies for instructional scaffolding and problem-solving were observed in the classroom practices. For example, through practicing questions like " $5 * 4=$ ?" (How much is five times four?) the students spoke Chinese and worked out the answer. Simple dialogues to fill the information gap were also observed. For example, when learning the word dong 懂 (understand), gaoxing 高 兴 (happy), kaixin 开心 (happy), Guo noticed that one student was not happy because 
his girl friend had left for China. The teacher made good use of the real situation and introduced 你想念她 (You miss her) to the students. This practice connected the writing form of the three new words: dong 懂 (understand), kaixing 开心 (happy), and xiangnian 想念 (miss) that all contain the element xin 心( heart). This practice also showed Guo's ability to make good adjustments on curriculum and her skills of turning the Chinese characters into something meaningful to students.

Classroom assessment included paper and pencil quizzes such as dictation. For comprehensive and speaking assessment, both Yes-no questions and Why questions were used. For example, “你姓什么?” (What is your family name?), “你叫什么?” (What is your first name?), “你忙吗?” (Are you busy?), “你渴吗?” (Are you thirsty?), “3* $4=$ ?" (How much is three times four?). The role of teacher tended to be a knowledge-giver rather than a facilitator. More English than Chinese was used in the classroom.

A student brought some lichee 荔枝(a fruit) to share in class. To respond to the students' request, Guo introduced a traditional Chinese story about lichees. The students enjoyed both the fruit and the story.

A brief discussion about Guo's views on methods and about her classroom teaching

Data collected reveal that Guo tried not to offer a boring class to her students as her former English teachers did. She realized that in that way, "My students will escape from my class" (Guo). Guo's practice agreed with Heimlich and Norland's (1994) argument that the knowledge of method is not the what but the why. Guo introduced 
more about how to use the Chinese language than grammar rules in her classroom teaching. The language used in the class was more English than Chinese when introducing cultural background. Guo's role in classroom was a mixture of expert, helper, and coordinator. The students looked happy in the class. This could be an indicator that the teacher was doing a good job and met students' individual needs (The researcher was not able to get this information from the students because she was not supposed to go into this area). As observed, the teacher responded to all individual students' questions nicely and patiently.

Hua's Remarks on Methods and Approaches

Another participant who tried to avoid adopting her former English teachers' methods was Hua. She stated:

... when I was at school as an English student, I learned from my teacher and it is pretty much a teacher-center-classroom, and what, the only thing we did was listening to the teacher. So, we could do, we could have grammar practice, we listened to the teacher, pretty, it was not creative, it was not interactive, we just listened, emn... I really don't think that works... Their teacher method doesn't work (laugh).

Then Hua talked about her way in classroom teaching:

So, I always like to have student center, something interactive, something, you know, project-based because that will, hopefully that will initiate students to talk in classroom instead of I am there and talking and they just listen.

Hua took the MA TESOL program at a university after she came to the United States. She stated that studying in the program helped learn truly effective approaches and methods of foreign language teaching, and supported her idea of what teaching could consist of. However, after she took a class on foreign language teaching methods, Hua believed that there were no perfect approaches. She remarked that project-based 
and communicative-based methods were better for various language skills. According to her own English learning experiences, Hua believed that students learn from actually using the language and from having fun.

\section{Helping students develop "A new habit"}

Hua stated that some students complained that her teaching method was not the way they learned a foreign language before. Students were used to traditional grammartranslation and teacher-centered classroom teaching. They were a bit confused, and felt pressure when Hua asked them to sit in a circle facing each other and to start talking in Chinese while still in the first few weeks of the 101 class. She stated that students' resistance to her new methodology would affect her mood in the classroom. However,

I will definitely stand at my principle. ... in class every day, if they don't arrange the class the way I like, I'll ask them to arrange that, and so that's a new habit for them, they know, when they see me, they have to rearrange the classroom, they need to face each other, they need to talk to each other. Or, I will force them to do that. And so, I think that is an example for new habit. So in my class, they need, they learn when they come to the class, they have to use the language, they have to talk in Chinese. And at the beginning, no one want to do that, they feel, you know, challenging, they feel embarrassed they don't say the word correctly. But now after eight nine weeks, they don't care, they just say the words, ... Yeah, I think it is a new habit. Because they know what's the routine in class, so it is OK for them to do so. And, definitely, I think it is a good thing, because they try different things, you know, learning language is trying different things. (Hua)

\section{A summary of the data collected from the observations for Hua}

The content delivered was new words and expressions, which were often organized as interrelated concepts, and introduced through questions and answers between the teacher and students. For example, in the 101 class, Hua connected the new word Youyisi 有意思 (interesting) to zhongwen 中文 (Chinese) and made a sentence zhongwen you yisi ma? 中文有意思吗? (Is Chinese interesting?). In this way, Hua 
connected the new word into an authentic situation and offered an opportunity for the students to learn the interrelated concepts of the new word.

The teaching methods and strategies tended to intermingle. For example, grammar-translation was adopted to explain the difference between xingqi si 星期四 (Thursday) and si ge xingqi 四个星期( four weeks). Grammar rules were introduced with students' practice. For example, after introducing the sentence pattern wo hen mang 我很忙. (I am busy.) Hua asked the students, “How to say 'he is tall'?” The students had formed the habit of sitting in a circle, prepared to talk to each other in Chinese, though sometimes some English was heard. Group learning, dialogues, and communicative discourse were frequently practiced. For example, the Chinese 101 class was often divided into groups. Hua gave each group a paragraph and had the students learn it by themselves, or organize disordered sentences into a meaningful paragraph. In the Chinese 203 class meetings, Hua asked the students to share their homework in small groups at the beginning of every class meeting observed. In class, most of the work was done in small groups, such as learning the text and discussing questions. A game was observed in the CHN 203 class, a competition between two groups to write measure words on the board, and Hua brought cookies as a reward for the whole class.

Classroom assessment tended more toward oral practice than paper-pencil quizzes. Questions asking for why and how were frequently observed in classroom assessment. For example, Hua read a paragraph from the textbook twice and raised a question: you mei you ren keyi gaosu wo, xianzai de ren shao chi yan, jiu, shao chi tang, weishenme? 有没有人可以告诉我, 现在的人少吃盐, 少吃糖, 酒, 为什么? (Is there anyone who 
can tell me why people eat less salt, less sugar, and less wine?) Another strategy that was often used in class was the practice of arranging several sentences listed out of sequence into a story to show the students' comprehension. The question-and-answer practices between teacher and students or among students tended to be a mini-social project for application of the words and expressions learned. For example, jintian ni qing wo chifan haoma? 今天你请我吃饭好吗? (Will you invite me to dinner today?) Shenme shihou guli pengyou? 什么时候鼓励朋友? (When do you give your friends encouragement?) During the five observations, only one paper-pencil-quiz was observed. Hua gave a dictation (a short paragraph) to the students but she did not collect the papers. Instead, she raised questions to check the students' comprehension of the paragraph.

The role of Hua in class tended to be that of a helper, partner, and facilitator. The time used for lectures was rather short. Hua spoke more Chinese than English in class. When the students were not able to follow her, she would draw pictures or use body language to help the students understand. No significant adjustments in specific content, or instructional strategies and activities, or assessment strategies were observed in class. Only once in the Chinese 101 class, when the students were not able to finish filling in the form with the information about Xiao Wang and Xiao Li, Hua asked the students to finish it at home. However, when the researcher asked Hua about this in the second interview, Hua said that she had not expected the students to finish the work in class, and had planned to have the students finish the form as homework. 
Hua was good at using humor to attract the students' attention, and to create an active atmosphere for learning. For example, she made a sad face when no student volunteered to read a sentence on the board; later when a student volunteered to read the sentence, Hua said to him, "I love you." This amused the whole class.

A brief discussion about Hua's views on method and about her classroom teaching

Here we see another example that the experience of boring classroom teaching and unsatisfactory learning outcomes would serve as counter-examples for teachers. The data collected show both the what and the why (Heimlich \& Norland, 1994) about Hua's choice of methods and approaches. After English learning experience through interacting with American people, Hua learned English as language acquisition rather than language learning (Krashen's, 1982) as Wen did. This experience became a strong support in her decision-making about classroom teaching. (Further discussion about Hua's classroom teaching will come in Knowledge of Method in the next section.)

Summary

There are three parts in this section: 1) Participants' priorities in teaching; 2) Transformative learning; and 3) The Lin Transformational Teaching and Professional Development Model.

\section{Participants' Priorities in Teaching}

As we see from the above discussion, each participant had his/her own understanding about foreign language teaching, and each had his/her own priorities in classroom teaching. Hua and Wen tended to believe communicative and speaking were essential to Chinese learning, and it was also apparent that conversational training was 
central in their class. Zhong stated that teachers should be knowledgeable with grammar rules, but it was essential to have students practice those rules to be able to use them. In classroom teaching, Zhong did what he said. Guo criticized the kinds of teaching that led to "deaf and dumb English"; she talked about the importance of culture in foreign language learning. Data shows that indeed more cultural information were introduced in her class. Ming's philosophy for foreign language learning was to develop students' communicative and task-based skills. She trained her students to give individual presentations in almost all class meetings.

Evidently, participants' decisions about contents and approaches to actual teaching were largely based on their beliefs about foreign language learning, and these beliefs mainly came from their personal experiences of English learning. This phenomenon agreed with the claim that "the knowledge of method is not the what but the why (Heimlich \& Norland, 1994, p. 163). As data indicated, the participants' views about method were consistent with their classroom practices. This consistency reified the relationship between the participants' pedagogical beliefs and their classroom teaching.

On the other hand, if we review the data about the changes involving the participants' beliefs about foreign language teaching and learning, we will see that they went through a process of transformative learning.

\section{Transformative Learning}

Transformative learning refers to the process by which we transform our takenfor-granted frames of reference (meaning perspectives, habits of mind, mind-sets) to make them more inclusive, discriminating, open, emotionally capable of change, and reflective so that they may generate beliefs and opinions that will prove more true or justified to guide action. (Mezirow, 2002, p. 9) 
Data collected from interviews for this study and findings drawn from cross-case analysis revealed the process by which participants transformed a problematic frame of reference, which they had uncritically assimilated from others, to a more dependable frame of reference, which gradually built, in their current Chinese teaching, through their critical reflections about their own and other's assumptions.

The five participants all talked about their English learning at schools in their hometowns. Most of them did not find it a pleasant learning experience. However, at that time, they had no clear ideas about how to make changes, because, it would seemed, the pure grammar-translation approach and teacher-centered classroom teaching worked as "cultural paradigms (collectively held frames of reference)" ( Mezirow, 2000, p. 16). When it came time to use the language, they realized that the traditional ways of learning did not work. Now the frames of reference that they had taken for granted, i.e. that learning English meant learning grammar rules and vocabulary, became problematic. This reflection led to a critical assessment of beliefs and assumptions. Since they could not fully trust what they knew or believed, they began to rely more on their own experiences and critical reflection. Once they realized that language learning worked best in a meaningful contextual environment, they had this reflection as a new frame of reference, which resulted from interpreting experience (Mezirow). This new frame of reference helped the participants generate beliefs and decisions that were more dependable in their Chinese teaching - communication should be the goal (National Standards, 2006), and culture should be the core (Lange \& Paige, 2003). As discussed earlier in this chapter, another issue that pushed participants to question their earlier 
frames of reference was teaching in a context of student diversity (Further discussion about their reflections will be in Knowledge of Learners in the next chapter). Their new understanding about foreign language teaching and students guided participants to make adjustments in their personal philosophy, values, and classroom teaching. This process of making adjustments became "a movement through time of reformulating reified structures of meaning by reconstructing dominant narratives” (Mezirow, 2000, p. 19). Characteristics of Mezirow's (2000) 10 Phases of Transformation can be recognized throughout the Chinese teachers' professional development (See Figure 13). A quote from Mezirow (2000) will sum up this section:

Transformative learning is a way of problem solving by defining a problem or by redefining or reframing the problem. We often become critically reflective of our assumptions or those of others and arrive at a transformative insight. (p. 20) 


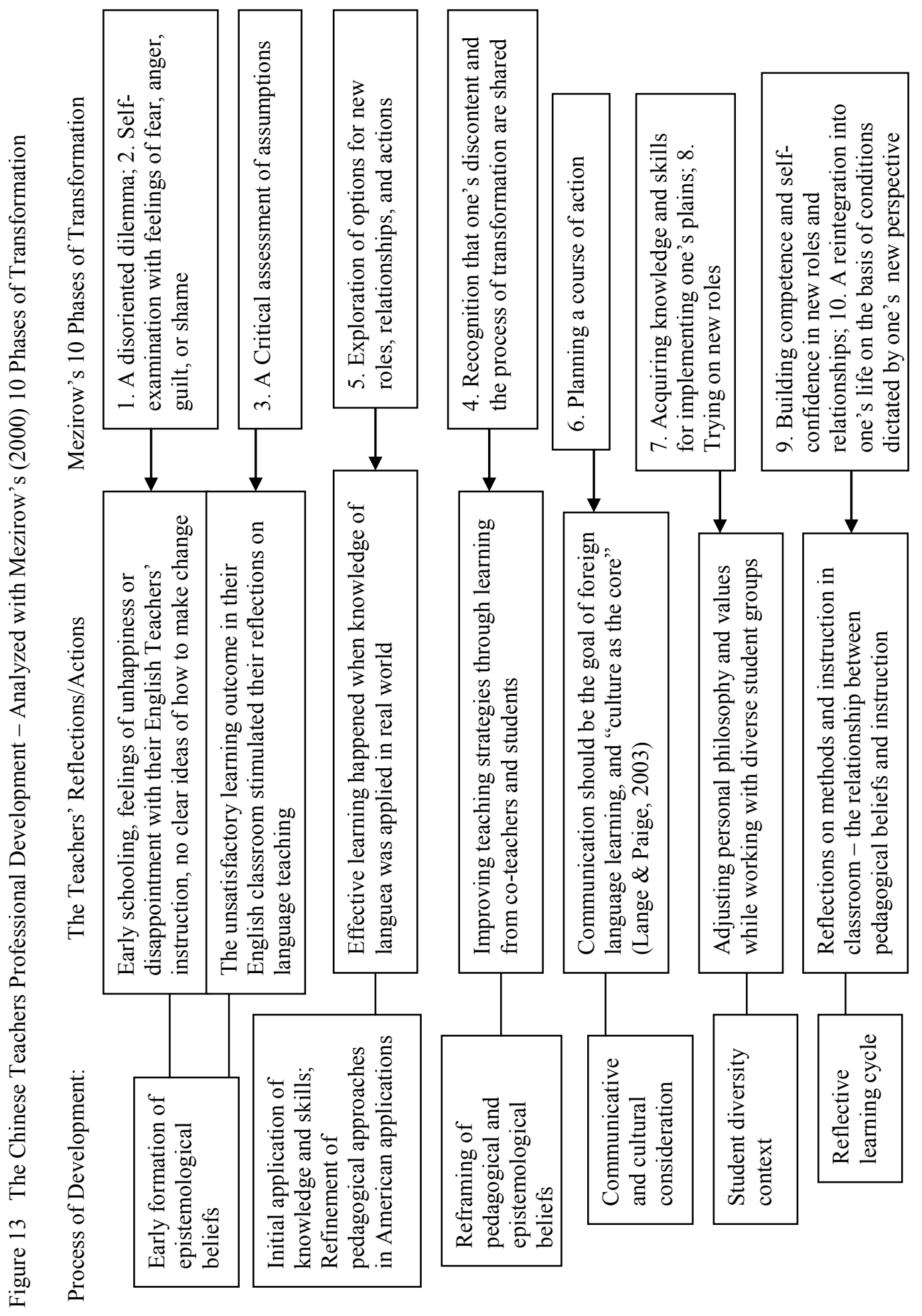


The Lin Transformational Teaching and Professional Development Model

If we review the data and findings about professional development of each participant, we will see that they moved from a traditional process to a transformational development (See Figure 14). The Lin Model was drawn from the findings of this study and was constructed based on this study's theoretical framework.

In a traditional process, a serious teacher would make improvements in his/her profession by continuous learning and making adjustments in instruction. However, he/she may not seriously question his or her beliefs and assumptions, which had been uncritically assimilated from others.

As discussed in the last section, Transformative Learning (Mezirow, 2000) focuses on critically questioning beliefs and assumptions shaped through taken-forgranted frames of reference. For example, these participants re-examined their beliefs about foreign language learning and teaching when they found what they had learned at school did not work; the change of student populations also stimulated their reflections on personal philosophy and value (See Knowledge of Learners in Chapter V). This process of self-directed learning is dynamic and profound. It can be called critical learning, which has the potential to transform (Dewey, 1916; Freier, 1992; Kolb, 1984; Mezirow, 2000). Transformative learning indeed helped the Chinese teachers construct new points of view about how foreign languages are learned; this in turn help them respond, with heightened awareness, to the complexities of how languages might best be taught (See Knowledge of Self and Knowledge of Method in Chapter V). This selfdirected learning process "may itself become a frame of reference, a dispositional 
orientation" (Mezirow, 2000, p. 19), and can become a reflective learning cycle if the learning process continues. 


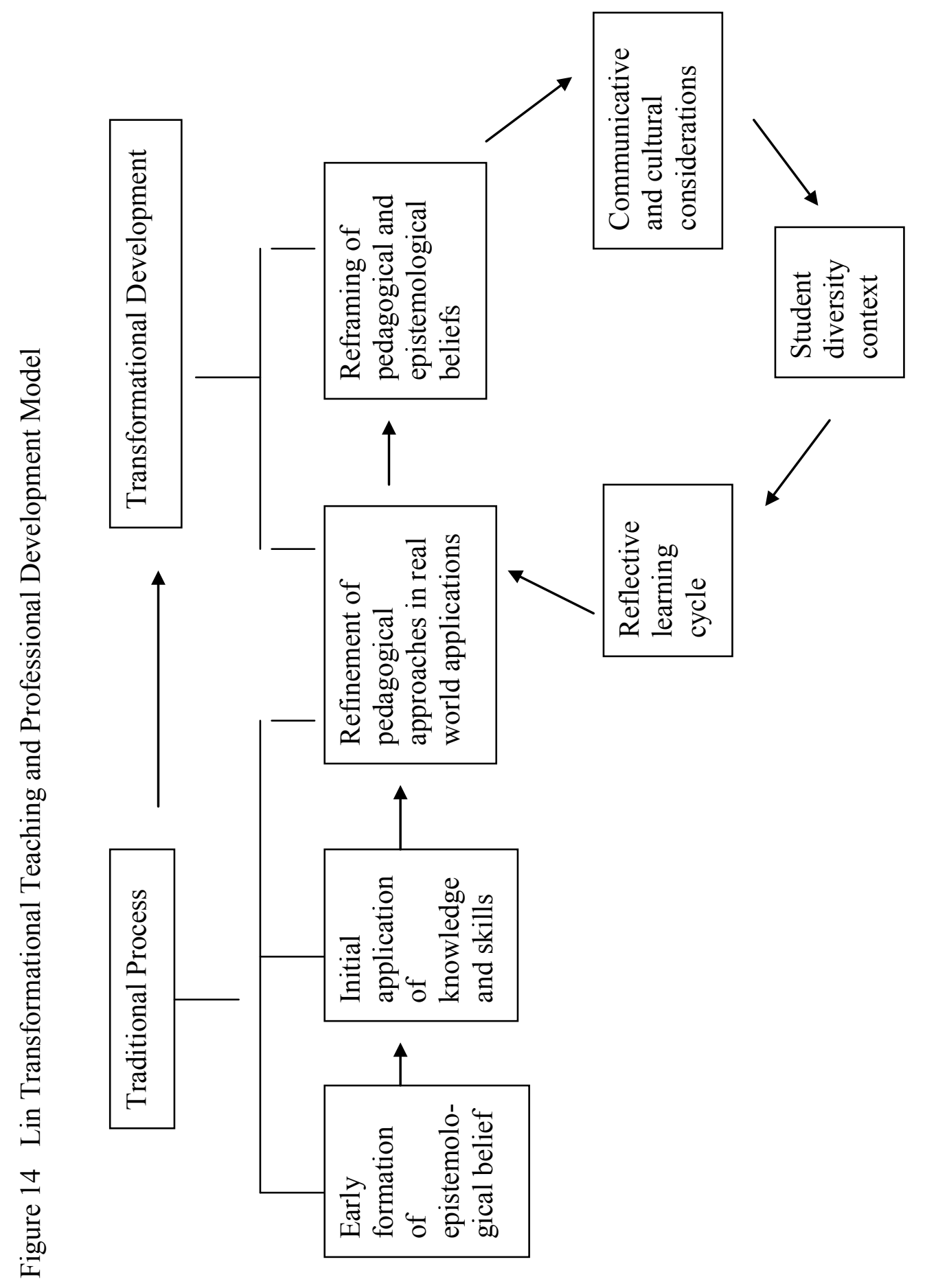




\section{CHAPTER V \\ DISCUSSION AND RECOMMENDATION}

There are four sections in this chapter: 1) Discussion; 2) Recommendation; 3) Assumptions and Limitations; and 4) Conclusion. The discussion focuses on the constructive work involved in the participants' beliefs and classroom teaching, and follows the arguments by Galbraith (1998): Knowledge of principles of practices, knowledge of self, knowledge of content, knowledge of methods, and knowledge of learners (Five areas). The recommendation includes a few suggestions for four areas: individual professional development, collaborative professional development, teacher training program, and students of Chinese. Assumptions and limitations of this study were demonstrated from four relevant dimensions.

\section{Discussion}

The discussion focuses on: 1) The triggers and preconditions by which the participants changed their beliefs about Chinese teaching; 2) The constructive work involved in their beliefs and assumptions; and 3) The relationship between their epistemological beliefs and pedagogical practices. The discussion follows the framework of Galbraith's (1998) five knowledge areas that he suggests for the development of a teaching style for adult learners (See Figure 15). 


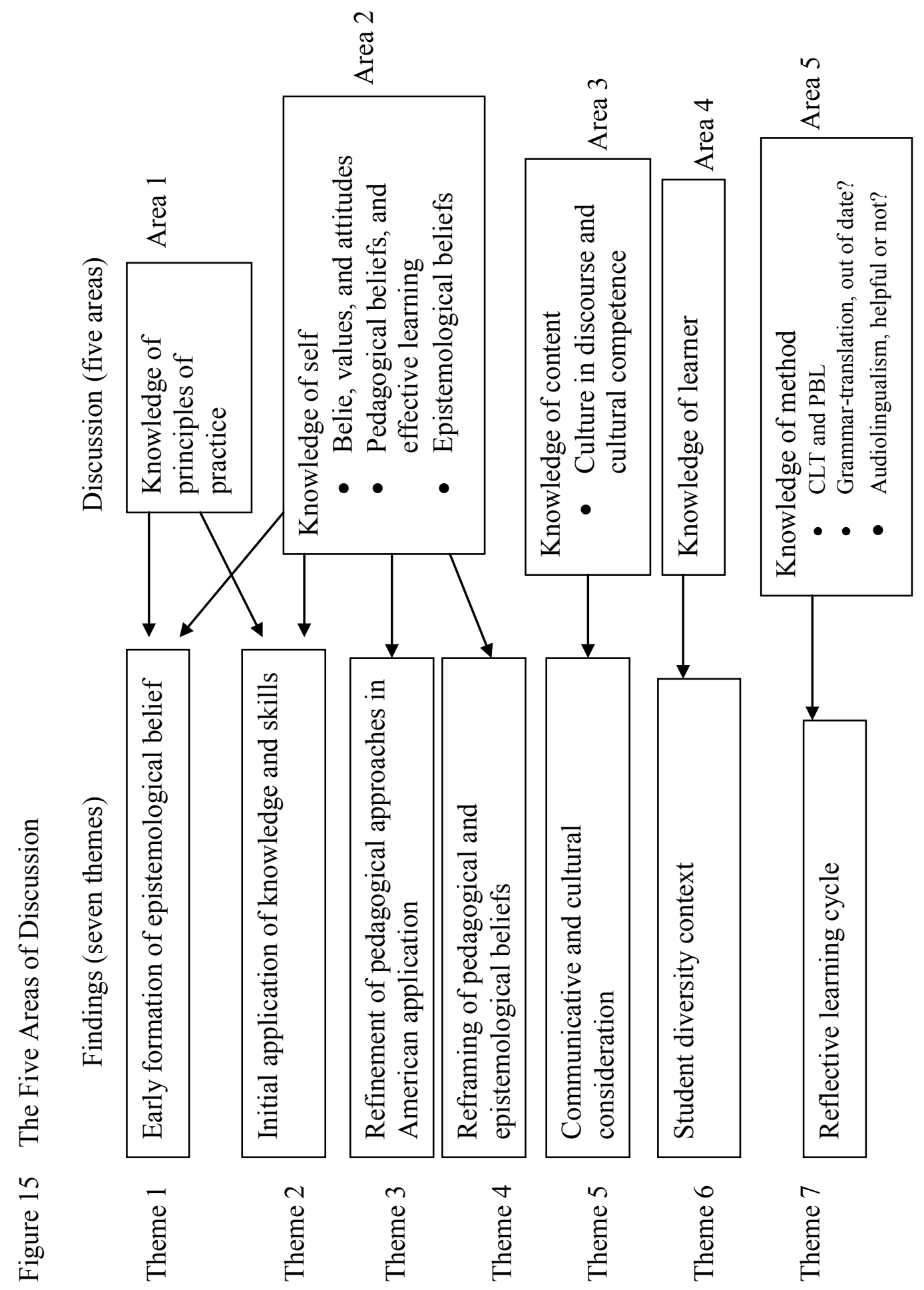




\section{Knowledge of Principles of Practice}

Galbraith (1998) suggested that teachers of adults should be alert about what occurs in the teaching and learning encounter that seems to be significant, and reflect on what principles guide their practice. To be an effective facilitator of learning, it is essential to compare what oneself does with what the literature has presented as principles of effective practice (Galbraith) (See Chapter II, Becoming an Effective Teacher of Foreign Language).

As we see in Theme 1: Early epistemological beliefs formation, in Chapter Four of this paper, the participants' descriptions about their English learning in class in their hometown were similar to Celce-Murcia's (2001) description of the analytical Grammar-Translation Approach: instruction is given in the first language and focuses on grammatical parsing. There is little use of the target language (the foreign language that is learned) in class. Instruction focused primarily on the memorization of words and grammar rules (National standards, 2006).

The participants' experiences of English learning tended to reveal their teachers' principles of practice, including their understanding of language and language teaching: Described as a traditional natural science oriented curriculum, language was not truly viewed as part of the social world (Hamp-lyons \& Condon, 2000; Lange, 2003). Thus, knowledge about English (pronunciation, intonation, vocabulary, grammar) was taught. Memorization of the content taught was required. The cultural context in which the language occurs was likely to go missing in the learning process. Fixed, normative phenomena of language use were taught without cross-cultural information (Cramsch, 
2003). Concomitantly, classroom teaching was teacher-centered. As their teachers acted as knowledge-givers and the participants as knowledge-receivers with little reflection or social interaction, Guo, Hua, Ming, and Wen found their English learning in class to be boring and not much help. Since few principles of effective practice as Galbraith (1998) suggests can be found in the participants' former teachers' instruction, the learning outcome was that Guo, Hua, and Wen were not able to communicate with Americans when they came to the United States, though they had learned plenty of English words and grammar rules.

On the other hand, according to Ming's experience of learning with Prof. Zhang and the effective learning outcome (See Theme 2: Initial application of knowledge and skills in the last section), a few items of Galbraith's 10 principles of practice can be traced in Zhang 's practice.

(1) An appropriate philosophy guided the educational encounter (Galbraith). Zhang encouraged students to use English instead of sticking to vocabulary and grammar rules.

(2) Challenging teaching and learning interactions occurred that presented learners with opportunities to scrutinize, question, and develop alternative ways of thinking and acting (Galbraith). Zhang required students to give a presentation each week.

(3) Authenticity and credibility were essential elements of the educational encounter (Galbraith). Zhang encouraged students to talk to professors who were English native speakers. 
(4) It was important to attend to how learners experience learning (Galbraith). From reading, attending lectures, doing assignments to giving lectures, talking to professors who were English native speakers, Ming experienced a truly integrated learning process.

(5) Independence was fostered in an effort to encourage autonomy, empowerment, and self-direction (Galbraith). The practice of giving presentations and learning from professors of English who were native speakers offered Ming opportunities to encourage autonomy, empowerment, and self-direction.

(6) Praxis should be fostered that enhances critical thinking and reflection (Galbraith). Learning under Prof. Zhang's guidance became a trigger to change Ming's understanding of foreign language learning.

The different learning outcomes at school between Ming and the other participants re-emphasize two messages we have learned from the literature review for this study: a) Teacher's beliefs about language and language learning matter (Freeman \& Freeman, 1994; Freeman \& Johnson, 1998; Freeman \& Richards, 1996; Velez-Rendon, 2002); and b) Language cannot be truly learned without communicative competence (Hymes, 1972, Kramsch, 2003; National Standards, 2006; Scarcella, Andersen \& Krashen, 1990; Swain, 1984). As Galbraith (1998) points out that it is essential to understand teachers' beliefs, values, attitudes and personal philosophy or vision of teaching in order to develop a teaching style that is meaningful, the following is a discussion about the constructive work involved in the participants' change of beliefs. 
Knowledge of Self

\section{Beliefs, Values, and Attitudes}

First, it is essential to identify the interrelationship among beliefs, values, and attitudes. "A belief is what we accept as truth" (Apps, as cited in Galbraith, 1998, p. 10). Galbraith adds, "While others may not agree with what we accept as truth, it is still our truth" (Galbraith, 1998, p. 10). Values "are principles that guide us and give us a sense of directing, that help us decide what is important and provide us with an ethical and moral foundation" (Apps, as cited in Galbraith, 1998, p. 10). "Attitudes are those affective elements that are connected to our like or dislike, positive or negative, and for or against feelings toward a person or thing (Galbraith, 1998, p. 10).

An example of the interrelationship of beliefs, values, and attitudes can be found in the findings from this study. Like thousands of students in China, the participants used to believe in whatever was taught in their classrooms. For example, "I used to be a bottle to accept the water that the teacher poured in..." (Guo). However, unsatisfactory learning outcomes drove the participants to question their former teachers' teaching, which can be described as the traditional natural science oriented curriculum and instruction. The reflection on this learning experience led them to devalue the traditional curriculum and instruction and so hold a negative attitude towards their teachers' instruction: "When I was at school as an English student, ... the only thing we did was listening to the teacher... it was not creative, it was not interactive, we just listened, ... I really don't think that works... Their teacher method doesn't work" (Hua). "It is yaba yingyu 哑吧英语 [“deaf and dumb English” means an English learner was not able to 
understand or speak English]. The classes were boring.... I cannot find anything from my teacher's English teaching that I can use for my teaching here [in the United States]" (Guo). Indeed, "Recognizing those attitudes related to being a teacher of adults is a necessary component of knowing more about self' (Galbraith, 1998, p. 10). Furthermore, this interrelationship of beliefs, values, and attitudes worked as a key linkage (Erickson, 1986) when it came to changes in the participants' pedagogical beliefs about foreign language teaching and learning (See Figure 16).

Figure 16 Changes in Beliefs about Foreign Language Teaching and Learning: A Schematic Diagram

\begin{tabular}{|l|l|l|l|l|}
\hline $\begin{array}{l}\text { A participant's former } \\
\text { English teachers' } \\
\text { beliefs and } \\
\text { assumptions about } \\
\text { language teaching }\end{array}$ & $\begin{array}{l}\text { Those English } \\
\text { teachers' } \\
\text { decisions about } \\
\text { approaches } \\
\text { and strategies } \\
\text { for classroom } \\
\text { teaching }\end{array}$ & $\begin{array}{l}\text { Those approaches } \\
\text { and strategies } \\
\text { influenced the } \\
\text { participant's English } \\
\text { language proficiency }\end{array}$ \\
\begin{tabular}{|l|l|l|}
\hline $\begin{array}{l}\text { The participants' } \\
\text { own learning } \\
\text { experiences led } \\
\text { them to } \\
\text { value/devalue } \\
\text { his/her teachers' } \\
\text { teaching }\end{array}$ \\
\cline { 1 - 2 }
\end{tabular} & $\begin{array}{l}\text { Reflection about one's own } \\
\text { learning experiences led to a } \\
\text { change in beliefs about foreign } \\
\text { language teaching and learning }\end{array}$ & $\begin{array}{l}\text { The } \\
\text { participant's } \\
\text { decisions } \\
\text { about } \\
\text { Chinese } \\
\text { teaching }\end{array}$ \\
\hline
\end{tabular}

\section{Pedagogical Beliefs and Effective Learning}

Although the triggers and preconditions by which the participants changed their beliefs about language teaching occurred in different settings (Ming was in her graduate program in China; Hua and Wen came to the US), the change all happened at the time when the participants realized that "learning happens most when you are doing it" (Hua). 
This constructive work involved in their change underlaid a new understanding of language and language learning, as Hymes (1972) states: the social rules of language use reveal that language cannot be understood fully without looking at language use. And language cannot be truly learned without communicative competence.

The application of English in the learning process led Hua, Ming, and Wen through Dewey's (1916) and Kolb’s (1981) procedures for effective learning (See Figure 2 and 3): 1) The sense of a problem/Concrete experience: Hua, Ming, and Wen were unable to communicate with English native speakers; 2) Observation of conditions/Reflective observation: Hua, Ming, and Wen listened and observed how English native speakers talked; 3) Formation and rational elaboration of a suggested conclusion/Abstract conceptualization: They compared what they had learned at school in their hometowns with what they watched in the United States; and drew a conclusion from what they had observed; 4) Active experimental testing/Active experimentation: They tried to talk to American people and see if they could be understood. As Dewey (1916) points out that learning must grow from the individuals' own experience, Hua, Ming, and Wen gained new insights in language learning and teaching from their own learning experiences.

\section{Epistemological Beliefs}

As Freeman and Johnson (1998) call for a broader epistemological view of language teaching, it is necessary to examine how the participants' and their former teachers' beliefs about language connected to their epistemological beliefs. 
As discussed in the literature review for this study, the influence of epistemological beliefs is subtle and tends to have more indirect effects than direct effects. Different beliefs about the organization and certainty of knowledge will lead to different attitudes and behaviors toward learning (Schommer, 1998). As discussed earlier in Chapter II, Figure 6 shows two kinds of teachers' epistemological beliefs. Most of the participants' former teachers focused on vocabulary, grammar, and memorization. Here knowledge tended to be regarded as isolated bits to be discovered. The learning result was that the participants were struggling when they applied the information they had learned at school. On the other hand, interactions with American people led the participants to realize that foreign language learning happened "at real world situations" (Ming), “in a social world” (Hymes, 1972, p. 272). Hence, knowledge is a complex and interrelated network. When interacting with American people, the participants were learning how to integrate and elaborate the information learned so as to be able to apply it effectively. These effective learning experiences helped participants recognize the communicative nature of CLT and PBL, as Ming and Hua mentioned during the interviews. Characteristics of CLT and PBL were observed in most participants' classes.

In addition, the participants went through the three essential aspects of adult learning: experience, reflection, and meaning-making (Taylor, Marienau, \& Fiddler, 2000). The unsatisfactory learning outcome at school became an unpleasant experience that pushed them to reflect on their former teacher's ways of teaching, while the interactions with American people became a new way of learning that was meaningful to 
them. This cognitive development agreed with Taylor, Marienau, and Fiddler's argument: It is important to explore one's past and current experiences through critical reflection while transforming one's way of knowing. As discussed earlier at the end of Chapter IV, the participants went through a process by which they transformed a problematic frame of reference, which they had uncritically assimilated from others, to a more dependable frame of reference, which gradually built though their critical reflections about their own and other's assumptions (Mezirow, 2000). This process led them to a journey of transformational development.

When Hua, Ming, and Wen learned about how learning actually happened, they were able to support their students more effectively. Still, these Chinese teachers were facing another challenge: culturally diverse student groups. As Galbraith (1998) points out that a teacher's beliefs are influenced by external and cultural forces, the participants of this study needed to adjust their beliefs, values, and attitudes while working with culturally diverse student groups.

\section{Knowledge of Learner}

To understand more and deeper about learners, Galbraith (1998) suggests teachers “first draw yourself as a learner... after you have completed drawing yourself, sit back and look deeply at what you drew. What concepts, issues, principles, characteristics, concerns, and so forth are reflected in your drawing? What does your drawing tell you about the complexity of being an adult learner?" (p. 12). This suggestion might work for a native Chinese teacher in China. There, the students' learning preferences (Lasley \& Matezynski, 1997) tend to be similar to their teachers, though the participants did 
mention that students in China are changing. However, it is unlikely that this suggestion would work for the same teachers from China when teaching Americans.

Weisser (2005), drawing from her own learning and teaching experiences, points out that the world has changed, even for Americans teaching Americans. Now there is a trend toward "student-centered pedagogy emphasizing the transfer of power and knowledge from teacher to learner," (p. 30). Therefore, “... It is no longer possible to reproduce my own educational experience and fantasies. I believed in my education; now students believe in themselves, or say they do." (p. 28). Therefore, it is unlikely that what a teacher draws from his/her imagination and inner self can guide him/her that much when he/she works in a classroom now. Different from the American ideology that values the individual "self" (Weisser, 2005), Chinese ideology tends to value the “集体 (collective)”, or described by Jones (1990) as “collateral”. Teachers from China who are cultural constructives would be confused when faced with notions such as "New Age psychology, the contemporary emphasis on self-esteem, and the high evaluation in post-Freudian society" (Weisser, 2005, p. 29), or when working with students who had been exposed to this American ideology, as we see in Theme 6: Student diversity context in the last section.

Ming's, Hua's, and Zhong's statements about the challenge of working with the American students were all related to an issue about student learning preferences and cognitive style. According to Ramirez, “... the significant role models in a child's life, the teaching styles of families, the types of learning encouraged, and the ways in which these learnings are encouraged, seem to contribute to the development of specific 
learning styles in children” (as sited in Lasley \& Matezynski, 1997, p. 30). Thus, “... family socialization practices play a major role in determining learning preferences in youngsters (Ramirez \& Castaneda; Witkin et al, as sited in Lasley \& Matezynski, 1997, p. 30). "Cognitive styles have been described as information processing habits representing the learner's mode of perceiving, thinking, problem-solving, and remembering” (Messick, as sited in Lasley \& Matezynski, 1997, p. 30). Also, Galbraith (1998) points out that a teacher's beliefs are influenced by external and cultural forces. "One of the greatest external forces for any individual is the culture in which that individual grew up, experienced learning, and may still continue to view life" (Apps, as cited in Galbraith, 1998, p. 9). Since the participants of this study grew up in the Chinese culture and had little chance to learn the American culture in schools in their hometowns, it is a serious challenge for them to meet culturally diverse students' needs in classroom teaching in the United States. They needed to first learn about the diverse cultures and to find out their culturally diverse students' learning preferences and cognitive style so as to make appropriate adjustments, as Ming stated. The following is the discussion about what should be taught in classrooms and what culture is.

\section{Knowledge of Content}

The participants' knowledge of content is introduced in Theme 5:

Communicative and cultural considerations in the last section. Overall, their views about what should be taught in the classroom were similar. They had identified that "Communication is the purpose of learning a language" (Zhong), and that students should be informed both about linguistic and cultural knowledge involving Chinese. 
The discussion about their views on linguistic teaching will be combined with the discussion about their approaches to classroom teaching in Knowledge of method in this section. The discussion here focuses on their views about cultural teaching.

Galbraith (1998) stated that "Knowledge of content serves as a mechanism for defining and developing a portion of our teaching style.... Content is the basis for the teaching event and is comprised of different elements. Content incorporates identifying certain knowledge skills, or attitudes to learners that result in learning outcomes" (p. 15). Indeed, the participants' knowledge of content served as a mechanism for defining and developing a portion of their teaching style as Galbraith (1998) describes. And a teacher's concept of what "content" is can change over times: Data collected from the interviews showed that the participants' understanding about what should be taught in the classroom had expanded from a traditional natural scientific oriented curriculum for foreign language teaching to a broader view of Chinese learning: Communication should be the goal, culture should be the core (Lange \& Paige, 2003). This understanding agrees with the statement that a language system is a means for attaining various outcomes: communicating, gaining cultural understanding, and connecting with other disciplines (National Standards, 2006). The constructive work involved in the participants' beliefs that culture should be the core grew out of their understanding of structure and organization of knowledge: As the cultural context of language use was introduced, knowledge came to be viewed as networks with many links rather than isolated compartments to be discovered. However, although they all stated that culture was 
important for foreign language learning, their understandings about culture seemed diverse. For example, Guo, Hua, and Wen talked about the strategies to introduce culture: watching videos, listening to music, explaining the meaning of a word, and how to talk and behave accordingly. Ming introduced culture through helping students learn the map of China. Guo remarked, "Culture is not just in book, it is in the life. Myself is also a culture in the classroom ... I am the first choice for them [students] to learn Chinese culture."

Since "The United States must educate students who are equipped linguistically and culturally to communicate successfully in a pluralistic American society and abroad" (National Standards, 2006), a deeper understanding about culture in discourse and cultural competence is necessary for teachers from China for two goals: 1) To work with culturally diverse student groups; and 2) To introduce Chinese culture to American students.

\section{Culture in Discourse and Cultural Competence}

From a sociolinguistic standpoint, “... the social reality we call culture is reflected in the way we use language in social contexts [italic in original], i.e., it is shaped by the linguistic choices we make" (Kramsch, 2003, p. 21). From the pragmatics standpoint, "Culture is an interpersonal process of meaning construction" [italic in original] (Kramsch, 2003, p. 21). Another insight provided by ethnographers and sociologists is that members of a social group would support each other, "which in part determines why they say what they say and act the way they do" (Carrol, 1987; Zarate, 1986, as cited in Kramsch, 2003, p. 23). Kramsch points out that this alignment is another cause of 
misunderstanding or misapprehension of foreign phenomena. Kramsch also points out that the temptation to view culture only in terms of national traits is obvious. However, national traits "cannot be adduced without further specification of other cultural factors such as age, gender, regional appurtenance, ethnic background, social class” (p. 22). For cultural competence, three categories were identified: "1) Sociolinguistic ability (verbal and nonverbal behavior patterns); 2) Knowledge of the culture area (France and francophone Europe, Black ...); 3) Attitudes (e.g. tolerance to other cultures)" (Kramsch, 2003, p. 19).

The temptation to view culture only in terms of national traits could be traced in some participants' remarks. And their understandings of culture and cultural competence to some degree influenced their decision-making about classroom teaching. As we saw in Theme 7: Reflective learning cycle in the last section, training in sociolinguistic ability was observed more than training in the other two competences during the classroom observations for this study. However, Guo, Ming, and Zhong demonstrated their knowledge about tolerance toward other cultures when talking about meeting students' needs, as we saw in Theme 6: Student diversity context in the last section.

The next section will discuss the participants' knowledge of method and how they incorporate their content knowledge into their classroom teaching.

\section{Knowledge of Method}

According to Galbraith (1998), "Methods are those tools to use within the instructional process to enhance the teaching and learning encounter." The knowledge of method, "is not the what but the why" which allows the teacher "to bring personal 
beliefs, values, and philosophy of teaching and learning to the application of the method" (Heimlich \& Norland, 1994, p. 163). Similar to Galbraith’s (1998) and Heimlich \& Norland's (1994) arguments on knowledge of method, Freeman and Freeman (1994) state that a teacher's knowledge of language and theory of a foreign language help form the teacher's orientation toward teaching the language. The data collected for this study show that based on their own English learning experiences, this group of Chinese teachers had switched from focusing on teaching behaviors and learner outcomes to focusing on learning about the nature of language teaching (Freeman \& Johnson, 1998; Freeman \& Richards, 1996). The following discussion will focus on the four approaches that the participants of this study adopted in their classroom teaching. Communicative Language Teaching (CLT) and Project-based Learning (PBL)

All the participants identified that communication should be the goal for foreign language learning, and indeed, characteristics of CLT and PBL could be traced in most participants' classroom teaching.

For example, Ming “put her students into the water to swim”, and Hua helped her students develop "a new habit." These practices came from their own learning experiences and were based on the principles of CLT or PBL. Ming and Hua's choice of applying this approach responded to the arguments that learners were capable of pursuing knowledge which comes from empirical evidence and reason (Belenky et al., 1986; Schommer, 1998; Schommer-Aikins, 2004). A successful application of CLT and PBL would create effective learning (Dewey, 1916; Galbraith, 1998; Kolb, 1981; Mezirow, 2000; Schommer, 1998; Schommer-Aikins, 2004; Taylor, Marienau \& Fiddler, 
2000; Walker, 2002). The learning outcomes observed during the classroom observations for this study demonstrated that Ming led their students through those procedures of effective learning: Every one of Ming's students was able to give a meaningful presentation within the limited time in every classroom meeting observed.

Some characteristics of the communicative approach were observed in the other participants' classroom teaching as well. For example, Wen had not received any training in foreign language teaching. However, her classroom activities showed some characteristics of the communicative approach. The classroom activities were mainly questions and responses between teacher and student, or among students. The questions were developed from among topics that the students were interested in. For example, “Ni zuotian youmeiyou chuqu 你昨天 有没有出去?” (Did you go out yesterday?) “Mingtian ni youmeiyou gongzuo 明天你有没有工作?” (Will you have work to do tomorrow?) “Ni shenmeshihou qu zhongguo 你什么时候去中国?” (When are you going to China?) “Ni xiang zai zhongguo zhu duojiu 你想在中国住多久?” (How long are you going to stay in China?) To answer these questions, there was an immediate and natural need for students to use Chinese. Although Wen acted as an expert to help her students with expressing their thoughts, she created a learning environment that was similar to the one described as Sociocultural perspectives on teacher-learner interaction in the second-language classroom (Anton, 1999). Similar to Ming and Hua, Wen's practice came from her own English learning experience. Wen believed that her English learning did not start with grammar rules but with her interaction with Americans. So her students could do the same way. 
Grammar-translation, Out of Date?

Influenced by traditional views on language and language teaching, most of the English teaching in China started with linguistic form, and most of the training that the participants had received in their classrooms was in grammar and translation. It is interesting to see that whether they liked it or not, all the participants talked about grammar and translation. Hua and Wen tended not to teach grammar in class, while Guo stated that a foreigner "can't step into the deep, deep level of Chinese culture" if he or she did not learn "the good, the perfect grammar, and to write the characters." Similarly, Zhong remarked that phonetics, the basic grammar rules, and the Chinese characters were essential. He said, "Grammar has to do [with] to learn [learning] the language more, more efficiently", though he recognized "grammar is far from [being] enough" to learn Chinese. Ming used translation to a lay linguistic foundation for students. Data collected from the classroom observations show that the participants' views on grammartranslation were closely connected to their classroom teaching (See Theme 7: Reflective learning cycle in the last section).

Zhong and Guo's views about grammar teaching and Chinese character learning responded to the issue of fluency vs. accuracy. Swain (1995) points out, "We know that fluency and accuracy are different dimensions of language performance, and although practice may enhance fluency, it does not necessarily improve accuracy (Ellis, 1988; Schmidt, 1992)” (p. 125). Accuracy requires learners to internalize linguistic knowledge. The National Standards (2006) state that memorizing words, grammar rules, verb conjugations, learning new ways of writing, and producing new sounds are still 
important in the foreign language classroom, though the focus has shifted to knowing them in terms of the meanings they convey. Because "... the nature of language...mirrors human mental processes or shapes the flow and character of thought..." (Chomsky, 2006, p. 1), and "Language can serve as an instrument of thought and self-expression" (p. 11), students need to achieve a high level of language proficiency to mirror or shape their thought. To reach this goal, classroom activities should be context embedded and require active cognitive involvement (Cummins, 1996) (See Language Proficiency in Chapter Two of this paper). According to Swain (1995), Acarcella, Andersen, and Krashen (1990) communicative competence involves at least four areas of knowledge and skills: grammatical, sociolinguistic, discourse, and strategic. It is a challenge for teachers from China to keep the balance between teaching linguistic knowledge and practicing CLT or PBL in order to help students know what to say to whom in what circumstances and how to say it (Hymes, 1972).

Data from this study show that Zhong's instruction focused on grammar rules, yet somehow he also carried out the communicative approach in his classroom. The explanations for the grammar rules were all in Chinese, as was the communication between Zhong and the students. While the students were reporting their grammar assignments in class, student oral practice, teacher classroom assessment, and error correction were all carried out simultaneously. Based on sociocultural theory (Vygotsky, 1978), Zhong acted as an expert, through negotiation, to help the students with grammar rules that were beyond their ability (Krashen's Monitor Model, 1982). Zhong's practice responded to Anton's (1999) main argument in his article The discourse of a learner- 
centered classroom: Sociocultural perspectives on teacher-learner interaction in the second-language classroom: “...teachers can engage learners in the negotiation of meaning, language forms, and classroom rules by using discursive moves, and in so dong can also promote learners' active mental participation, ...” (p. 304).

\section{Audiolingualism, Helpful or Not?}

Characteristics of Audiolingualism were observed in Ming's classroom during the classroom observations for this study. As described in Summary of the classroom observations for Ming's teaching in the last section, the example of learning the word zhoumo 周末 demonstrated Ming had internalized the three approaches: communicative, grammar-translation, and audiolingualism. She made good use of the advantages of the grammar-translation and audiolingualism approach to help students build up a communicative competence. No wonder the learning outcome was significant: after only four weeks of learning, every one of Ming's students was able to give a presentation as required, both fluently and accurately.

It is true that " The problem was, while those who learned from that method [grammar-translation] might be able to read in a foreign language, they were often not very good at talking with native speakers" (Bollag, 2007, Changing lessons section 91 ), and thousands of students in China learned "deaf and dumb English" as Guo described. Also, Skinner's claim for explaining language, based on his S-R mode, as a set of habits gradually built up over the years is "inadequate in a fundamental way" (Chomsky, 2006, p. 3). However, since communicative competence involves five areas of knowledge and skills: grammatical, sociolinguistic, discourse, strategic (Swain,1984; Acarcella, 
Andersen, \& Krashen,1990), and cultural (Kramsch, 2003), it is crucial for teachers from China to internalize the nature of each approach to foreign language teaching, and develop an appropriate method for classroom teaching as Ming and Zhong did.

\section{Summary}

Galbraith's (1998) argument about knowledge of method is right. The methods that the participants adopted brought out their principles of practice, self, content, and learners. The participants' beliefs and assumptions about foreign language teaching and learning were mainly built on their personal experiences of English learning. Once again, personal experiences of English learning served as one of the important factors that formed this group of Chinese teachers' pedagogical beliefs about language teaching. As we see in the participants' statements and classroom teaching, each participant had his/her own beliefs and assumptions about methods and approaches, and the data collected during their classroom teaching was consistent with their beliefs, (See Theme 7 Reflective learning cycle in the last section). This consistency indicates a close relationship between these Chinese teachers' epistemological beliefs and their pedagogical practices; it also echoes the argument that the knowledge of method, "is not the what but the why" (Heimlich \& Norland, 1994, p. 163).

In sum, early schooling, language learning, and initial teaching experiences have a powerful effect on Chinese teachers' epistemological beliefs and pedagogical practices. When these beliefs are embedded and unexamined, they can inhibit effective teaching of Chinese language and lead to traditional behaviorist-centered learning approaches. However, findings indicate that critical reflection on preconceptions, beliefs, values, 
principles, and practices can become a precursor for constructivist and transformational Chinese language teaching and learning.

As discussed earlier in the last chapter, data revealed the process of participants' professional development (See Figure 14), moving from a traditional process to a transformational development. The Lin model demonstrates how traditional Chinese language approaches can be transformed into more effective epistemological and pedagogical strategies through assessment and reframing, consideration of cultural contexts, incorporation of diversity, and inclusion of continual professional reflection. To increase teacher competence and learner proficiency, this study suggests the following recommendations.

\section{Recommendation}

Suggestions from this study are made in four areas: individual professional development, collaborative professional development, teacher training program, and students of Chinese (See Figure 17). 
Figure 17 Suggestions for Four Areas

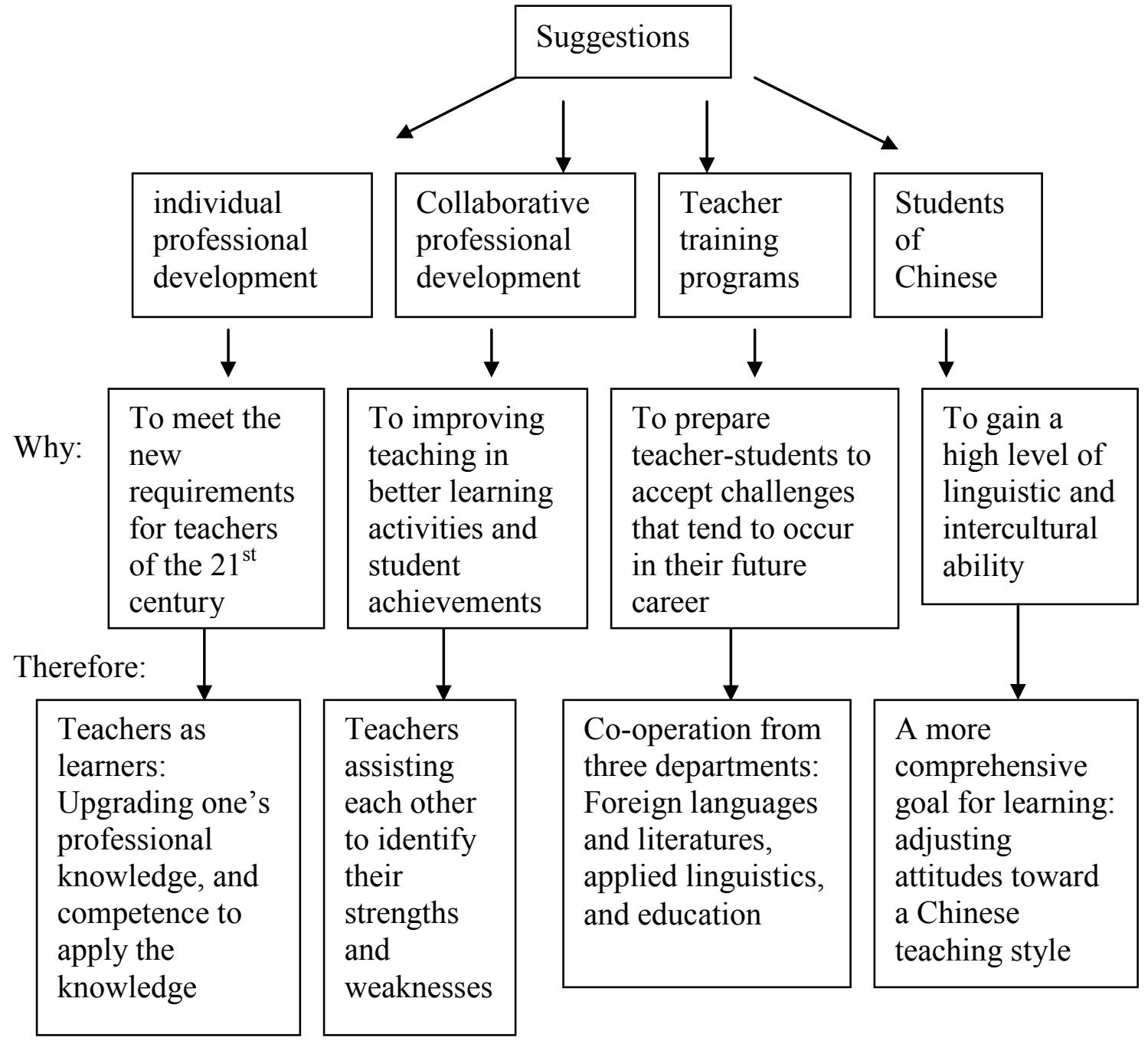

Individual Professional Development

Kagan (19920 states "Researchers have found that a teacher's beliefs usually reflect the actual nature of the instruction the teacher provides to students" (P. 73). Further, Richardson (1996) offers a connection between beliefs and actions, “... the perceived relationship between beliefs and actions is interactive. Beliefs are thought to drive actions; however, experiences and reflection on action may lead to change in and/or addition to beliefs" (p. 104). 
Findings from this study support the above arguments that the interaction between beliefs and instruction appears close and direct. Because teachers in the United States have a higher degree of autonomy in their daily practice than teachers do in almost any other country in the world (Kennedy, 1997), and because teachers have a powerful capacity for modifying their classroom practices (Allen, 2002; Prawat, 1992), it is well worth while for teachers in this country to explore possibilities for change, to become more effective as Galbraith (1998) advocates. This study suggests that the teacher reconsider or re-examine his or her own prior assumptions, beliefs, and values about language and language learning (Freeman \& Freeman, 1994; Kagan, 1992; Kennedy, 1997). This might ultimately pave the way for changes in instruction.

One of the participants in this study stated "We need to learn, to adjust" so as to meet students' needs, and another participant remarked "[teaching should be] from theory to practice, and from practice to theory." Their voices should be heard by more teachers from China. This study suggests that we can think of language teachers as learners (Freeman \& Johnson, 1998), and as researchers (Erickson, 1986). (See Figure 18) 
Figure 18 Teachers as Learners

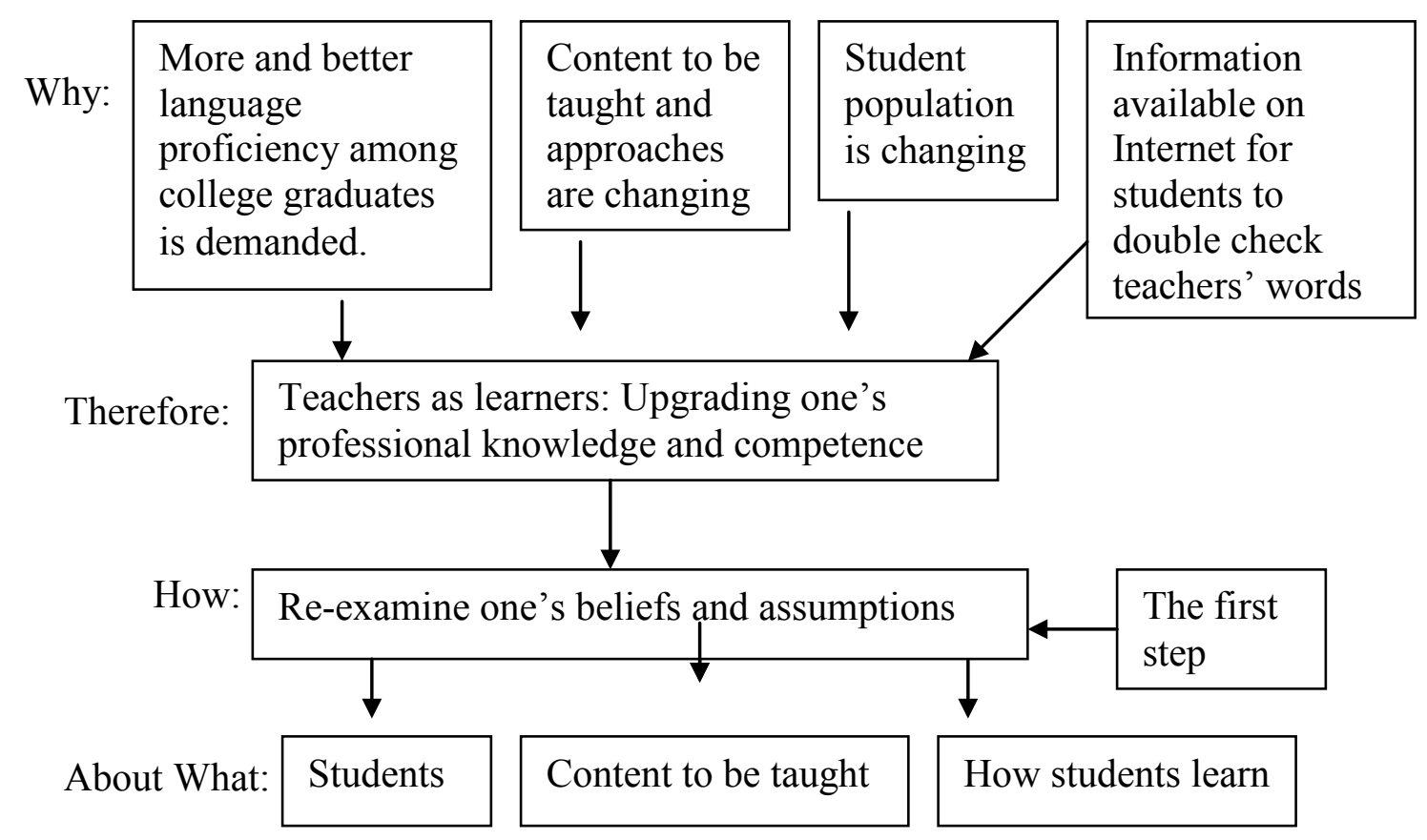

\section{Teachers as Learners of Language Teaching}

Freeman and Johnson (1998) point out that the process of learning to teach is socially negotiated, normative, and lifelong. “... it is built out of and through experiences in social contexts, as learners in classrooms and school, and later as participants in professional programs" (p. 401). Indeed, it is a lifelong learning process to become an effective teacher (Galbraith, 1998) of language, especially for teachers in the 21 century because: 1) An increasingly global economy demands more and better professionals in foreign languages and literatures (e.g., Bollage, 2007; Fischer, 2007; Millman, 2007; MLA, 2007; Oleksak, 2007); 2) Content to be taught and approaches to foreign language teaching are changing in response to social and business requirements; 3) The American student population is changing: This population is remarkably heterogeneous, perhaps more so than in any other country in the world (Kennedy, 1997), 
and the number of non-traditional students with mature social experiences is increasing (Bronte, 1997); and 4) Ample information on the Internet available for students to double check teachers' words. Therefore, what was acceptable in classroom teaching ten years ago might become questionable now. For example, two participants of this study commented that they found little they could adopt or learn from among the methods their own language teacher had used. To catch up with the changing world, Chinese teachers "need to acquire knowledge and competencies not required two decades ago" (Velez-Rendon, 2002, p. 463).

Upgrading Knowledge, and Competence to Apply the Knowledge

Kagan (1992) points out:

Most of a teacher's professional "knowledge" can be regarded more accurately as "belief"... A teacher's knowledge of his or her profession is situated in three important ways: in context (it is related to specific groups of students), in content (it is related to particular academic material to be taught), and in person (it is embedded within the teacher's unique belief system). (pp. 73-74)

Similarly, Freeman and Johnson (1998) believe "Teachers must understand their own beliefs and knowledge about learning and teaching and be thoroughly aware of the certain impact of such knowledge and beliefs on their classroom and the language learners in them" (p. 412). They point out that there are four main factors that influence the process of learning to teach: a person's experiences, the content to be taught, one's students, and classroom life (Freeman \& Johnson).

Findings of this study agree with the above arguments. To upgrade one's professional knowledge, this study suggests that a teacher re-examine his or her beliefs and assumptions about students, content to be taught, and how students learn. 
Re-examining Assumptions about Students

Findings of this study indicated: To understand students, current Chinese teachers can no longer draw themselves as learners according to their own previous schooling (Galbraith, 1998). Furthermore, Phillips and Soltis (2009) point out:

...culture integrates in very complex ways with learning and the processes of schooling more generally. Understanding something about the culturally shaped assumptions, practices, and values of students will enable a teacher to be more effective in promoting learning, but will also make the teacher more sensitive to his or her own deep-seated cultural assumptions and how these might be shaping the attitude that is being adopted towards students who seem to be "different." (Phillips \& Soltis, 2009, p. 64)

Therefore, this study suggests that teachers recognize: a) The trend toward "student-centered pedagogy emphasizing the transfer of power and knowledge from teacher to learner" (Weisser, 2005, p. 30); b) The cultural differences between the American ideological "self" and the Chinese ideological "collective"; and c) The diverse students in one's classroom: a teacher must be ready to learn from them.

Re-examining Beliefs about Content

Galbraith (1998) states that knowledge of content is the basis for the teaching event, and content incorporates identifying certain knowledge, skills, and attitudes to students that result in learning outcomes. Similarly, Grossman et al (as cited in Kagan, 1998) found that English teachers' orientation to English literature influences their goals and methods of instruction; and Wilson and Wineburg (as cited in Kagan, 1998) found similar results with regard to history teachers. Findings of this study likewise indicated that a teacher's particular understanding about Chinese and Chinese teaching determines the nature of his/her instruction. This study emphasizes that it is essential for language 
teachers to recognize the nature of language (Chomsky, 2006), the social characteristics of language (Hymes, 1972; Schieffelin, as cited in Backett, 2009), and the nature of knowledge (Schommer, 1998; Schommer-Aikins, 2004; User, Bryant, \& Johnston, 1997) so as to deepen their understanding about the nature of language teaching (Freeman \& Johnson, 1998; Freeman \& Richards 1996; Gilsan, 1996; Hamp-Lyons \& Condon, 2000; Lange, 2003; the National Standards, 1999, 2006).

\section{Upgrading Assumptions about Learning -- Constructivism}

Findings of this study show that some participants were more prepared to issues about how to teach than how to learn. This phenomenon could be included in the issue that theories about learning have not received enough attention in the practice of language teacher education as Galbraith (1998) states “... since most teachers of adults in the multitude of adult education programs are experts in the content they teach, but usually have little preparation in the instructional process of helping adults learn" (p. 4). Furthermore, Phillips and Soltis (2009) point out:

[Theories of learning] stimulate you to think about learning, about the forms it takes, and about what you, as a teacher, might do to promote it in students. (p. 2) Having an implicit learning theory is different from having explicit theories at hand. Having an implicit theory is limiting; it's nonreflective. You don't know why you're doing what you're doing when you teach, you just do it.... (p. 103)

According to the above arguments by Galbraith (1998), and Phillips and Soltis (2009), the researcher of this study suggests that constructivism, a theory of learning, is necessary for language teachers to learn theoretically about how students learn.

According to Walker (2002), "Constructivism has become a theory of learning that has emerged from a theory of knowing. It is an epistemological concept that draws from 
a variety of fields, including philosophy, psychology, and science” (p. 7).

About 60 years before, John Dewey “challenged prevailing views of learning by suggesting that education is an internal process in which the learner uses prior knowledge and experience to shape meaning and to construct new knowledge" (Walker, 2002, p. 6 ). About 20 years later, Piaget articulated a theory of knowing (Walker). He distinguished four stages in which a child develops cognitive structures: sensorimotor, concrete operations, logical structures, and conceptual reasoning (Phillips \& Soltis, 2009). Piaget viewed learning as the individual's construction and modification of structures for dealing successfully with the world and as they learn certain aspects of logical reasoning. Piaget's ideas have stimulated many subsequent theories of learning. However, the social dimension of learning from Dewey, Vygotsky, Pandura, and other scholars state that learners are embedded in a social network (Phillips \& Soltis). Parents, siblings, teachers, peers, TV, films, and social environments all influence what and how we learn. Salomon and Perkins (as cited in Phillops \& Soltis, 2009) point out “...there is ample evidence to show that individuals' learning is facilitated by others, that meaning is often socially constructed..." (p. 54). For example, Dewey points out:

As a matter of fact every individual has grown up, and always must grow up, in a social medium. His responses grow intelligent, or gain meaning, simply because he lives and acts in a medium of accepted meanings and values. Through social intercourse, through sharing in the activities embodying beliefs, he gradually acquires a mind of his own. (As cited in Phillips \& Soltis, 2009, p. 55)

Vygotsky's (1978) notion of the zone of proximal development (ZPD) is another inquiry in the social cultural theory of mind to recognize the social nature of learning. According to Phillips and Soltis (2009), social constructivism, the social construction of 
knowledge, has aroused great interest among philosophers, sociologists, and others. For educators, constructivism suggests the following principles to enhance student learning:

1. Learning is an active rather than a passive process.

2. Learning is by nature social and is most likely to occur when learners share ideas, inquire, and problem solve together.

3. Learners, to go beyond rote learning, must have opportunities to make sense of new knowledge and create meaning for themselves based on individual and shared experiences.

4. Reflection and metacognition contribute to the construction of knowledge and the process of sense-making.

5. New learning is mediated by prior experience, values, and beliefs. (Lambert \& Szabo, 2002, p. 205)

Equipped with constructivism, a Chinese teacher is armed with learning theories to explore the core of different approaches to foreign language teaching, and to combine effectively the advantages of each approach for instruction. For example, Anton (1999), based on the theory of ZPD, explores learner-centered and teacher-centered discourse in interactive exchanges between teachers and learners in second language classroom. He argues:

Teachers can engage learners in the negotiation of meaning, language forms, and classroom rules by using various discursive moves, and in so doing can also promote learners' active mental participation, which may have a role in L2 [second language] learning. (p. 304)

To end this section, a quote from several educators would re-emphasize the significance of re-examining one's own pedagogical beliefs as the first step to upgrade one's professional knowledge and competence to apply the knowledge:

After entering service, teachers continue to solve instructional problems largely by relying on their own beliefs and experiences (Aston \& Webb, 1986; Hoy, 1969; Rosenholtz, 1989; Smylie, 1989). When teachers do accept information from outside sources (e.g., colleagues or university or inservice courses), they filter it through their own personal belief systems, translating and absorbing it into their unique pedagogies (Berliner, 1987; Carter \& Doyle, 1989). (Kagan, 1992, p. 75) 


\section{Collaborative Professional Development}

According to Chou (2006), teachers of Chinese in the United States come from three fields: Chinese literature, foreign language (usually English), and applied linguistics. Chou comments that teachers with a foreign language or applied linguistics background are short of knowledge about Chinese literature, therefore, they are capable to be "drill instructors" but tend to be limited when teaching a higher level class. Jiang (2007) argues that teachers from these three fields all have offered specific contributions to the development of Chinese teaching in the United States.

Findings of this study show that it is true that teachers of Chinese come from those three fields. Because all the classes observed for this study were lower-level classes (first and second year), no specific data could be drawn from this study to support Chou's (2006) argument about teachers' abilities to teach higher or lower level classes. However, four participants talked about the advantages of learning from co-teachers. Since teachers of Chinese come from a relatively wide range of fields, this researcher assumes that they have more opportunities to acquire knowledge of other fields through interaction with colleagues than teachers of other disciplines (e.g. math). This can be an advantage, because "fellow teachers are the first source of professional help in schools" (Blumberg; Lortie; Sergiobanni \& Staratt; as cited in Zahoric, 1989). This researcher suggests that classroom observation be a direct way to learn from fellow teachers. As this study shows, rich and valuable information can be learned through observing an experienced teacher's classroom instruction, if a serious observer has carefully planned what and how to observe. Figure 19 is an example. 
Figure 19 Seven Areas for Foreign Language Classroom Observation

\begin{tabular}{|c|c|c|}
\hline Area 1 & $\begin{array}{l}\text { Content } \\
\text { delivered }\end{array}$ & $\begin{array}{l}\text { Are language forms and cultural context } \\
\text { both introduced? }\end{array}$ \\
\hline Area 2 & $\begin{array}{l}\text { Instruction } \\
\text { conducted }\end{array}$ & $\begin{array}{l}\text { How are language forms and cultural } \\
\text { context introduced? }\end{array}$ \\
\hline Area 3 & $\begin{array}{l}\text { Methods/ } \\
\text { teaching } \\
\text { strategies }\end{array}$ & $\begin{array}{l}\text { What approaches to foreign language } \\
\text { teaching are adopted? Or, can } \\
\text { characteristics of certain approaches be } \\
\text { recognized? }\end{array}$ \\
\hline Area 4 & $\begin{array}{l}\text { Classroom } \\
\text { assessment }\end{array}$ & $\begin{array}{l}\text { How does the teacher evaluate the learning } \\
\text { results? Yes-no questions? Paper-pencil } \\
\text { quizzes? Mini-sociocultural projects, for } \\
\text { the application of language? }\end{array}$ \\
\hline Area 5 & $\begin{array}{l}\text { Role of } \\
\text { teacher }\end{array}$ & $\begin{array}{l}\text { What role does the teacher play: controller, } \\
\text { manager, expert, facilitator, helper, coordinator, or } \\
\text { partner? }\end{array}$ \\
\hline Area 6 & $\begin{array}{l}\text { Language } \\
\text { used }\end{array}$ & $\begin{array}{l}\text { Which language is more spoken in classroom } \\
\text { activities, the target language or students' first } \\
\text { language? }\end{array}$ \\
\hline
\end{tabular}

Area 7

$$
\begin{aligned}
& \text { Meeting } \\
& \text { student needs }
\end{aligned}
$$

How well does the teacher understand culturally and cognitively diverse students? Any adjustments in specific content, instructional strategies and activities, or assessment strategies?

As discussed in Chapter Four of this paper (See Pedagogical and epistemological beliefs reframing), teachers tend to obtain most of their ideas from actual practices, chiefly from their own and from the practice of fellow teachers (Zahorik, 1987). Evidence indicates that even at the preservice stage, student teachers are more influenced by their cooperating teachers than by their supervisors (Kagan, 1992). Change in one's views of teaching is embedded in collaborative planning and in the 
critiquing of instruction. On the other hand, effective collaborative professional development must be built on the base of individual professional development.

\section{Teacher Training Programs}

If re-examining one's beliefs and assumptions in foreign language teaching works as the first step to upgrade one's professional knowledge and competence in foreign language teaching, the strategy of this conceptual change could be used to good effect in teacher training programs, based on what Kagan (1992) states:

We can assume that preservice candidates, like other kinds of students, probably bring preconceptions and personal beliefs to the study of pedagogy and that these personal beliefs are resistant to change. In fact, studies of preservice teachers have shown that candidates enter programs with well-established beliefs about students and classrooms (Book, byers, \& Freeman, 1983; Feiman-Nemser, McDiarmid, Melnick, \& Parker, 1988; Weinstein, 1989). It is likely that these beliefs have been shaped by the thousands of hours spent in classrooms as students, internalizing models of good and poor teaching (Feiman-Nemser \& Buchmann, 1987;

Tabachnick, \& Zeichner, 1984). (Kagan, 1992, p. 76)

Similarly, Freeman and Johnson (1998) state, "Much of what teachers know about teaching comes from their memories as students, as language learners, and as students of language teaching" (p. 401). These "beliefs and past experiences as learners tend to create ways of thinking about teaching" (p. 401). Therefore, it is crucial to "acknowledge that prior knowledge is a powerful factor in teacher learning in its own right, one that clearly deserves our attention and study if we mean to strengthen and improve, rather than simply preserve and replicate, educational practice" (p. 401).

Indeed, findings of this study demonstrated that the participants' pedagogical beliefs came from the sum of their personal experiences, their understanding of external standards, and their knowledge of Chinese, of linguistics, of culture, and of education. 
These pedagogical beliefs played a vital role in the teachers' decisions about classroom teaching - what to teach and how to teach. Based on this study's findings and theoretical framework, a suggestion is made for teacher training programs.

Teachers' pedagogical beliefs tend to be shaped by six independent variables: Previous learning experiences (in and out of school), subject matter knowledge, pedagogical content knowledge, understanding of external standards, knowledge of educational psychology, and issues of political power and social value. Teachers' pedagogical beliefs influence their thinking about teaching and play a vital role in making decisions for classroom teaching - what to teach and how to teach. These questions of what and how become two dependable variables, derived from teachers' pedagogical beliefs (See Figure 20 and 21).

Schulz (2000) has drawn our attention to the significant relationship between foreign language teaching and education. Similarly, based on the relationship among the six independent variables, teachers' pedagogical beliefs, and the two dependant variables, this study argues that effective foreign language teaching required knowledge and competences to apply the knowledge from three fields (foreign languages and literatures, applied linguistics, and education). These requirements reveal a need for three different types of departments (foreign languages and literatures, applied linguistics, and education) to share the task of training future language teachers. 


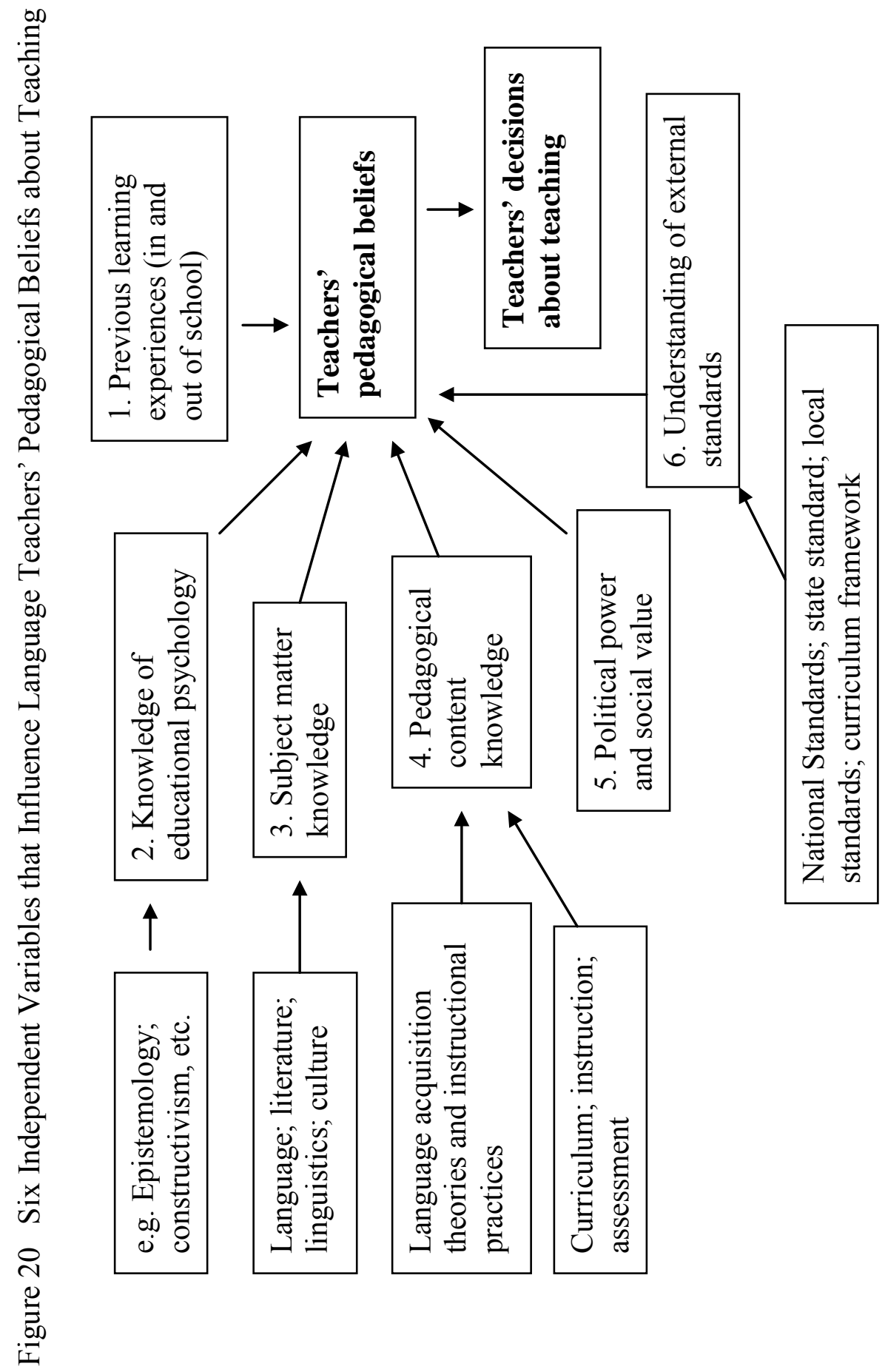




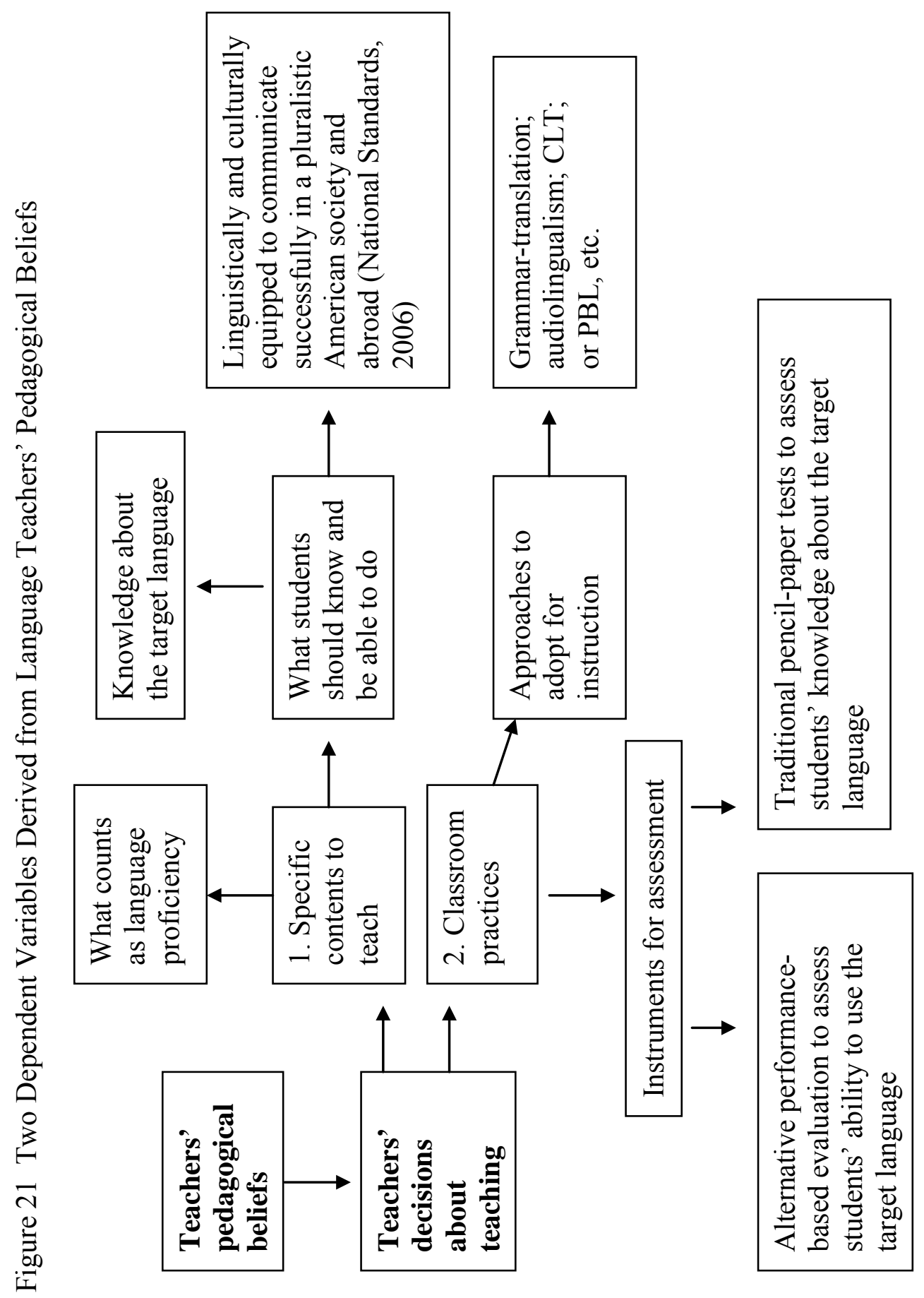




\section{Students of Chinese}

Data collected from the classroom observations for this study show that some students of Chinese seemed not able to recognize the close relationship between learning the Chinese language and (the practice of) Chinese culture. Attending a class taught by a teacher from China is one way to learn something about Chinese school culture. Unawareness of this relationship can cause misunderstandings. For example, two students gave an unpleasant look to the teacher when the latter tried to stop their giggling and reminded them to pay attention to another student's presentation. A few minutes later, the two students giggled again; this time, the teacher said nothing but sighed slightly. But it seemed that the two students did not notice the teacher was looking at them again. This phenomenon showed a cultural gap between the students and the teacher. Under the influence of the traditional Chinese educational philosophy, such as “教不严, 师之惰 Jiao bu yan, shi zhi duo” (“Lax discipline means a lazy teacher"), most teachers in China would not allow a single student, during class meetings, to do something that does not involve learning activities. It would seem that the two students were still retaining cultural values based on "the long-standing Western individualistic/liberal tradition" (Phillips \& Soltis, 2009, p. 53). Such cultural differences between the American ideological "self" and the Chinese ideological "collective" could signal a major difference between classrooms in China and in the United States.

Some comments from participants about student learning supported the above assumption drawn from classroom observation, for example, "[some] students pay more 
attention to themselves", or "the bottle is half full" instead of "half empty." In the previous section of this chapter, this researcher suggested that teachers from China adjust to cultural differences in their classrooms; in this section, the researcher would like to suggest that students likewise adjust their attitudes towards their teachers' Chinese teaching style, and clarify their own goals for learning Chinese.

\section{A More Comprehensive Goal for Learning Chinese}

Language learning is not learning a set of rules, but is the acquisition of linguistic as well as sociocultural knowledge (Schieffelin \& Ochs as cited in Beckett \& Miller, 2006). According to this language socialization view, we can assume that, in a Chinese classroom, the language should be treated both as a focus of study and a medium for studying Chinese culture. If bodies of knowledge (e.g. history, science, literary canon, etc.) are all social products (Phillips \& Soltis, 2009), the Chinese language and culture can be considered social products that have been developing for about 5,000 years. Up until now, surface aspects of Chinese culture can be recognized by most foreigners who are interested in China. However, the underlying values of the culture are much more complicated, complex, and challenging for a foreigner to understand or even to see.

When a student chooses to learn Chinese, whether it is because of the attraction of business in China, or martial acts, calligraphy, etc., these things are all at the surface level of Chinese culture. But once that student enters a class taught by a serious teacher from China, the underlying values of the culture will emerge continuously through the teacher's teaching style, and "culture shocks" could appear in the classroom, such as the phenomenon mentioned at the beginning of this section. The specific process can be 
unpredictable, because Chinese teaching styles are not all the same: teachers from China demonstrate a great range of behaviors, depending on their particular understanding and appreciation of Chinese philosophy and values, as mentioned by Paige (2003) who notes that members in the target culture community "display a great range of behaviors, and different levels of attention to the guiding value orientations" (Paige, et. al., 2003, p. 176).

Adjusting Attitudes towards a Chinese Teaching Style

If a student of Chinese has learned about language socialization (Schieffelin \& Ochs, as cited in Beckett \& Miller, 2006), and about culture as the core for foreign language learning, he/she will tend to treat the language not only as a focus of study but also a medium for studying Chinese culture. To learn the target language better and faster, it is not necessary to wholly embrace or be assimilated by the target culture, but at least one must try to understand or respect the differences between one's own culture and the target culture is helpful during the learning process. By the same token, resistance to understanding those differences between one's own culture and the target culture is likely to slow down one's learning, or could prevent one from reaching his/her learning goal, because: “... the person who learns language without learning culture risks becoming a fluent fool” (Bennett, et al, 2003, p. 237). When a student learns Chinese outside China, the teacher's teaching style is one way for him/her to learn about Chinese culture, and the classroom is a place to develop his/her intercultural competence (Bennett, Bennett, \& Allen). Therefore, this study suggests that students of Chinese be 
encouraged to adjust their attitudes towards a Chinese teaching style; this will become a starting point to narrow the gap between one's own culture and the target culture.

Assumptions and Limitations

\section{Assumptions}

As in the field of research known as teacher cognition reveals " ... teaching can not be characterized simply as behaviors that were linked to thinking done before and during the activity (known as preactive and interactive decisions) but rather that the thought process of teaching included a much wider and richer mental context" (Freeman \& Johnson, 1998, p. 400). The researcher of this study believed that classroom teaching connected with at least four dimensions: Teacher, student, learning environment, and assessment (see Figure 22). 


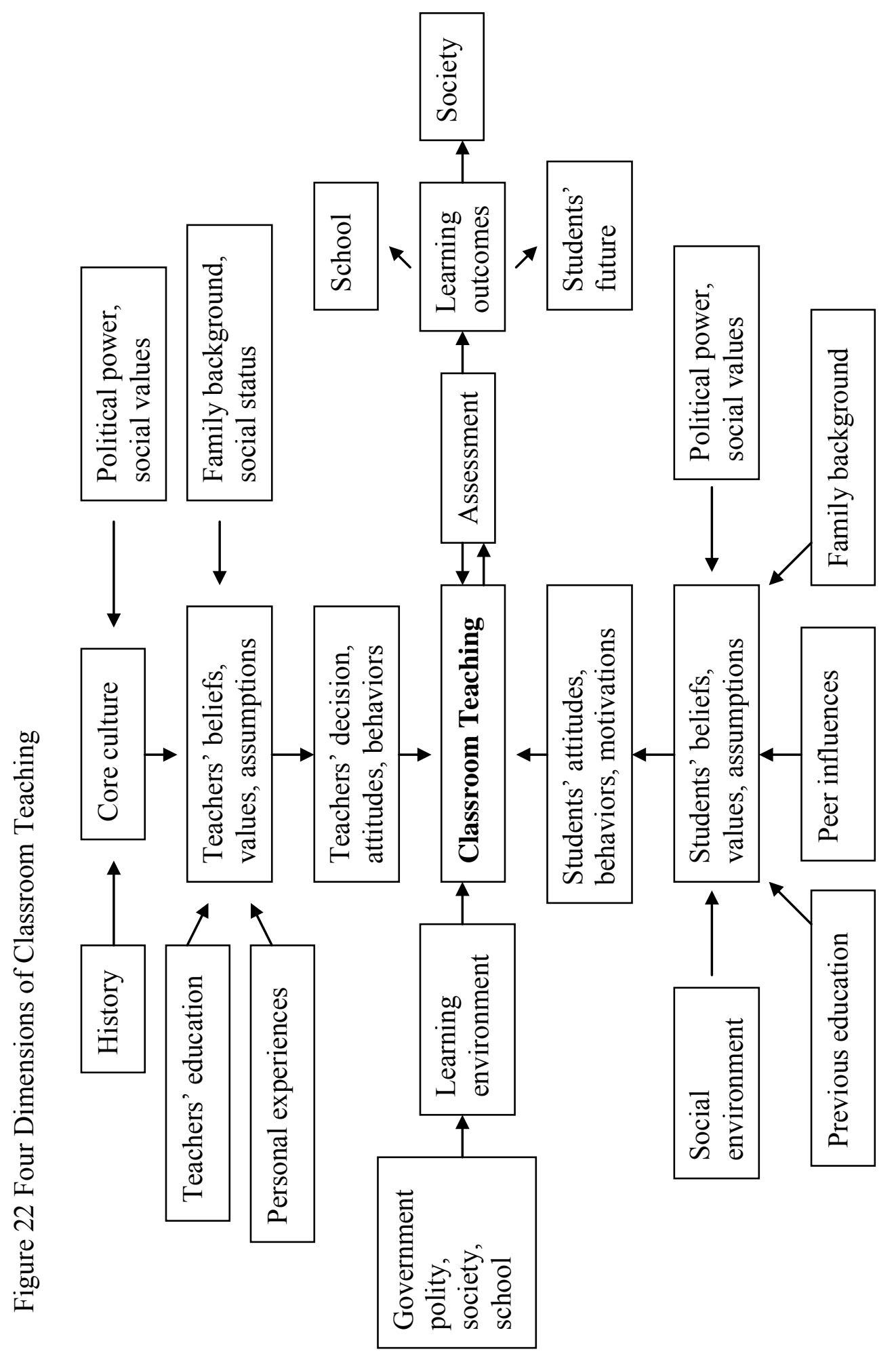




\section{Limitations}

This study presented some limitations that might restrict the extent of generalizations that could be made from the findings: 1) The study focused on only one of the four dimensions of classroom teaching (See figure 20): Teachers' beliefs, values, assumptions; teachers' decisions, attitude, behaviors. The other three dimensions (learning environment, students, and assessment) related to classroom teaching were not covered. 2) The sample size was relatively small. Some factors might exist but not be detectable from five participants; 3) To narrow the scope of the study, the survey focused on the college level; findings might not be extendable to K-12 schools; and 4) All the information was provided by teachers who were born and grew up in China, therefore, traditional Chinese philosophy tended to affect their beliefs (as with many foreign language teachers born in the target country, whose native culture can likewise impact their beliefs). However, the results of this study were reported honestly, and may help fill in one area of the puzzle.

\section{Conclusion}

As we enter the $21^{\text {st }}$ century,

Challenges swirl around us as language educators. From all corners we are asked to be accountable. The parents of students in elementary and middle school language programs want to know how their children are doing in our classrooms. High school and post-secondary students want to know how the content of our language courses will develop their proficiency and help their careers. The public want to know how their schools are doing compared to those in other communities. Employers want to know if new graduates are ready for the world of work. In such an era of accountability, research is essential. Research must tell us what works best and how we can be the most effective as teachers. (Sandrock, 2006, p. 549) 
Indeed, foreign language has become a critical factor that impacts the future of a country, as in the case of the critical languages and the United States. The U.S. Government and American business need people who can conduct high-level negotiations in Chinese and other critical languages (Bollage, 2007; Fischer, 2007; Millman, 2007). When students learn a foreign language far away from the target country, school teachers become a chief academic resource who can help them gain language proficiency and intercultural competence. If key instructional activities are likely to become the vehicles that translate teacher beliefs into classroom instruction (Kan, 1992), and if teachers are indeed the most powerful agent for modifying classroom practices (Prawat, Richard \& Anders; Tedick \& Walker as cited in Allen, 2002), research is needed into the development of foreign language teachers' pedagogical beliefs and the relationship between those beliefs and their teaching. This study was designed specifically to investigate how Chinese teachers' pedagogical beliefs influence their decisions about classroom teaching. The results of this study suggest: 1) Personal learning experiences affect teachers, both as a factor in how teachers' pedagogical beliefs change, and as a guide to their decisions about classroom instruction; 2) Gaining competence in foreign language teaching - including knowledge of content to be taught and knowledge about one's students - is a process that lasts throughout a teacher's career; and 3) The task of training future language teachers should be shared by three different types of departments (foreign languages and literatures, applied linguistics, and education). 
In addition, this study has been of personal benefit to the researcher, and in precisely these ways. During her twenty years of foreign language teaching, she has experienced two educational systems, the Chinese and the American. First, teaching English to Chinese students, then teaching Chinese to American students; moving from a belief in absolute knowledge to a belief in constructivism; originally following the outward form of an approach to foreign language teaching, then later wondering how to grasp the nature of different approaches, she, too, is seeking a way to become an effective foreign language educator in the $21^{\text {st }}$ century. 


\section{REFERENCES}

Allen, L. Q. (2002). Teachers' pedagogical beliefs and the standards for foreign language learning. Foreign Language Annals. 35 (5), 518-527.

Angrosino M. V., \& Mays de Perez, K. A. (2000). Rethinking observation. In N. K. Denzin \& Y. S. Lincoln (Eds.), Handbook of qualitative research (pp. 673-702). CA: Thousand Oaks: Safe Publications, Inc.

Anton, M. (1999). The discourse of a learner-centered classroom: Sociocultural perspectives on teacher-learner interaction in the second-language classroom. Modern Language Journal, 83, iii, 303-318.

Aratani, L. (2006, August 26).With a changing world comes an urgency to learn Chinese. Washington Post. p. A01

Aronoff. M., \& Rees-Miller, J. (Eds.). (2001). The handbook of linguistics. Malden, MA: Blackwell

Atkinson, P., \& Silverman, D. (1997). Kundear's Immortality: The interview society and the invention of self. Qualitative Inquiry, 3, 304-325

Bachelor's, master's and doctor's degrees conferred by degree-granting institutions, by sex of student and field of study: 2003-04. National Center for Education Statistics. Retrieved October 29, 2008 from http://nces.ed.gov/programs/digest/d05/tables/dt05 252.asp

Bachelor's, master's and doctor's degrees conferred by degree-granting institutions, by sex of student and field of study: 2005-06. National Center for Education Statistics. Retrieved October 29, 2008 from http://nces.ed.gov/programs/digest/d07/tables/dt07 265.asp

Beckett, G. H. \& Miller, P. C. (Eds.). (2006). Project-based second and foreign language education. Greenwich, CT: Information Age Publishing.

Belenky, M.F., Clinchy, B.M., Goldberger, N.R., \& Tarule, J. M. (1986). Women's ways of knowing: The development of self, voice, and mind. New York: Basic Books.

Banks, A. \& Banks, S. P. (1991). Unexpected barriers: The role of translation in interpersonal communication. In S. Ting-Toomey (Ed.), Cross-cultural interpersonal communication. (pp. 171-185). Park, CA: Sage Publishing, Inc.

Bennett, J. M., Bennett, M. J., \& Allen, W. (2003). Developing intercultural competence in the Language classroom. In D. L. Lange \& R. M. Paige (Eds.), Culture as the core (pp. 19-35). Greenwich, CT: Information Age Publishing.

Berg. B. (2004). Qualitative research methods for the social sciences ( $5^{\text {th }}$ edition). Boston: Allyn and Bacon.

Bernhardt, E., \& Hammadou, J. (1987). A decade of research in foreign language teacher education. Modern Language Journal, 71, 289-299.

Bollag. B., \& Field, K. (2006). Foreign students: Uncle Sam wants you. (2006, January 20). The Chronicle of Higher Education. Retrieved October 30, 2008, form http://chronicle.com/weekly/v52/i20/20a04501.htm

Bollag, B. (2007). A failure to communicate. (2007, April 27). The Chronicle of Higher Education. Retrieved November 2, 2008, from http://chronicle.com/weekly/v53/i34/34a02401.htm 
Bollag, B. (2007). MLA report calls for transformation of foreign-language education. (2007, May, 24). The Chronicle of Higher Education. Retrieved November 7, 2008, from http://chronicle.com/weekly/v53/i40/40a01202.htm

Bollag, B. (2007). Foreign-language departments bring everyday texts to teaching. (2007, November 8). The Chronicle of Higher Education. Retrieved November 1, 2008, from http://chronicle.com/weekly/v54/i11/11a00103.htm

Bolman, L. G. \& Deal, T.E. (2003). Reframing organizations: Artistry, choice, and leadership ( $3^{\text {rd }}$ ed). San Francisco: Jossey-Bass

Bronte, L., (1997, May/Jun/Jul/Aug). Learning to change. Adult Learning, 11-13.

Brookfield, S. D. (1999, January-February). What is college really like for adult students? About Campus, 10-15.

Brookhart. S. \& Freeman. D. (1992). Characteristics of entering teacher candidates. Review of Educational Research. 62, 37-60

Castro, O. (2006). Learning Styles --- How making too many "wrong mistakes" is the right thing to do: a response to Sparks. Foreign Language Annals. 39 (3), 529-535.

Castro, O., \& Peck, V. (2005). Learning styles and foreign language learning difficulties. Foreign Language Annals, 38 (3), 401-409.

Celce-Murcia, M. (2001). Teaching English as a second or foreign language ( ${ }^{\text {rd }}$ Ed.). Boston: Heinle \& Heinle / Thomson Learning.

Collentine, J., \& Freed, B. F. (2004). Learning context and its effects on second language acquisition. Studies in Second Language Acquisition. 26 (2), 153-171. New York: Cambridge University Press.

Chomsky, N. (2000). The architecture of language. New York: Cambridge University Press.

Chomsky, N. (2006). Language and mind. New York: Cambridge University Press.

Chou, C. (2006). Letters from readers. Journal of the Chinese Language Teachers Association. 41, (1), i-v.

Clinchy, B. M. (2000). Toward a more connected vision of higher education. New Directions For Teaching And Learning, 82, 27-35.

Collentine, J., \& Freed, B. F. (2004). Learning context and its effects on second language acquisition. Studies in Second Language Acquisition. 26 (2), 153-171. New York: Cambridge University Press.

Cummins, J. (2001). Negotiating identities: Education for empowerment in a diverse society $\left(2^{\text {nd }} \mathrm{Ed}\right)$. Los Angeles: California Association for Bilingual Education.

Creswell, J. W. (2008). Educational Research Planning, conducting, and evaluating quantitative and qualitative research ( $3{ }^{\text {rd }}$ ed.). Upper Saddle River, N.J.:

Pearson/Merrill Prentice Hall.

Dewey, J. (1916). Democracy and education. New York: The Free Press.

Denzin, N. K., \& Lincoln, Y. S. (Eds.). (2000). Handbook of qualitative research. Thousand Oaks, CA: Sage Publications, Inc.

Dinklage, K. T. (1971). Inability to learn a foreign language. In G. Blaine \& C. MacArthur (Eds.), Emotions of the student (pp. 185-206). New York: AppletonCentury-Crofits.

Drikx, J.M. (2001) The power of feelings: emotion, imagination, and the construction of 
meaning in adult learning. In New Directions for Adult and Continuing Education, 89, San Francisco: Jossey-Bass.

Ehman, M. E. (1996). Understanding second language learning difficulties. Thousand Oaks, London, New Delhi: Sage Publications.

Elias, J., \& Merriam, S. (1995). Philosophical foundations of adult education ( ${ }^{\text {nd }}$. Ed.). Malabar, FL: Krieger.

Ellis, R. (1994). The study of second language acquisition. Oxford, UK: Oxford University Press.

Ellis, R. (1997). SLA research and language teaching. Oxford, UK: Oxford University Press.

Erickson, F. (1986). Qualitative methods in research on teaching. In M. C. Wittrock (Ed.), Handbook of Research on Teaching ( ${ }^{\text {rd }}$ Ed) (pp. 119-161). New York: Macmillan Publishing Co.

Fairclough, M. (2006). Language placement exams for heritage speakers of Spanish: Learning from students' mistakes. Foreign Language Annals. 39 (4), 595-617.

Field, K. (2006). Bush proposes \$114-million for training in 'critical' languages. The Chronicle of Higher Education. (2006, January, 6). Retrieved January 15, 2009, from http://chronicle.com/daily/2006/01/2006010601n.htm

Fisher, K. (2008). New report reveals missed results in colleges' efforts at international education. The Chronicle of Higher Education. (2008, May 30). Retrieved April 2, 2009, from http://chronicle.com/weekly/v54/i38/38a02401.htm

Fontana, A., \& Frey, J.H. (2000). The interview from structured questions to negotiated text. In N. K. Denzin \& Y. S. Lincoln (Eds.), Handbook of qualitative research (pp. 645-672). Thousand Oaks, CA: Sage Publications, Inc.

Foreign Language Teacher Standards Writing Team (2002, August 1). Program standards for the preparation of foreign language teachers.

Foreign languages and higher education: New structures for a changed world. Modern Language Association (2007, May). Retrieved November 7, 2008, from http://www.mla.org/pdf/forlang news pdf.pdf

Freeman, D. E., \& Freeman, Y. S. (1994). Between worlds: Access to second language acquisition. Portsmouth, NH: Heinemann

Freeman, D., \& Richards, J. (Eds.) (1996). Teacher learning in language teaching. New York: Cambridge University Press.

Freeman, D., \& Johnson, K. (1998). Reconceptualizing the knowledge-base of language teacher education. TESOL Quarterly, 32 (3), 397-417.

Freire, P. (c2000). Pedagogy of the oppressed. New York: the Continuum International Publishing Group. Ltd

Furman, N., Goldberg, D., \& Lusin, N. (2007). Enrollments in languages other than English in United States institutions of higher education, Fall 2006. Modern Language Association (13 November 13, 2007). Retrieved January 29, 2009, from http://www.mla.org/pdf/06enrollmentsurvey final.pdf

Galbraith, M. W. (Eds.). (1998). Becoming an effective teacher of adults. In M. W. Galbraith (Ed.), Adult learning Methods ( $2^{\text {nd }}$ Ed., pp. 3-19). Malabar, FL: Krieger Publishing Co. 
Glisan, E. W. (1996). A collaborative approach to professional development. In R. C. Lafayette (Ed.), National standards: A catalyst for reform (pp.57-95). Lincolnwood, IL: National Textbook.

Given, L.M. (2008). The sage encyclopedia of qualitative research methods. Thousand Oaks, CA: Sage Publications, Inc.

Good, T.L. \& Brophy, J.E. (1987). Looking in classrooms. New York: Harper \& Row Hamp-Lyons, L. (1998). Ethical test preparation practice: the case of the TOEFL. TESOL Quarterly, 32, 2, 329 - 337.

Hamp-Lyons, L., \& Condon, W. (2000) Assessing the portfolio, Cresskill, NJ: Hampton Press, Inc.

Handy, O. (2001). Teaching language in context. Stamford, CT: Heinle \& Heinle. Holstrin, J. A., \& Gubrium, J. F. (1995). The active interview. Thousand Oaks, CA: Sage. Howard, J. (2007). Enrollments in Foreign-Language Courses Continue to Rise. The Chronicle of Higher Education (November 23, 2007). Retrieved November 2, 2008, from http://chronicle.com/weekly/v54/i13/13a01301.htm

Houston, W. R. (Ed.) (1990). Handbook of research on teacher education. New York: Macmillan.

Hymes. D. H. (1972). On communicative competence. In J. B. Pride \& J. Homes (Eds.) Sociolinguistics (pp. 269-293). New York: Penguin Books.

Jarvis, P. (1995). Adult and continuing education. New York: Routledge.

Jiang, M. 蒋冕华, (2007). Letters from readers. Journal of the Chinese Language Teachers Association, 42, (1), iii-viii.

Jones, W. T. (1990). Perspectives on ethnicity. New Directions for Student Services, $51,59-72$.

Kagan, D. M. (1992). Implications of research on teacher beliefs. Educational Psychologist, 27 (1), 65-90.

Kane, R., Sandretto, S. \& Heath, C. (2002). Telling Half the Story: A Critical Review of Research on the Teaching Beliefs and Practices of University Academics. In Review of Educational Research, 72, 2, 177-228.

Kempson, R. (2001). Pragmatics: Language and communication. In M. Aronof \& J. Rees-Miller (Eds.), The handbook of linguistics (pp. 394-427). Malden MA: Blackwell Publisher Inc.

Kennedy, M.M. (1997). The connection between research and practice. Educational Research, 26, 4-12.

Kennedy, T. J. (2006). Language learning and its impact on the brain: Connecting language learning with the mind through content-based instruction. Foreign Language Annals, 39 (3), 471-486.

King, P. K., \& Kitchener, K.S. (2004). Reflective judgment: Theory and research on the development of epistemic assumptions through adulthood. Educational Psychologist, 39 (1), 5-18.

Kolb, D. A. (1981). Learning styles and disciplinary differences. In A. W. Chickering \& Associates (Eds.), The modern American college: Responding to the realities of diverse students and a changing society (pp.127-137). San Francisco: Jossey-Bass. 
Kramsch, C. (2003). Teaching language along the cultural faultline. In D. L. Lange \& R. M. Paige (Eds.), Culture as the core (pp. 19-35). Greenwich, CT: Information Age Publishing.

Krashen, S. (1982). Principles and practice in second language acquisition, New York: Pergamon Press.

Krashen, S. (1985). Inquiries and insights. Haywood, CA: Alemany Press

Kuhlmann, A. (1992). Collaborative research among the Kickapoo tribe of Oklahoma. Human Organization, 51, 274-283

Lange, D.L. (2003). Implications of theory and research for the development of principles for teaching and learning culture in second language classrooms, In D. L. Lange \& R. M. Paige (Eds.), Culture as the core (pp. 271-336). Greenwich, CT: Information Age Publishing.

Lambert, L. (2002). Toward a deepened theory of constructivist leadership. In L. Lambert, D. Walk, D. P. Zimmerman, J. E. Cooper, M. D. Lambert, M.E. Gardner, et al (Eds.), The constructivist leader ( $2^{\text {nd }}$ Ed., pp. 34-62). New York: Teachers College Press.

Lasley, T. J., \& Matczynski, T. J. (1997). Strategies for teaching in a diverse society. Belmont, CA: Wadsworth Publishing.

Liebowitz, R. D. ( 2006). What American must do to achieve competence. (2006, March 24). The Chronical Review. Retrieved November 1, 2008, from http://chronicle.com/weekly/v52/i29b01001.htm

Lincoln, Y. S., \& Guba, E. G. (1985). Naturalistic inquiry. Newbury Park, CA: Sage Publications, Inc.

Lincoln, Y. S., \& Guba, E. G. (2000). Paradigmatic controversies, contradictions, and emerging confluences. In N. K. Denzin \& Y. S. Lincoln (Eds.) Handbook of qualitative research (pp. 163-188). Thousand Oaks, CA: Sage Publications, Inc.

Lofland, J. (1971). Analyzing social settings: A guide to qualitative observation and analysis. Belmont, CA: Wadsworth.

Lortie, D. (1975). School teachers: A sociological study. Chicago IL: University of Chicago Press.

Marshall, C., \& Rossman G. (1999). Designing qualitative research ( ${ }^{\text {rd }}$ Edition). Thousand Oaks, CA: Sage Publications.

Marshall, C., \& Rossman, G. (2006). Designing qualitative research. (4 ${ }^{\text {th }}$ Edition). Thousand Oaks, CA: Sage Publications.

Matsumoto, V. (1996). Reflections on oral history: Research in a Japanese American community. In D. L. Wolf (Ed.), Feminist dilemmas in fieldwork (pp. 160-169). Boulder, CO: Westview.

Maxwell, J. A. (2005). Qualitative research design. Thousand Oaks, CA: Sage Publications.

Merriam, S. B. (1998). Qualitative research and case study applications in Education. San Francisco, LA.: Jossey-Bass Publishers

Mezirow, J. (2000) Learning to think like an adult: core concepts of transformation theory. In J. Mezirow (Ed.) Learning as transformation: critical perspectives on a theory in progress / Jack Mezirow and Associates. San Francisco: Jossey-Bass. 
Miles, M. B., \& Huberman, A.M. (1994). Qualitative data analysis: An expended source-book ( $2^{\text {nd }}$ Ed.). Thousand Oaks, CA: Sage Publications.

Miller, J. (2001). (Ed.). The Handbook of Linguistics. Malden, MA: Blackwell Publishers Inc.

National Standards in Foreign Language Education Project ( $3^{\text {rd }}$ Ed., 2006). Standards for foreign language learning in the $21^{\text {st }}$ century. Lawrence, KS: Allen Press, Inc.

Nieto, S. (2002). Language, culture, and teaching. Mahwah, NJ: Lawrence Erlbaum Associates publishers.

Paige, R. M., Jorstad, H. L., Siaya, L., Klein, P., \& Colby, J. (2003). Culture learning in language education. In D. L. Lange \& R. M. Paige (Eds.), Culture as the core (pp. 173-236). Greenwich, CT: Information Age Publishing.

Palmar, P. (1997, November-December). Teaching and learning in community. About Campus, 4-13

Palmer, P. (1998). The courage to teach: Exploring the inner landscape of a teacher's life. San Francisco: Jossey-Bass.

Patton, M.Q. (1985, April). Quality in qualitative research: Methodological principles and recent developments. Invited address to Division J of the American Educational Research Association, Chicago.

Patton, M. Q. (1990). Qualitative evaluation methods ( $2^{\text {nd }}$ ed.) Thousand Oaks, CA: Sage.

Philips, D. C. (2004). The good, the bad, and the ugly: The many faces of constructivism. Educational Researcher 24 (7), 5-12.

Phillips, D. C. \& Soltis, J. F. (2004). Perspectives on learning ( $3^{\text {rd }}$ ed). NY: Teachers College Press.

Phillips, D. C. \& Soltis, J. F. (2009). Perspectives on learning ( $5^{\text {th }}$ ed). NY: Teachers College Press.

Pratt, D. D. (1998). Five perspectives on teaching in adult higher education. Malabar, FL: Krieger Publishing Co.

Punch, M. (1994). Politics and ethics in qualitative research. In N.K. Denzin \& Y. S. Lincoln (Eds.), Handbook of qualitative research (pp. 83-97). Thousand Oaks, CA: Sage.

Prawat, R. S. (1992). Teachers' beliefs about teaching and learning: A constructivist perspective. American Journal of Education, 100, 354 - 395.

Ratcliffe, J.W. (1983). Notions of validity in qualitative research methodology. Knowledge: Creation, diffusion, utilization. 5 (2), 147-167.

Redden, E. (2007). More students, more languages. Inside Higher Education. Retrieved November 11, 2008, from http://www.insidehighered.com/2007/11/14/languages

Resnick, L. B., \& Resnick, D. P. (1991). Assessing the thinking curriculum: New tools for educational reform. In B. R. Gifford \& M. C. O’Connor (Eds.), Changing Assessments: Alternative views of aptitudes, achievement and instruction. Boston: Kluwer.

Richard, R. Day. (1990). Teacher observation in second language teacher education. In Richards, J. C. \& Nunan, D. (Eds.) Second language teacher education. (pp. 43 61). New York: Cambridge University Press. 
Richardson, V. (1996). The role of attitudes and beliefs in learning to teaching. In J. Sikula (Ed.), Handbook of research on teacher education (2 ${ }^{\text {nd }}$ Ed., pp. 102-119). New York: Association of Teacher Education.

Ryan, G. W., \& Bernard, H. R. ( 2000). Data management and analysis methods. In N. K. Denzin \& Y. S. Lincoln (Eds.), Handbook of qualitative research (pp. 769-802). CA: Thousand Oaks: Sage Publications, Inc.

Sandrock, P. (2006). President's message. Foreign Language Annals, 39, 4, 549.

Sato, K., \& Kleinsasser, R. C. (1999). Communicative language learning (CLT): practical understanding. The Modern Language Journal, 83, 494-517.

Scarcella, R. C., Andersen, E. S., \& Krashen, S. D. (Eds.). (1990). Developing communicative competence in a second language. New York: Newbury House Publishers.

Seelye, H. N. (1993). Teaching Culture. Lincolnwood, Illinois: National Textbook Company.

Schatzman, L., \& Strauss, A. (1973). Field research: Strategies for a natural sociology. Englewood Cliffs, NJ: Prentice Hall.

Schommer-Aikins, M. (2004). Explaining the epistemological belief system: introducing the embedded systemic model and coordinated research approach. Educational Psychologist, 39(1), 19-29.

Schommer, M. (1998). The role of adults' beliefs about knowledge in school, work, and everyday life. In C. A. Santa \& T. Pourchot (Eds.), Adult learning and development: Perspectives from educational psychology. London: Launce Erlbaum and Associates.

Schommer-Aikins, M. (2004). Explaining the epistemological belief system: Introducing the Embedded systemic model and coordinated research approach. Educational Psychologist. 39 (1), 19-29.

Schulz, R.A. (2000). Foreign language teacher development: MLJ perspectives - 19161999. The Modern Language Journal. 84, 495-522.

Schwandt, T. A. (2007). The sage dictionary of qualitative inquiry. Thousand Oaks, CA: Sage Publications, Inc.

Shrum, J. L., \& Glisan, E. W. (2005). Teacher's handbook: Contextualized language instruction ( $3^{\text {rd }}$ Ed.). Boston: Heinie.

Silverman, D. (1997b). Towards an aesthetics of research. In D. Silverman (ed.), Qualitative research: Theory, method and practice (pp. 230-253). London: Sage.

Stake, R. (2000). Case studies. In N. Denzin \& Y. Lincoln (Eds.), Handbook of qualitative research. Thousand Oaks, CA: Sage Publications, Inc.

Stark, J. S., \& Lattuca, L. R. (1997). Shaping the college curriculum: Academic plans in action. Meedham Heights. NA: Allyn and Bacon.

Swain, M. (1995). Three functions of output in second language learning. In G. Cook and B. Seidlhofer (Eds.) Principle and Practice in Applied Linguistics (pp. 125144). Oxford: Oxford University Press.

Taylor, K., Marienau, C. S., \& Fiddler, M. (2000). Developing Adult learners. San Francisco: Jossey-Bass. 
Usher, R., Byant, I., \& Johnston, R. (1997). Adult education and the postmodern challenge. New York: Rutledge.

Velez-Rendon, G. (2002). Second language teacher education: A review of the literature. Foreign Language Annals. 35 (4), 457-527.

Vygotsky, L. S. (1978). Mind and society: The development of higher psychological processes. Cambridge, MA: Harvard University Press.

Vygotsky, L. S. (1986). Thought and language. Cambridge, MA: MIT Press.

Walker, D. (2002). Constructivist leadership: standards, equity, and learning - weaving whole cloth from multiple strands. In L. Lambert, et al (Eds.), The constructivist leader $\left(2^{\text {nd }}\right.$ Ed. pp. 1-33). New York: Teachers College Press.

Wasley, P. (2008). MLA report on foreign-language education continues to provoke debate. (2008, March 14). The Chronicle of Higher Education. Retrieved November 1, 2008, from http://chronicle.com/weekly/v54/i27/27a01201.htm

Welles, E. (2004). Foreign language enrollments in United States institutions of higher education, fall 2002. ADFL Bulletin 35(2-3), 7-26. Retrieved January 29, 2009 from http://www.adfl.org/resources/enrollments.pdf

Wilbur, M. L. (2007). How foreign language teachers get taught: Methods of teaching the methods course. Foreign Language Annals, 40 (1), p. 79-101.

Wilkerson, C. (2006). College Faculty perceptions about foreign language. Foreign Language Annals, 39 (2), 310-319.

Wolcott, H.F. (1994). Transforming qualitative data: Description, analysis, and interpretation. Thousand Oaks, CA: Sage.

Wolf, D. L. (1996). Situating feminist dilemmas in field work. In D. L. Wolf (Ed.), Feminist dilemmas in fieldwork (pp. 1-55). Boulder, CO: Westview.

Woods, P. (1987). Life histories and teacher knowledge. In J. Smyth (Ed.). Educating teachers: Changing the nature of pedagogical knowledge (pp. 121-136). New York: Falmer Press.

Zahorik, J. A. (1987). Teachers' collegial interaction: An exploratory study. The Elementary School Journal. 87, 385-396. 


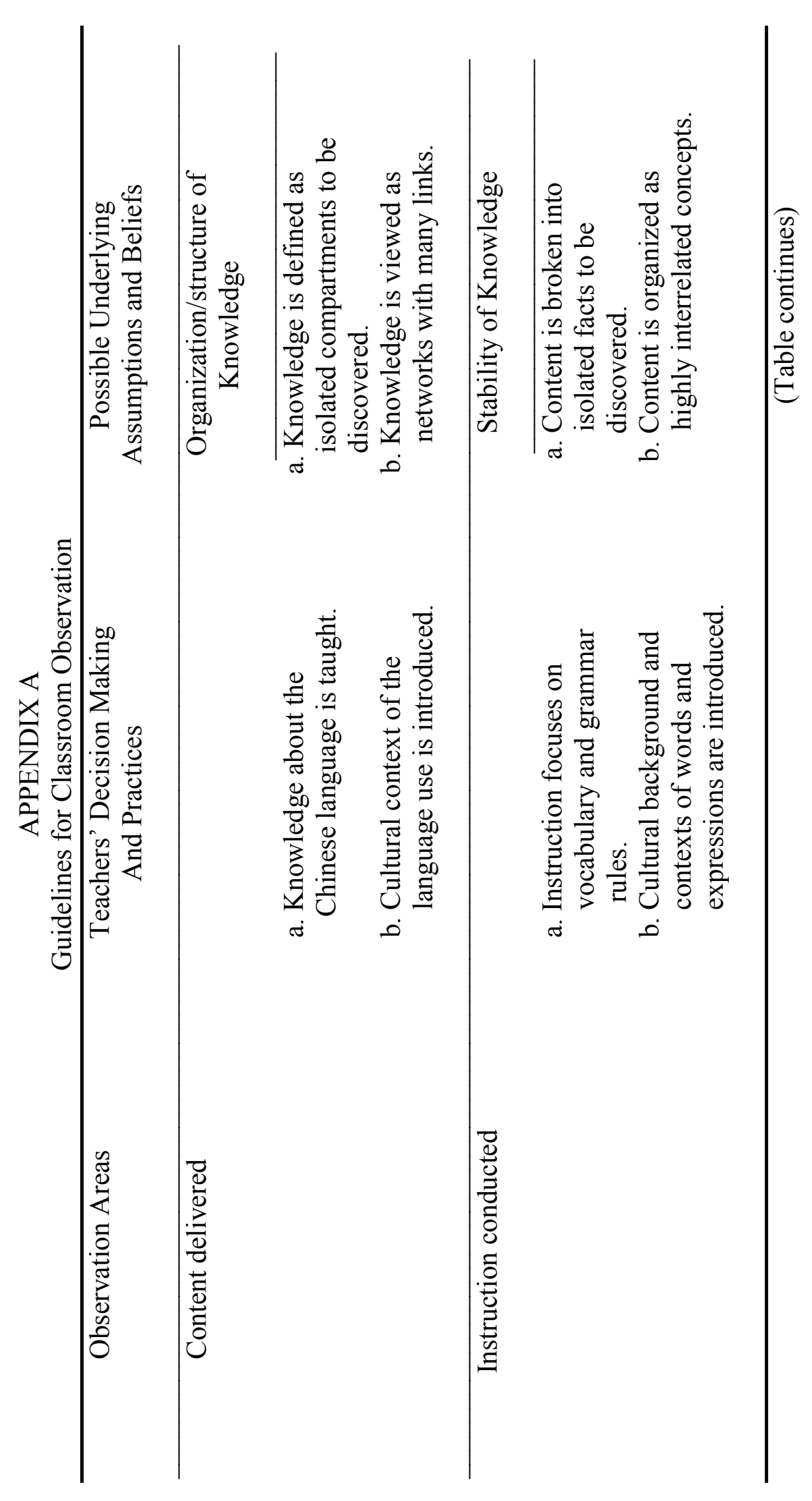

215 


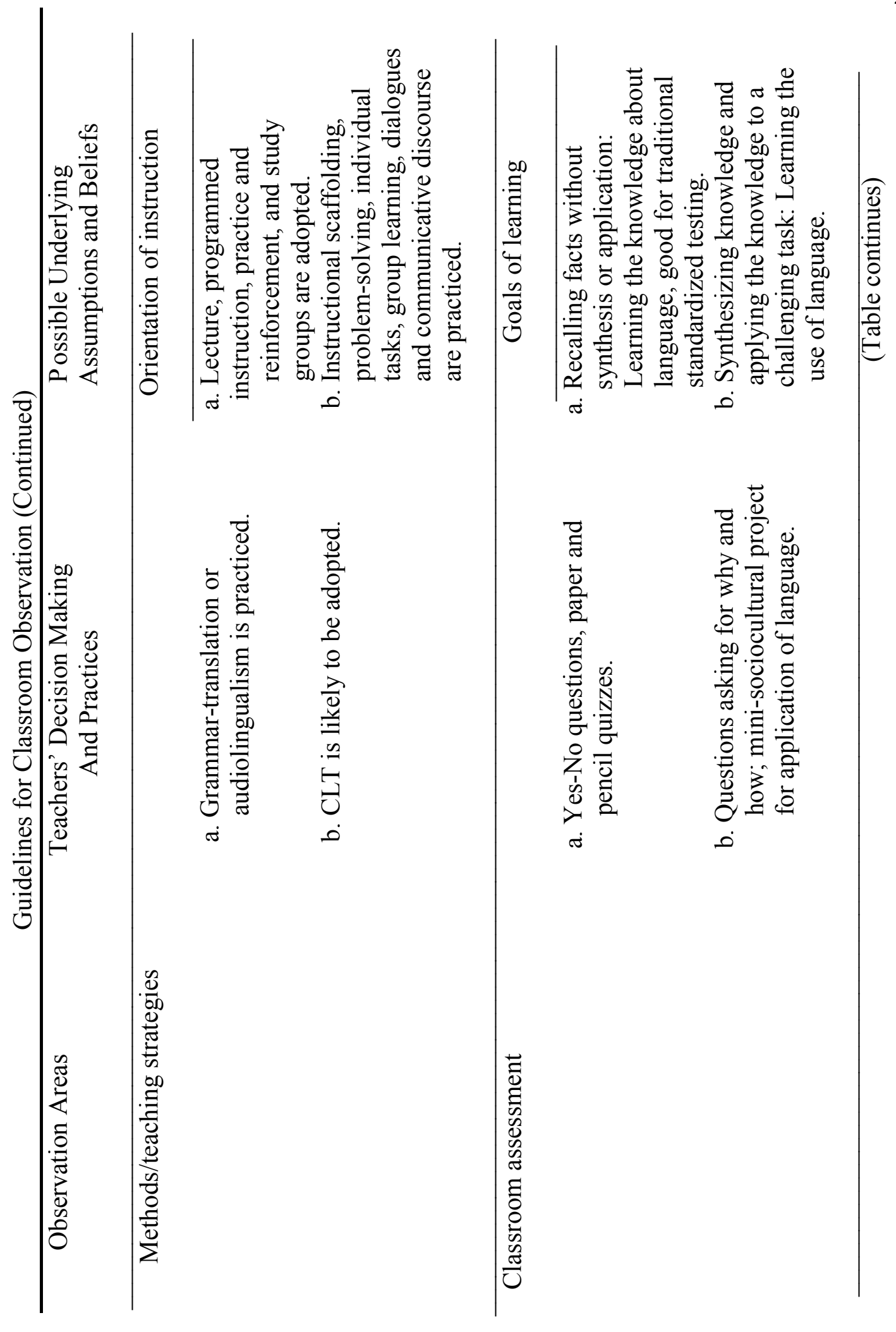




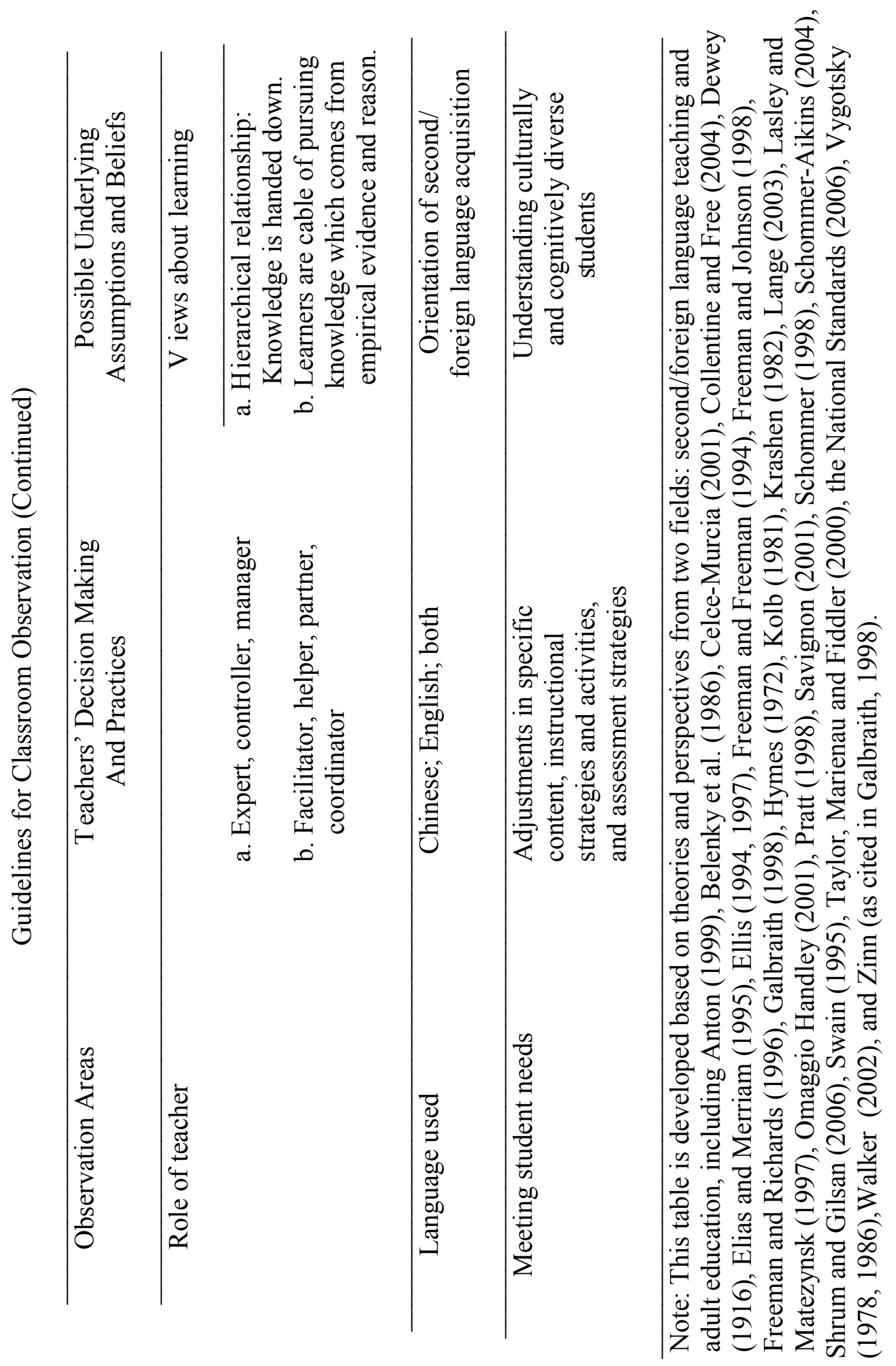




\section{APPENDIX B}

\section{Fieldnotes for Classroom Observation}

Date of observation:

Place:

Time:

Instructor:

Class level:

Textbook used:

Student number:

Site description:

Observation areas: content delivered; instruction conducted; methods/teaching strategies; classroom assessment; role of teacher; language used; meeting student needs

\begin{tabular}{|l|l|l|}
\hline Time & Descriptive notes & \\
\hline & & \\
& & \\
& & \\
& & \\
& & \\
& & \\
& & \\
\hline
\end{tabular}




\title{
APPENDIX C-1
}

\author{
Questions for the First Interview
}

\section{Introduction}

Several writers state that each teacher is a theorist. Teachers develop personal theories about events as ways to reduce ambiguity and explain paradox. Professional teachers tend to explore the most effective ways to encourage learning for their students. Our interview will focus on how you develop your theory on foreign language classroom teaching, and how you put your theories into practice. We shall talk about this step by step. Shall we start with the first question?

\section{Questions}

1. What knowledge prepared you to be a teacher of Chinese? (Epistemic beliefs about knowledge; second/foreign language acquisition)

2. How did you attain this knowledge? (Identify and understand interviewee's perspectives about foreign language teaching and link them to their beliefs in the organization and certainty of knowledge)

3. Could you please talk about how you learned to teach Chinese? (Former schooling and experiences, components for shaping teaching style)

4. Does what you learned from your former schooling helps with your current teaching? And how? (Transformation of early-formed pedagogical framework in current teaching)

5. What should be introduced and how to teach in Chinese language classes? (Organization/structure and stability of knowledge; foreign language learning)

6. What counts as language proficiency? (The nature of language and language teaching; the goal of foreign language learning)

7. How do students learn Chinese? (Orientation of instruction; role of teacher; philosophy of adult education)

8. Some writers state that students' needs and past experiential development affect how teachers teach, what would you say? (Understanding about culturally and cognitively diverse students)

9. Could you please explain why you ask your students to do ... in class? (organization/structure of knowledge; knowledge of method; second/foreign language acquisition)

10. So far, you have offered important information. Thanks so much. Could you please sum up your ideas, theories, philosophies, and methods about Chinese language teaching? (Indicators for beliefs, assumptions, and values).

11. Could you please talk about how you put your theories into practice? (Characteristics for the connection between beliefs and practices)

12. How familiar are you with the National Standards? (Understanding about the philosophy, goal, contents, and methods stated in the National Standards) 
APPENDIX C-2

Questions for the Second Interview

\section{A Brief Statement to Begin with the Interview}

Our first interview was informative. It is great to talk with an experienced teacher like you. Thank you so much. To understand your point of view more accurately and to go deeper into your theories, I would like to raise a few more questions. Shall we begin now?

Questions will start like the following:

1) Could you please explain ...?

2) Could you give an example of ...?

3) Could you please explain why ...?

4) Will you tell me more about ...?

5) What does ... mean?

6) Suppose .... What would it be like?

7) Are you sure about ..., why?

\section{Closing Questions before Ending the Interview}

1) If a new teacher of Chinese asks you for some advice, what would you say?

2) Would you like to add anything before we end this interview?

\section{The Ending Remark}

Thanks so much for your contribution to this study. The transcription of the second interview will be sent to you soon. Please feel free to contact me if you have anything more that you'd like to share with me, or any corrections, clarifications, or changes that you would like to make on both transcriptions of the interviews. 
APPENDIX D

Dear Introductory Script: E-mail

This is Lin Shaojuan, a doctoral student of the Graduate School of Education at Portland State University. I am writing to request your participation in my dissertation research study. The study is about foreign language teaching in U.S. higher education classrooms, focusing on the relationship between teachers' pedagogical beliefs and classroom teaching.

If you agree to participate in this research project, you will be interviewed twice, and the researcher will observe your classroom teaching 3 times. Each interview will take approximately 60-90 minutes. You can skip any questions if they are uncomfortable for you. Tape-recording will occur during the interviews.

Your participation in the research process is voluntary. Any information linked to your identity will be kept confidential throughout and following the study.

Your may not receive any direct benefits from your participation in this study. However, the literature review for this study reveals that few studies have focused on the relationship between foreign language teachers' pedagogical beliefs and their classroom teaching, or how teachers of Chinese develop their theories on teaching and put them into practice. Therefore, your participation and contributions in this study will help foreign language educators, teachers, and learners seek ways to improve foreign language learning.

If you agree to participate, I will make an appointment to meet you, and you will sign an Informed Consent Letter which presents more details about your involvement in this study. Also you will be asked to complete a demographic information form as shown at the end of this letter.

If you have any questions, please feel free to contact me by e-mail (lin@pdx.edu).

Thank you for your consideration.

\section{Lin Shaojuan}

Postsecondary, Adult \& Continuing Education

The Graduate School of Education at Portland State University

Demographic Information

(Participants' name will not be kept with any data collected. All information will remain confidential.)

\begin{tabular}{|c|c|c|}
\hline 1 & Gender & a. female \\
\hline 2 & Age & a. $25-34$ b. $35-44$ c. $45-54$ d. $55-65$ \\
\hline 3 & Highest level of education & a. Bachelors b. Masters c. Doctorate \\
\hline 4 & Field of your highest degree & \\
\hline 5 & Where did you get the degree & b. The U.S. C. \\
\hline 6 & Total years of learning English & \\
\hline 7 & $\begin{array}{l}\text { Working as an English teacher } \\
\text { in China }\end{array}$ & $\begin{array}{l}\text { a. Yes. How many years: } \\
\text { b. No. }\end{array}$ \\
\hline 8 & $\begin{array}{l}\text { Working as a Chinese teacher in } \\
\text { the U.S. }\end{array}$ & How many years: \\
\hline
\end{tabular}




\title{
APPENDIX E INFORMED CONSENT FORM
}

\author{
Doctoral Program in Educational Leadership \\ Department of Educational Leadership and Policy \\ Graduate School of Education \\ Portland State University
}

Foreign Language Teaching in U.S. Higher Education Classrooms: An Investigation of

the Relationship between Teacher Pedagogical Beliefs and Classroom Teaching

Dear

You are invited to participate in a research study conducted by Lin Shaojuan from the Graduate School of Education in Portland State University. Under the guidance of Dr. Christine Cress, Professor of Education, the researcher is conducting this study in partial fulfillment of the requirements for the doctoral degree in Educational Leadership. The research is about the relationship between foreign language teachers' pedagogical beliefs and their classroom teaching, and how teachers of Chinese develop their theories of teaching and put them into practice. You were selected because you are an experienced teacher of Chinese and teach at a college level.

If you decide to participate, you will be interviewed twice, and the researcher will observe your classroom teaching three times. Each interview will take approximately 60-90 minutes. You can skip any questions if they are uncomfortable for you. Audiorecording will occur during the interviews. The options for videotaping classroom teaching will be left to you and your students. If videotaping classroom observation is approved by you and your students, I will make sure that no students will be on film, only you.

The researcher will fully transcribe the audiotapes. You will have an opportunity to review all the transcripts and make any changes or clarifications in the transcripts. This is to make sure that your responses to the interview questions reflect your actual views.

Any information linked to your identity will be kept confidential throughout and following the study. You will be identified by a pseudonym in the dissertation report. As required by federal regulations, all data and records will be kept confidentially on file for three years following the completion of the research. Then all data and records will be destroyed.

Your may not receive any direct benefits from your participation in this study. However, the literature review for this study reveals that few studies have focused on the relationship between foreign language teachers' pedagogical beliefs and their classroom teaching, or how teachers of Chinese develop their theories on teaching and put them 
into practice. Therefore, your participation and contributions in this study will help foreign language educators, teachers, and learners seek ways to improve foreign language learning.

If you have concerns or questions about your participation in this study or your rights as a research subject, please contact the Human Subjects Research Review Committee, Office of Research and Sponsored Projects, 600 Unitus Bldg., Portland State University, (503)725-4288 or 1-877-480-4400. If you have any questions about the study itself, please e-mail me (slin@pdx.edu) or talk to me on the phone (503-725-5281).

Your signature indicates that you have read and understand the above information and agree to take part in this study. Please understand that you may withdraw your consent at any time without penalty, and that, by signing, you are not waiving any legal claims or rights. The researcher will provide you with a copy of this consent form for your records.

Signature

$\mathrm{D}$ ate 